\title{
WestVirginiaUniversity
}

THE RESEARCH REPOSITORY @ WVU

Graduate Theses, Dissertations, and Problem Reports

2007

\section{Finite element analysis of slope stability}

\author{
Pinar Wanstreet \\ West Virginia University
}

Follow this and additional works at: https://researchrepository.wvu.edu/etd

\section{Recommended Citation}

Wanstreet, Pinar, "Finite element analysis of slope stability" (2007). Graduate Theses, Dissertations, and Problem Reports. 4347.

https://researchrepository.wvu.edu/etd/4347

This Thesis is protected by copyright and/or related rights. It has been brought to you by the The Research Repository @ WVU with permission from the rights-holder(s). You are free to use this Thesis in any way that is permitted by the copyright and related rights legislation that applies to your use. For other uses you must obtain permission from the rights-holder(s) directly, unless additional rights are indicated by a Creative Commons license in the record and/ or on the work itself. This Thesis has been accepted for inclusion in WVU Graduate Theses, Dissertations, and Problem Reports collection by an authorized administrator of The Research Repository @ WVU. For more information, please contact researchrepository@mail.wvu.edu. 


\title{
Finite Element Analysis of Slope Stability
}

\author{
By \\ Pinar Wanstreet \\ Thesis Submitted to the \\ College of Engineering and Mineral Resources \\ at West Virginia University \\ in partial fulfillment of the requirements \\ for the degree of \\ Master of Science \\ in \\ Civil Engineering
}

Hema J. Siriwardane, Ph.D., P.E., Chair

Udaya B. Halabe, Ph.D., P.E.

Roger C. Viadero, Ph.D.

Department of Civil and Environmental Engineering

Morgantown, West Virginia

2007

Keywords: Slope stability, soil nailing, factor of safety, finite element analysis 


\section{ABSTRACT \\ Finite Element Analysis of Slope Stability \\ Pinar Wanstreet}

Slope stability is an important aspect of geotechnical engineering. The use of finite element analysis of slope stability has gained popularity in recent years due to its capability to handle complex problems. The primary focus of this research was to study the influence of soil nailing on the factor of safety of stability of slopes by using finite element analysis, and to investigate failure mechanism. In this paper, stability of various soil slopes was analyzed using the Shear Strength Reduction (SSR) technique. Finite element analysis was performed on both reinforced and unreinforced soil slopes and the results were compared with results from various traditional methods. Finite element results show that analysis of stability of slopes using the SSR technique is a useful alternative compared to traditional methods, especially when geometry is complex. 


\section{ACKNOWLEDGEMENT}

I would like to express my sincere appreciation to Dr. Hema Siriwardane for giving me the opportunity to pursue this degree under his guidance and support. His timely appreciation of my work was a great source of encouragement. His expertise in geotechnical engineering and finite element modeling improved my research skills and prepared me for future challenges. I thank Dr. Udaya Halabe and Dr. Roger Viadero for accepting to serve in my committee and for their participation.

I would like to thank my fellow graduate student Raj Gondle for his help and sharing his valuable knowledge for my research study.

I would also thank to my husband Josh for his continuous support, care and patience during my Masters study.

Finally, thanks to my family for their endless love, support and care. Their encouragement is much appreciated. 
TABLE OF CONTENTS

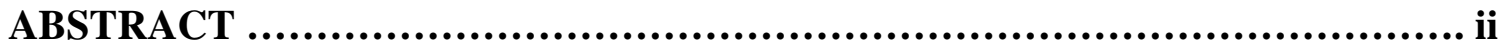

ACKNOWLEDGEMENT .............................................................. iii

TABLE OF CONTENTS ........................................................ iv

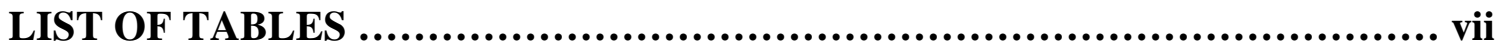

LIST OF FIGURES ............................................................. viii

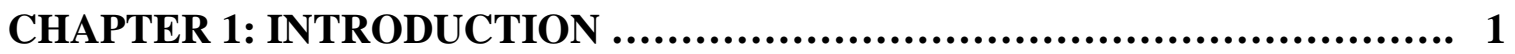

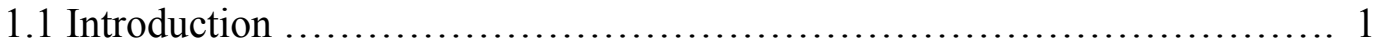

1.2 Types of Slope Failures and Instability Mechanism ....................... 2

1.3 Conventional Techniques to Improve the Stability of Slopes ................. 4

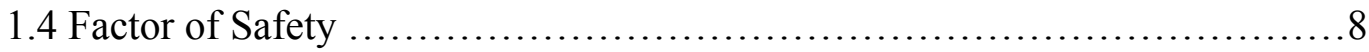

1.5 Problem Statement ....................................................... 8

1.6 Scope of Work .................................................... 10

1.7 Research Objectives ................................................ 10

1.8 Previous Studies ................................................... 11

CHAPTER 2: LITERATURE REVIEW....................................... 12

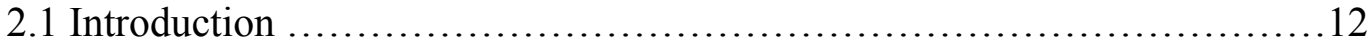

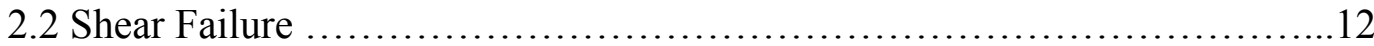

2.3 Mohr-Coulomb Model Description ...................................13

2.4 The Shear Strength Reduction (SSR) Technique .........................13

2.5 Determination of Factor of Safety (FOS) ...............................15

2.6 Slope Stability with Soil Nails ....................................... 17

2.6.1 Historical Background of Soil Nailing ..........................18

2.6.2 Reinforcing Mechanism in Soil Nailing .........................18

2.6.3 Soil Nail Installation ........................................20

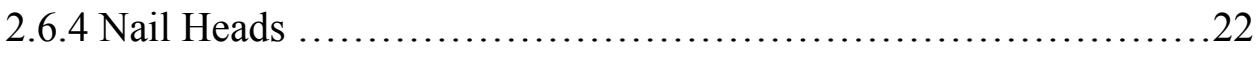

CHAPTER 3: NUMERICAL METHODOLOGY .............................. 26

3.1 Introduction ...................................................... 26 
3.2 Finite Element Method (FEM) …................................ 26

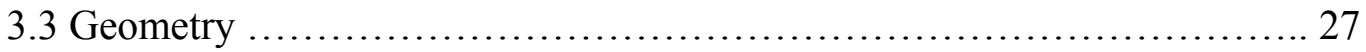

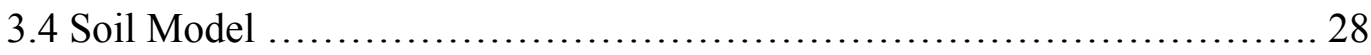

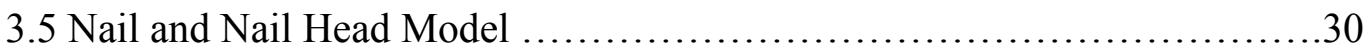

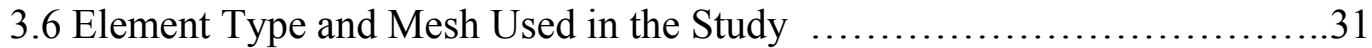

3.6.1 Mathematical Details of Triangular Elements (CPE6) …......... 32

3.6.2 Mathematical Details of Quadrilateral Elements (CPE8) ............ 34

3.6.3 Mathematical Details of 2-noded Beam Element ...................35

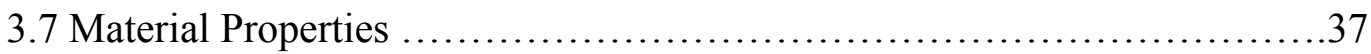

3.8 Loading and Boundary Conditions .................................. 37

3.8.1 Loading ......................................................... 37

3.8.2 Boundary Conditions ...................................... 38

3.9 Case Studies: Numerical Modeling of Unreinforced Slopes ................. 39

3.9.1 Case 1: A Homogenous Slope with No Base .......................39

3.9.2 Case 2: A Homogenous Slope with Base ........................ 42

3.10 Numerical Modeling of Reinforced Slopes ............................. 44

3.10.1 Influence of Soil Nail Length ................................44

a) Benchmark with No Soil Base with One Nail .................44

b) Benchmark with Soil Base with One Nail ....................45

3.10.2 Influence of Soil Nail Inclination .............................46

3.10.3 Influence of Soil Nail Location ...............................47

3.10.4 Influence of Multiple Nails ....................................47

CHAPTER 4: RESULTS and DISCUSSIONS ................................ 49

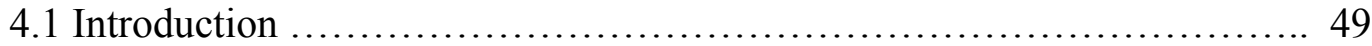

4.2 Results for Unreinforced Slopes .................................... 49

4.2.1 Case 1: A Homogenous Slope with No Base .................... 49

4.2.2 Case 2: A Homogenous Slope with Base ....................... 53

4.2.3 The Radius of failure circle compare with Limit Equilibrium

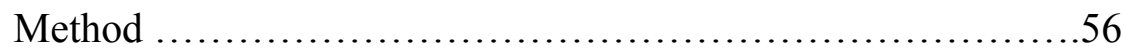

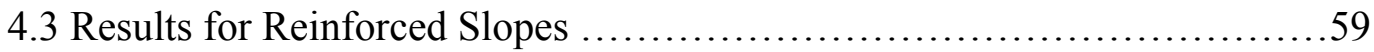

4.3.1 Influence of Soil Nail Length ..................................60 
a) Benchmark with No Soil Base with One Nail ..............60

b) Benchmark with Soil Base with One Nail .................63

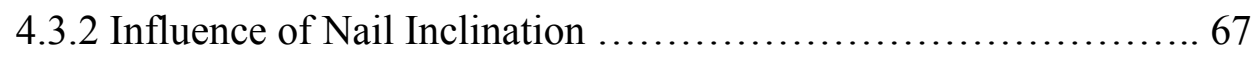

4.3.3 Influence of Nail Location ................................ 70

4.3.4 Influence of Number of Nails ................................ 72

CHAPTER 5: SUMMARY AND CONCLUSIONS .............................. 74

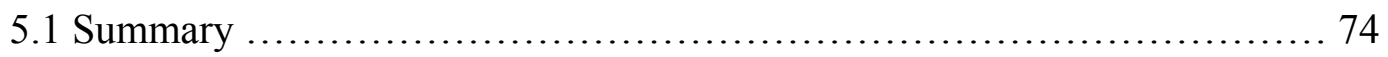

5.2 Numerical Modeling of Unreinforced Slopes ........................ 75

5.2.1 Case 1: A Homogenous Slope with No Base ....................75

5.2.2 Case 2: A Homogenous Slope with Base .......................76

5.3 Numerical Modeling of Reinforced Slopes .............................76

5.3.1 Influence of Soil Nail Length .................................76

a) Benchmark with No Soil Base with One Nail ...............76

b) Benchmark with Soil Base with One Nail .................77

5.3.2 Influence of Nail Inclination .............................. 77

5.3.3 Influence of Nail Location ....................................77

5.3.4 Influence of Number of Nails ..............................77

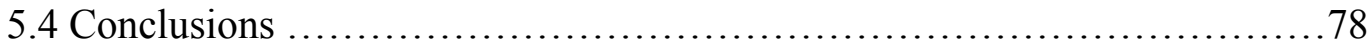

5.5 Recommendations .............................................. 79

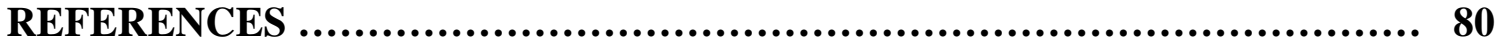

APPENDIX A: Influence of Soil Base on Factor of Safety $\quad$..................... 83 


\section{LIST OF TABLES}

Table 2.1: Recommended Minimum Values of Factor of Safety (Duncan and

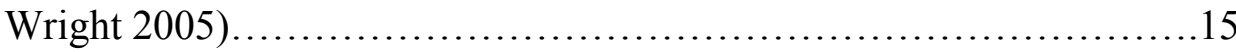

Table 2.2: Factor of Safety Criteria from U.S. Army Corps of Engineers' Slope

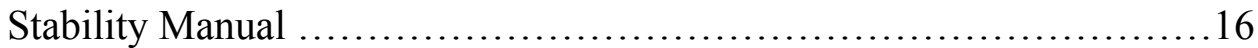

Table 2.3: Reinforcing steel properties ASTM A615 (Grade 60\& 75),

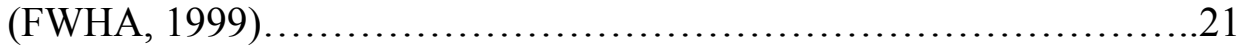

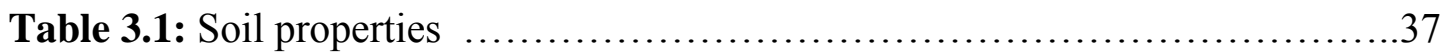

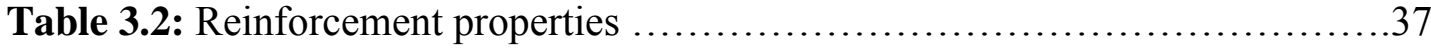

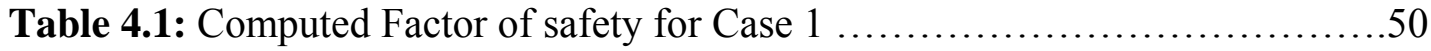

Table 4.2: Computed Factor of safety results for Case $2 \ldots \ldots \ldots \ldots \ldots \ldots \ldots \ldots \ldots \ldots$

Table 4.3: Computed Factor of safety for unreinforced slope and one-nail case .....62

Table 4.4: Factor of safety results for influence of number of nails on the factor

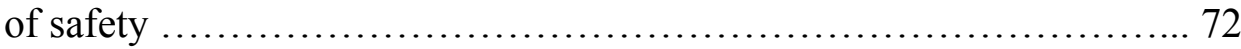

Table 5.1: Factor of safety results for homogeneous slope with no base (Case 1)...74

Table 5.2: Factor of safety results for homogeneous slope with base (Case 2)..... 75

Table A 1: Computed Factor of safety for Case 1 and Case 1 with a 5m

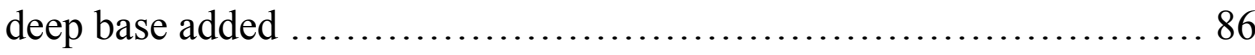




\section{LIST OF FIGURES}

Figure 1.1: Basic schematic diagram of a typical failure plain .................

Figure1.2: (a) Toe Failure, (b) Deep-Seated Failure, (c) Slope Failure, and (d) Compound Failure (Duncan, 2005, Chen, 1995) ...............2

Figure1.3: Schematic diagram of a slope stability improvement by excavation.

(Duncan and Wright, 2005) ................................4

Figure1.4: Schematic diagram of a slope with berm .......................5

Figure1.5: Schematic diagram of a retaining wall (Das, 2004) .................5

Figure1.6: Schematic diagram of a slope with vegetation $\ldots \ldots \ldots \ldots \ldots \ldots \ldots \ldots$

Figure 1.7: Typical soil nailing detail, (modified after Broms and

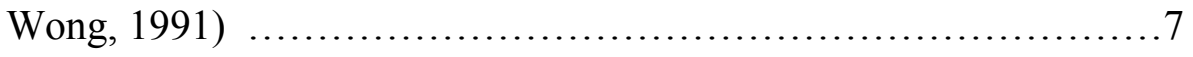

Figure 2.1: Typical slope slip surface detail (modified after Duncan and

Wright, 2005) ......................................... 17

Figure 2.2: Load transfer mechanism of soil nail structure, (Shiu and

Chang, 2004) ..............................................19

Figure 2.3: A typical soil nail detail, (Shiu and Chang, 2004) ...................19

Figure 2.4: Two commonly used soil nail section; Threaded Form (Williams Form Engineering Corp., 2006) .............................20

Figure 2.5: Typical soil nail, and nail head detail (Broms and Wong, 1991) ......23

Figure 2.6: Typical punching shear of bearing plate (Broms and Wong, 1991) ...24

Figure 2.7: Typical facing pressure distribution on nail head detail (Broms

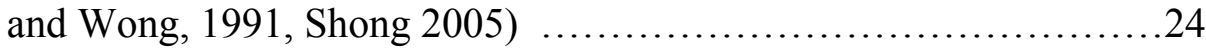

Figure 3.1: Nail head cross section used in the analysis (Abaqus, 2006) ...........30

Figure 3.2 a: Schematic detail of the connection of soil nail and the nail head.....30

Figure 3.2 b: Nail and nail head detail in FEA ............................. 31 
Figure 3.3: Nail and nail head element mesh details .32

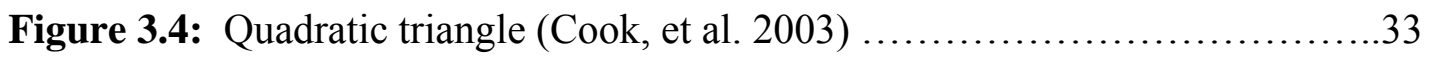

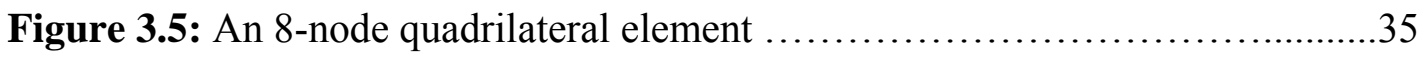

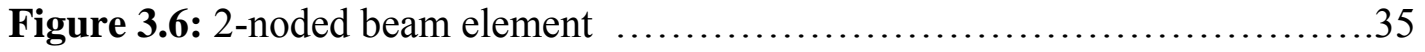

Figure 3.7: Boundary conditions used in benchmark model with no

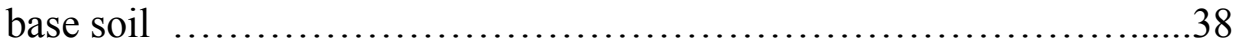

Figure 3.8: Boundary conditions on benchmark model with base soil ...............38

Figure 3.9: Geometry of the benchmark model with no base model ...............39

Figure 3.10: 6-node quadratic plane strain triangle elements with approximate global size of 0.8

Figure 3.11: 8-node biquadratic plane strain quadrilateral elements with

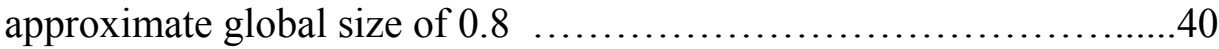

Figure 3.12: 6-node quadratic plane strain triangle elements with approximate

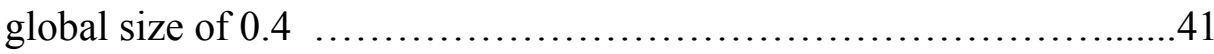

Figure 3.13: 8-node biquadratic plane strain quadrilateral elements with

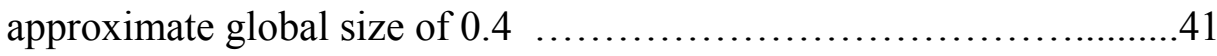

Figure 3.14: Geometry of the benchmark model with base soil ...................42

Figure 3.15: 6-node quadratic plane strain triangle elements (CPE6) ..............43

Figure 3.16: 6-node quadratic plane strain triangle elements (CPE6) ...............43

Figure 3.17: 6-node quadratic plane strain triangle elements (CPE6) ..................44

Figure 3.18: Geometry of the benchmark with one soil nail. ...................45

Figure 3.19: Geometry of the benchmark with base with one soil nail. ..............46

Figure 3.20: Geometry of the benchmark with base with inclined nail ................47

Figure 3.21: Geometry of the benchmark with base with different locations ..........47

Figure 3.22: Geometry of the benchmark with base with multiple nails ............48 
Figure 4.1 (a): Deformed mesh with CPE6 elements (Analysis 1) .................50

Figure 4.1 (b): The equivalent plastic strain contour for Analysis $1 \ldots \ldots \ldots \ldots \ldots \ldots . .51$

Figure 4.2 (a): Deformed mesh with CPE8 elements (Analysis 2) .................51

Figure 4.2 (b): The equivalent plastic strain contour for Analysis $2 \ldots \ldots \ldots \ldots \ldots \ldots . \ldots 1$

Figure 4.3 (a): Deformed mesh with CPE6 elements (Analysis 3) .................52

Figure 4.3 (b): The equivalent plastic strain contour for Analysis $3 \ldots \ldots \ldots \ldots \ldots \ldots . .52$

Figure 4.4 (a): Deformed mesh with CPE8 elements (Analysis 4) .................52

Figure 4.4 (b): The equivalent plastic strain contour for Analysis $4 \ldots \ldots \ldots \ldots \ldots \ldots . .53$

Figure 4.5 (a): Deformed mesh with 728 elements (Analysis 1) ...................54

Figure 4.5 (b): The equivalent plastic strain contour for Analysis $1 \ldots \ldots \ldots \ldots \ldots \ldots 5$

Figure 4.6 (a): Deformed mesh with 1164 elements (Analysis 2) ..................55

Figure 4.6 (b): The equivalent plastic strain contour for Analysis 2...............55

Figure 4.7 (a): Deformed mesh with 1397 elements (Analysis 3) ..................56

Figure 4.7 (b): The equivalent plastic strain contour for Analysis $3 \ldots \ldots \ldots \ldots \ldots . \ldots 56$

Figure 4.8: Limit equilibrium solution for Analysis 1 generated with

Geo-Studio, Slope/W ...........................................57

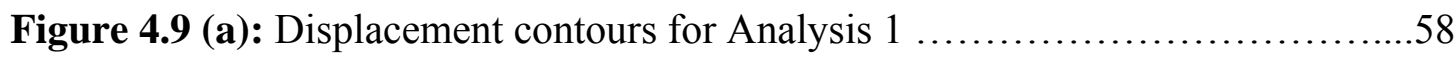

Figure 4.9 (b): The equivalent plastic strain contour for Analysis 1 ...............59

Figure 4.10 (a): Deformed mesh for the case with a $10 \mathrm{~m}$ long nail ................60

Figure 4.10 (b): Displacement contours for the case with a $10 \mathrm{~m}$ long nail ..........61

Figure 4.11 (a): Deformed mesh for the case with a $15 \mathrm{~m}$ long nail ................61

Figure 4.11 (b): Displacement contours for the case with a $15 \mathrm{~m}$ long nail ..........61

Figure 4.12 (a): Deformed mesh for the case with a $20 \mathrm{~m}$ long nail ................62 
Figure 4.12 (b): Displacement contours for the case with a $20 \mathrm{~m}$ long nail 62

Figure 4.13: Variation of factor of safety against length of the soil nail .63

Figure 4.14: Schematic location of point "A" ................................64

Figure 4.15: Variation of displacement at point ' $A$ ' with the length of soil nail ......64

Figure 4.16: The equivalent plastic strain contour for $4 \mathrm{~m}$ long nail .................65

Figure 4.17: The equivalent plastic strain contour for $6 \mathrm{~m}$ long nail .................66

Figure 4.18: The equivalent plastic strain contour for $8 \mathrm{~m}$ long nail ................66

Figure 4.19: The equivalent plastic strain contour for $15 \mathrm{~m}$ long nail ...............67

Figure 4.20: Variation of factor of safety with inclination angle of a soil nail .........68

Figure 4.21: The equivalent plastic strain contours for nail inclination of

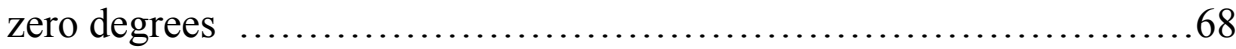

Figure 4.22: The equivalent plastic strain contours for nail inclination of 20 degrees (counterclockwise) .69

Figure 4.23: The equivalent plastic strain contours for nail inclination of 45 degrees . 69

Figure 4.24: Variation of factor of safety with nail location $\ldots \ldots \ldots \ldots \ldots \ldots \ldots \ldots \ldots \ldots$

Figure 4.25: The equivalent plastic strain contours for the case in which nail was located at the toe.

Figure 4.26: The equivalent plastic strain contours for one nail at $9 \mathrm{~m}$ above from the toe of slope 71

Figure 4.27: The equivalent plastic strain contour for one nail at the toe of slope $\ldots . .73$ Figure 4.28: Displacement contour of three-nail case .73

Figure A 1: Geometry of the benchmark model with no base model (Case 1) ........83 
Figure A 2: Geometry of the benchmark model with a $5 \mathrm{~m}$ deep base added

Figure A 3: Deformed mesh for Case 1 (from Analysis 1) ..................... 84

Figure A 4: Deformed mesh for Case 1 with base ........................... 84

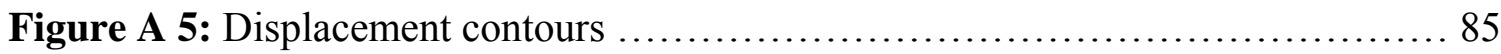

Figure A 6: The equivalent plastic strain contours $\ldots \ldots \ldots \ldots \ldots \ldots \ldots \ldots \ldots \ldots \ldots \ldots \ldots$ 


\section{CHAPTER 1 \\ INTRODUCTION}

\subsection{Introduction}

Analysis of the stability of complex soil slopes is an important and challenging aspect of geotechnical engineering. Over the past 70 years, extensive engineering and research studies have been conducted to develop conventional methods for analysis of slope stability (Duncan and Wright, 2005). Although several advances have been made over the past decades, slope stability analysis still remains a challenge in geotechnical engineering (Duncan and Wright, 2005).

Depending on the geometric details and soil properties, slope failures occur along a failure surface in the soil mass as shown in Figure 1.1. Slope stability analyses by either limit equilibrium method or finite element method using the shear strength reduction (SSR) technique can be used to assess the original factor of safety and the improvement after strengthening (Dawson et al, 1999; Griffith and Lane, 1999).

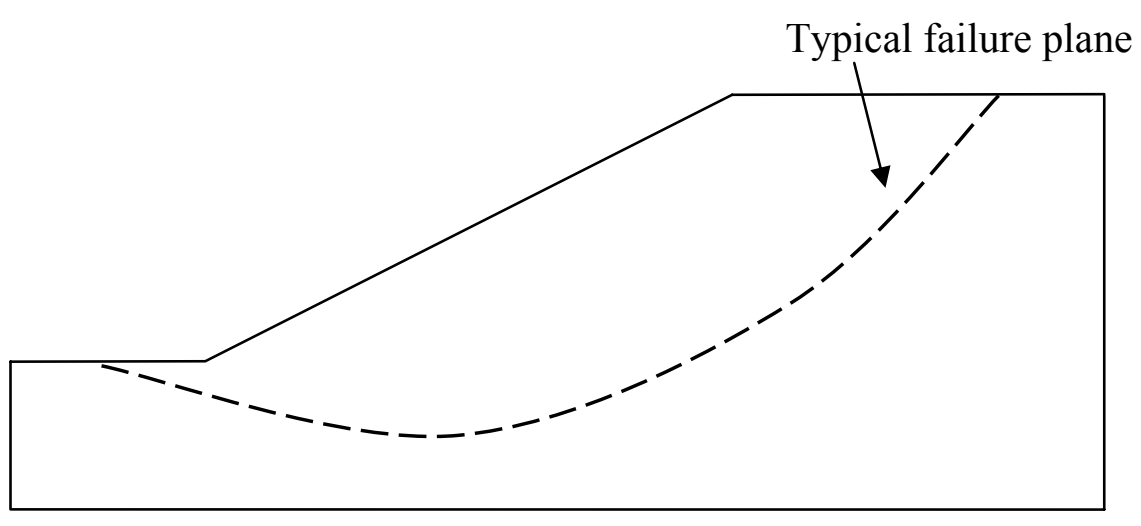

Figure 1.1: Basic schematic diagram of a typical failure plane 


\subsection{Types of Slope Failures and Instability Mechanism}

A common mode of slope failure is a rotational slip along an almost circular failure surface (Duncan, 2005). Brief descriptions of the different types of slope failures are given below:

- Toe Failure, in which failure occurs along the surface that passes through the toe [Figure1.2 (a)]

- Base Failure, in which the failure surface passes below the toe [Figure1.2(b)]

- Slope Failure, in which the failure occurs along a surface that intersects the slope above the toe [Figure1.2(c)]

- Compound Failure, in which the failure is a combination of the rotational slips and the translational (infinite) slip. Generally occurs when a hard stratum exists at a quite large distance from the slope surface. [Figure1.2(d)]

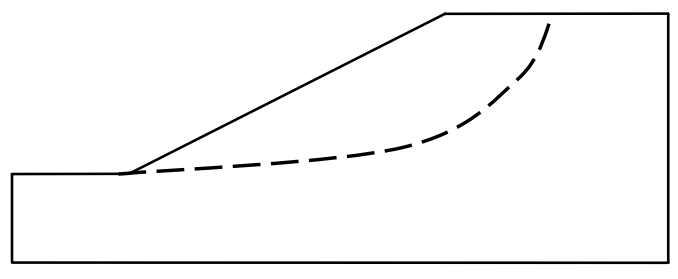

(a)

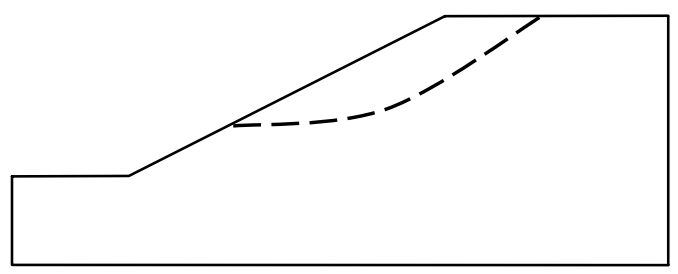

(c)

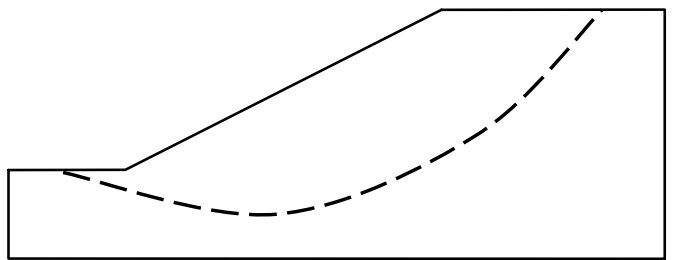

(b)

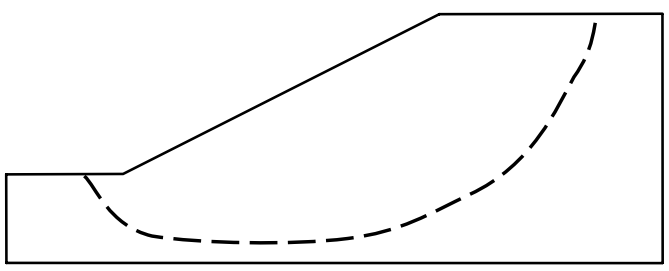

(d)

Figure1.2: (a) Toe Failure, (b) Deep-Seated Failure, (c) Slope Failure, and (d) Compound Failure (Duncan, 2005; Chen, 1995). 
It is important to understand the causes of instability in slopes for purposes of designing and constructing new slopes, and for the purposes of repairing failed slopes. For stability of a slope, the shear strength of the soil must be greater than the shear stress requirement for equilibrium. The instability condition can be reached through two mechanisms (Duncan and Wright, 2005):

- A decrease in the shear strength: The loss of the shear strength may occur due to an increase in moisture content, pore water pressure, shock or cyclic loads, weathering, etc.

- An increase in the shear stress: The stresses may increase due to weight of water causing saturation of soils, surcharge loads, seepage pressure, etc.

In most cases, several causes exist simultaneously. According to Sowers (1979), it is usually not possible to identify the cause that acted alone and resulted in instability. Attempting to identify which one finally produced the failure is not only intricate, but also technically inaccurate (Duncan and Wright, 2005). Hence, in designing and constructing new slopes, it is important to consider potential changes in properties and conditions that may affect the structure during its lifespan so that it will remain stable regardless of these changes. 


\subsection{Conventional Techniques to Improve the Stability of Slopes}

There are many methods available to improve the slope stability (Duncan and Wright, 2005). Brief descriptions of the different methods are given below:

- Unloading, which reduces the weight of the mass tending to slide.
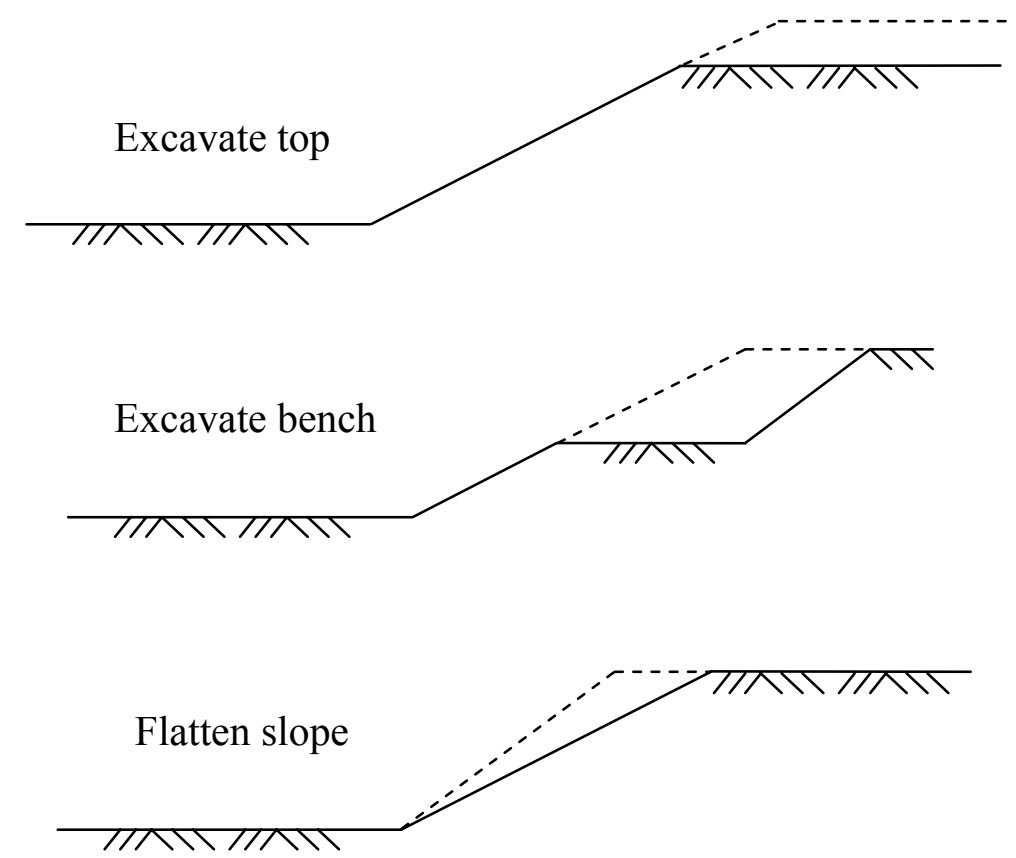

Figure1.3: Schematic diagram of a slope stability improvement by excavation (Duncan and Wright, 2005) 
- Placing a berm at the toe to increase the resisting forces. It is especially useful when base failure is anticipated (Figure1.4).

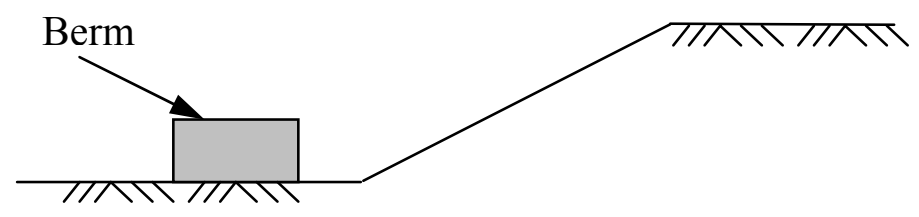

Figure1.4: Schematic diagram of a slope with berm

- Drainage, which helps reducing the seepage forces that may increase the stability, the zone of subsurface water is lowered and infiltration of the surface water is prevented.

- Reinforcement and retaining walls which help increase stability by providing lateral support (Figure1.5).

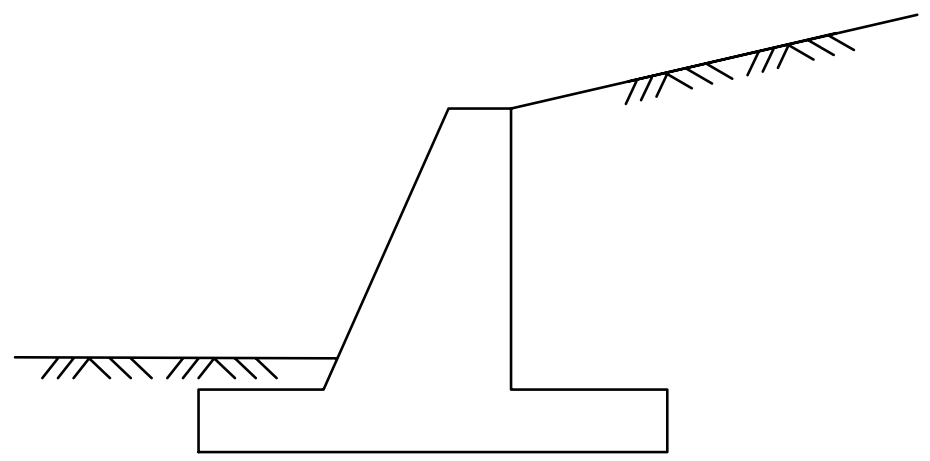

Figure1.5: Schematic diagram of a retaining wall (Das, 2004) 
- Vegetation, which reduces the effects of runoff on the slope by intercepting precipitation. It can only provide surficial stabilization within the root zone (Figure1.6).

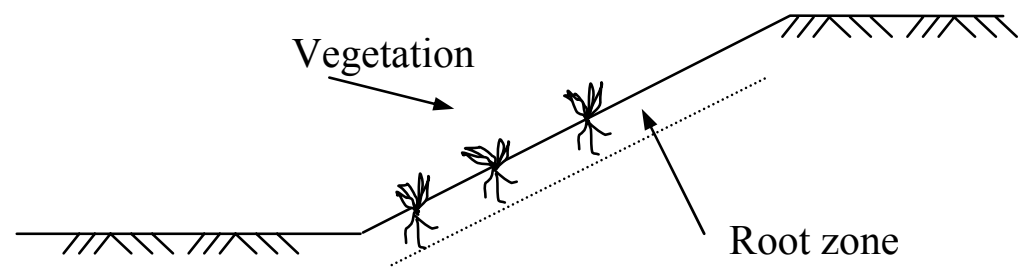

Figure1.6: Schematic diagram of a slope with vegetation

- Soil hardening, which can be provided by using grouting and injecting of cement or other compounds into specific zones to increase the stability.

- Densification by explosives, vibroflotation, or terra probe, which helps increase the shear strength in cohesionless soils.

Reinforcements can be used in many different applications in geotechnical engineering such as in embankments, cut slopes, soil slope reinforcement, and retaining walls. The use of soil nailing is becoming a rapidly growing technology in soil slope stability techniques.

Soil nails are either installed in drilled bore holes or secured with grout, or they are driven into the ground. The soil nails are generally attached to concrete facing located at the surface of the structure (Broms and Wong, 1991) (Figure 1.7). 


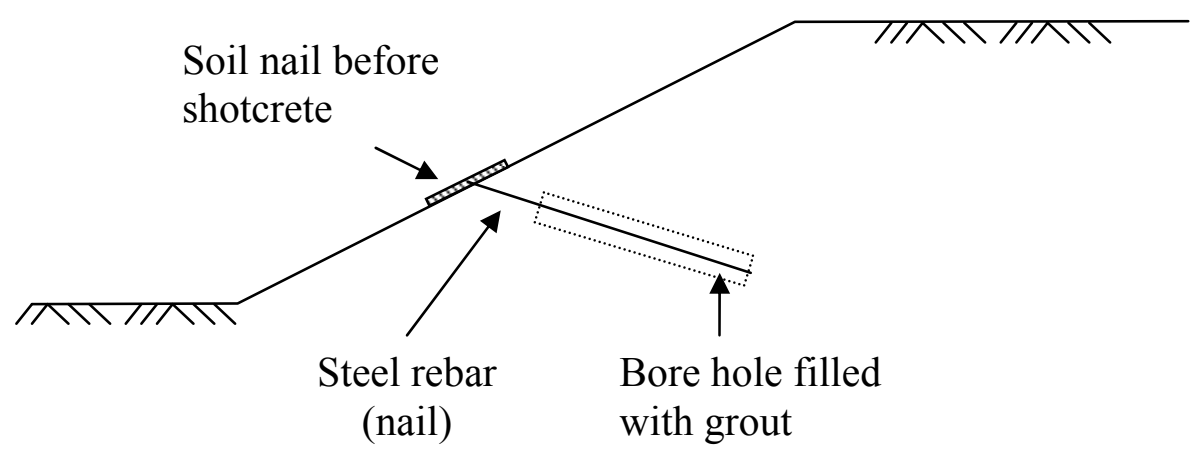

Figure 1.7: Typical soil nailing detail, (modified after Broms and Wong, 1991)

Soil nailing is one of the in-situ methods to reinforce ground by installing closely spaced reinforcing elements, usually steel bars, to increase the overall shear strength of the soil and reduce potential displacements. The method is an effective process for retention of deep excavations, stabilization and remediation of slopes when properly engineered (Ann et al, 2004). The structural reinforcing elements provide resisting tensile forces, shear stresses and bending moments through the friction mobilized at the interfaces of nail and in-situ soil. It can improve soil performance, increase the safety factor, and reduce the construction cost for a project (Goldstein, 2001). 


\subsection{Factor of Safety}

The factor of safety $\left(\mathrm{F}_{\mathrm{s}}\right)$ is very important when performing slope stability analyses. The most widely used definition of factor of safety for a slope is the ratio of shear strength of the soil to shear stress required for equilibrium (Duncan and Wright, 2005). It can be determined from a limit equilibrium analysis using factored strength parameters (Griffiths and Lane, 1999). For a slope analysis a unique factor of safety can be determined using conventional methods based on limit equilibrium methods (Ann et al, 2004).

The classical approach for factor of safety of the slope is determined by considering a range of failure surfaces with different centers and radii to find the slip circle that gives the minimum factor of safety. However, these methods cannot be easily used for complex geometries and reinforced slopes.

\subsection{Problem Statement}

Evaluation of the stability of soil slopes using the finite element method has gained popularity in recent years. The slope stability analyses are conventionally assessed using Limit Equilibrium Methods (LEM) (Ann et al, 2004). Limit Equilibrium Methods have limitations in dealing with this type of strain and compatibility problems in reinforced soil slopes.

In this research, three different types of slopes were analyzed by using the finite element method.

1. A benchmark problem

2. An embankment with no reinforcement

3. An embankment with soil nail(s) 
The first model was created to study the effects of meshing on slope factor of safety. It was compared with conventional methods and previous research findings. The second model and the third model were created to better understand the stability improvements by using soil nails, and their influence on failure plane and the factor of safety. The second model was also compared with conventional methods and previous research findings. Soil-nailed embankment included the following aspects: Influence of nail inclination, nail location, and nail length.

The finite element method is and non-associative Mohr-Coulomb plasticity were used in all models throughout this paper. Numerical simulations were performed to investigate states of failure and investigate the location of the slip surface due to strength parameters and existing conditions. Using the numerical analysis, it was possible to obtain an accurate factor of safety of slopes analyzed in previous research studies by using conventional methods such as, Bishop's Modified Method (Bishop, 1955), Janbu's Modified Method (Janbu, 1968), Morgenstern and Price's Method (Morgenstern and Price, 1965), and Spencer's Method (Spencer, 1967). In addition to these methods the General Limit Equilibrium (GLE) is mentioned. These methods generally differ from one to another in the equations of static equilibrium and the relationship between the interslice and the shear forces (Shiu et al., 2006). A difficulty with all the conventional methods that they are based on assumption of the shape or the location of failure surface the (Griffiths and Lane, 1999).

The computer software package GeoStudio 2004-SLOPE/W developed by GEOSLOPE was used in determining the factor of safety values are obtained from the limit equilibrium methods that were mentioned above. 


\subsection{Scope of Work}

A literature review was conducted to investigate deformation-based slope stability analyses, effects of meshing, and to investigate the stress distribution in the nails and resulting improvement in stability. A well known finite element package 'ABAQUS' was used to calculate the factor of safety for both reinforced and unreinforced slopes. The factors of safety obtained from different theories and previous research studies were compared with the numerical results to assess how close or far the slopes are from failure. Also, the results obtained from the finite element analyses were compared with results obtained in previous studies (Griffiths and Lane, 1999). Factor of safety was determined by using the shear strength reduction (SSR) technique (Griffiths and Lane, 1999; Dawson et al, 1999). Two-dimensional models were used in all cases presented in this paper.

\subsection{Research Objectives}

The primary objectives of this study were:

- Review existing literature of slope stability analysis and procedures

- Select an appropriate element type to create the models

- Perform finite element analysis for each model

- Study the influence of density of meshing and reinforcement on factor of safety values as well as on the failure mechanism

- Study the effects of soil nails on slope factor of safety and failure zone

- Compare the findings from finite element analysis with previous research studies. 


\subsection{Previous Studies}

In one particular study (Griffiths and Lane, 1999), slope stability analysis by finite element analysis was performed on several examples. This study compared the finite element results with traditional methods of slope stability analysis. The slope stability examples were performed on both slopes with no foundations and slopes with foundations using various material properties. The study concluded that the finite element method in conjunction with an elastic-perfectly plastic (Mohr-Coulomb) stressstrain method was reliable and robust assessing the factor of safety of slopes.

In another study (Ann et al, 2004), a finite element analysis of a soil nailed slope was investigated. Reinforced slope stability analysis by using finite element method and limit equilibrium method were compared. Sensors and strain gages were located along selected soil nails. The mobilization of soil nail forces at various stages of excavation and the lateral displacement of the nailed slope due to stress-relief was monitored. The results show that both FEM and LEM methods provided similar factor of safety values and failure mechanism pattern for 30 degree slope face. The factor of safety values were dissimilar for a steeper slope face of 75 degrees.

Another study examined the load transfer mechanism of soil nails and nail heads, and the effect of nail inclination on slope stability using numerical analysis (Shiu and Chang, 2004). Numerical simulations were performed on Fast Lagrangian Analysis of Continua (FLAC), and Mohr-Coulomb model was used for the soil. Two dimensional plane strain analysis was used in numerical analyses. The study examined nailed-slopes with no nail head and with nail heads and it was concluded that the factor of safety increased when nail heads were introduced to soil nails. Also, slopes with no reinforcement and with reinforcement were analyzed. The factor of safety of unreinforced slope increased from 1.0 to 1.2 when soil nails were introduced to the analyses. 


\section{CHAPTER 2}

\section{LITERATURE REVIEW}

\subsection{Introduction}

In geotechnical engineering, slope stability problems are affected by shear strength of the soil. Shear strength of soils is the result of the resistance to mass deformation formed from movement of particles, particle interlocking, physical bonds, and chemical bonding across particles (Terzaghi, 1996). The shear strength of soil is usually expressed in terms of two soil parameters: angle of friction (ø) and cohesion (c).

The finite element analysis can be used to compute stresses and displacements in a soil mass subjected to external loads. However, the stability of a slope cannot be determined directly from the finite element analysis. Only, the computed stresses in a slope can be used to obtain a factor safety. In this sense, finite element analysis is a complex method for computing factor of safety of slope stability problems (USACE, 2003). In the present research paper, the Shear Strength Reduction (SSR) technique was used to compute the factor of safety based on the finite element analysis.

\subsection{Shear Failure}

A shear failure involves sliding of a portion of an embankment, or an embankment and its foundation, relative to the adjacent stationary mass. A shear failure is usually considered to occur along a discrete surface as assumed in stability analyses, although the shear movements may in fact occur across a zone of appreciable thickness. Failure surfaces are frequently approximately circular in shape. For soils, failure occurs at $15 \%$ to $20 \%$ of strain (Holtz and Kovacs, 1981). Failure of a soil element at a certain location does not mean failure of the system. However, it could mean a reduction of the factor of safety. 


\subsection{Mohr-Coulomb Model Description}

There are different criteria that can define failure. Some of these criteria are based on strain level, while most are based on the shear stress in comparison to the shear strength. The Mohr-Coulomb failure criterion is the most commonly used one in soil mechanics. The Mohr-Coulomb failure model was used in this study. It is defined as (Das, 2002):

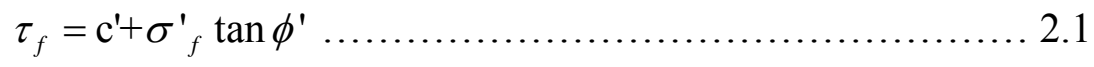

Where $\tau_{f}$ shear strength at failure, $\mathrm{c}^{\prime}$ is effective cohesion, $\sigma_{f}^{\prime}$ is effective stress at failure, and $\phi^{\prime}$ is the effective angle of friction. The Mohr-Coulomb model is a perfectly elastic-plastic model. It has been widely used in geotechnical applications (Hammah et al, 2004).

\subsection{The Shear Strength Reduction (SSR) Technique}

Shear Strength Reduction method is a new technique in finite element method to obtain factor of safety of earth slopes. The finite element method was first applied to geotechnical engineering in 1966 (Rocscience, 2004). In the mid 1970s, slope stability analysis started appearing in the literature. According to the SSR method, soil shear strength is reduced to bring a slope to verge of failure (Duncan and Wright, 1996). In the finite element method, such a state is detected by the inability to reach equilibrium. In the SSR technique, it is assumed that the slope materials have elasto-plastic behavior. The material strength is reduced until failure occurs. 
In this technique, the Mohr-Coulomb material shear strength is reduced by a factor F, which is also called the "factor of safety". The definition is expressed as:

$$
\frac{\tau}{\mathrm{F}}=\frac{\mathrm{c}^{\prime}}{\mathrm{F}}+\frac{\tan \phi^{\prime}}{\mathrm{F}}
$$

The equation can be written as

$$
\frac{\tau}{\mathrm{F}}=\mathrm{c}^{*}+\tan \phi^{*}
$$

Where

$$
\begin{aligned}
& \mathrm{c}^{*}=\frac{\mathrm{c}^{\prime}}{\mathrm{F}} \\
& \phi^{*}=\arctan \left(\frac{\tan \phi^{\prime}}{\mathrm{F}}\right)
\end{aligned}
$$

For Mohr-Coulomb materials, the steps for systematically searching for the critical factor of safety value, F, which brings a previously stable slope to the verge of failure, are given below (Rocscience. 2004):

Step 1: Develop an FE model of a slope, using the deformation and strength properties established for the slope materials. Compute and record the maximum total deformation in the slope by using the finite element method.

Step 2: Increase the value of $\mathrm{F}$ and calculate factored Mohr-Coulomb material parameters as described above. Enter the new strength properties into the slope model and re-compute deformation. Record the maximum total deformation. 
Step 3: Repeat Step 2, using systematic increments of F, until the FE model does not converge to a solution. In other words, continue to reduce material strength until the slope fails. The critical $\mathrm{F}$ value beyond which failure occurs will be the slope factor of safety, based on the finite element method.

For a slope that is initially unstable, factor of safety values in steps 2 and 3 must be reduced until the finite element model converges to a solution (Rocscience, 2004).

\subsection{Determination of Factor of Safety (FOS)}

The most widely used definition of factor of safety for a slope is the ratio of shear strength of the soil to shear stress required for equilibrium. Shear strength is often the largest uncertainty in slope stability analyses. A value of $\mathrm{F}=1.0$ indicates that a slope is on the boundary between stability and instability. If all the factors are computed precisely, even a value of 1.01 would be acceptable. However, the computed values of FOS are not precise, due to uncertainty of variables. Therefore, the factor of safety should be larger to be on the safe side (Duncan and Wright, 2005).

The value of factor of safety should be matched to uncertainty of analysis conditions. Recommended minimum values of factor of safety are shown in Table 2.1 (Duncan and Wright, 2005).

Table 2.1: Recommended Minimum Values of Factor of Safety (Duncan and Wright 2005)

\begin{tabular}{|l|l|l|}
\hline \multirow{2}{*}{ Cost and consequences of slope failure } & \multicolumn{2}{|l|}{ Uncertainity of analysis conditions } \\
\cline { 2 - 3 } & Small & Large \\
\hline $\begin{array}{l}\text { Cost of repair comparable to incremental } \\
\text { cost to more conservatively designed slope }\end{array}$ & 1.25 & 1.5 \\
\hline $\begin{array}{l}\text { Cost of repair much greater than } \\
\text { incremental cost to construct more } \\
\text { conservatively designed slope }\end{array}$ & 1.5 & 2.0 or greater \\
\hline
\end{tabular}


The recommended values of factor of safety shown in Table 1.2 from the U.S. Army Corps of Engineers' slope stability manual is based on experience.

Table 2.2: Factor of Safety Criteria from U.S. Army Corps of Engineers' Slope Stability Manual

\begin{tabular}{|l|l|c|c|}
\hline \multirow{2}{*}{ Types of Slopes } & \multicolumn{3}{|l|}{ Required factors of safety } \\
\cline { 2 - 4 } & $\begin{array}{l}\text { For end of } \\
\text { construction }\end{array}$ & $\begin{array}{l}\text { For long-term } \\
\text { steady seepage }\end{array}$ & $\begin{array}{l}\text { For rapid } \\
\text { drawdown }\end{array}$ \\
\hline $\begin{array}{l}\text { Cost of repair comparable to } \\
\text { incremental cost to more } \\
\text { conservatively designed slope }\end{array}$ & 1.3 & 1.5 & $1.0-1.2$ \\
\hline
\end{tabular}

Another approach of factor of safety of slopes refers to the ratio of resisting moment to overturning moment on circular slip surfaces (Duncan, 2005).

Referring to the slope and circular slip surface shown in Figure 2.1, factor of safety, F can be written as:

$$
\mathrm{F}=\frac{\text { available resisting moment }}{\text { actual driving moment }}
$$

Available resisting moment,

$$
\mathrm{Mr}=\frac{\mathrm{clr}}{\mathrm{F}}
$$

Where, $\mathrm{c}$ is cohesion, 1 is the length of the circular arc, and $\mathrm{r}$ is the radius.

Actual driving (overturning moment),

$$
\mathrm{Md}=\mathrm{W} \chi
$$

Where, $\mathrm{W}$ is the weight of the soil mass and $\chi$ is the moment arm.

$$
\mathrm{F}=\frac{\mathrm{clr}}{\mathrm{W} \chi}
$$




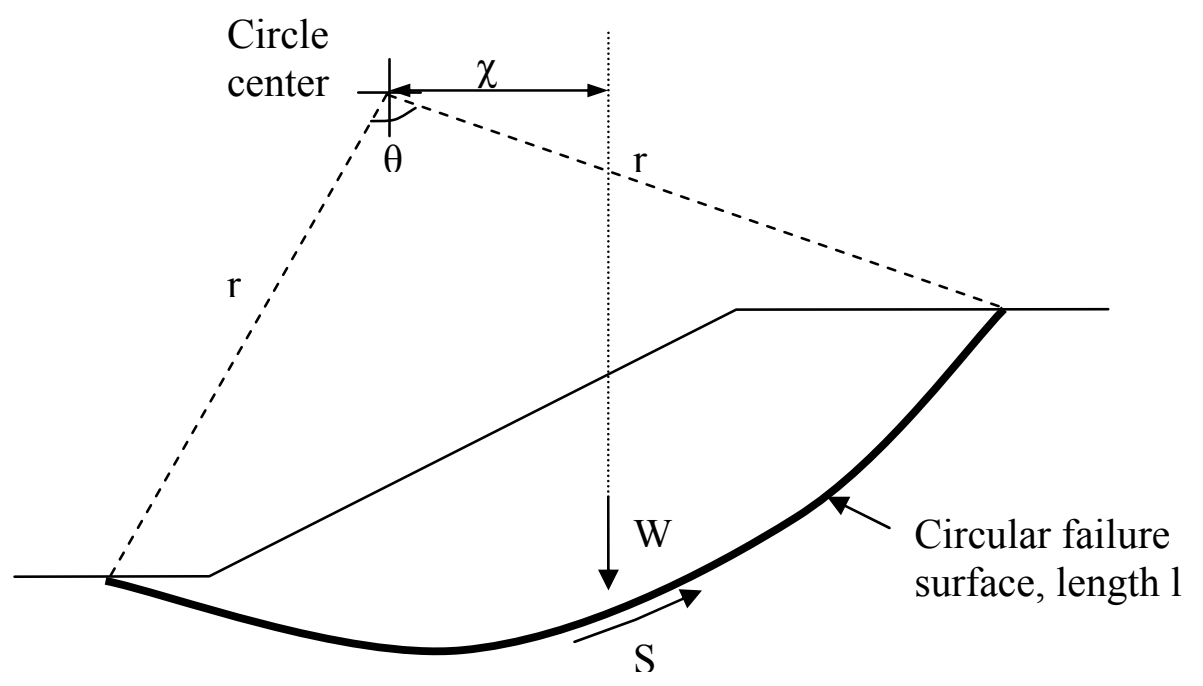

Figure 2.1: Typical slope slip surface detail (modified after Duncan and Wright, 2005)

When a soil mass is reinforced with reinforcing elements such as soil nails, the shear failure is much more complex. Different factors of safety can be used for reinforcement and soil strength (Duncan and Wright, 1996). This requires a more detailed treatment in the finite element analysis.

\subsection{Slope Stability with Soil Nails}

Soil nailing is a slope stabilization method that uses an array of nails inserted into the ground (Goldstein, 2001). Soil nailing can be used for both temporary and permanent slopes (Chance, 1999). It also can be used to support slopes or to repair slipping embankments and gravity walls. Soil nailing is commonly used in soft rocks and stiff clays. Soil nails tend to work best in areas where there is a high content of clay material in the soil (KUTC, 2006).

\subsubsection{Historical Background of Soil Nailing}


The soil nailing technique was developed in late 1960's and has been popular throughout the world (Chance, 1999). Soil nailing originated in Europe in the early 1960s with the introduction of the New Austrian Tunneling Method (NATM) (Karakus and Fowell, 2004). Rock bolts and shotcrete have been used to support the tunnels, and the soil nailing emerged as a result of the experience from rock bolts. This technology was reportedly first used to support retaining walls in France in 1961 (Chance, 1999). The use of grouted soil nails and driven soil nails, which consist of solid steel bars and steel iron, continued to grow in the 1960s in France and Germany. It has been reported that soil nails were used to support a wall in grouted sand in France in 1972 (Chance, 1999). This 60-foot wall was sitting on a 21 degree slope to support an excavation of a railroad track (Banerjee et al., 1998).

The first application of soil nailing in North America seems to be a temporary retaining wall in Vancouver, BC, in the late 1960s (Chance, 1999). A soil nailing construction project was for an excavation of a hospital foundation in Portland, OR was reported in 1976 (Chance, 1999). According to the reports from project managers in Portland, the construction time was reduced by up to $50 \%$ and yielded a cost savings of 15\% over conventional tieback construction by using soil nailing (Goldstein, 2001).

\subsubsection{Reinforcing Mechanism in Soil Nailing}

The stability of a soil mass reinforced with soil nails improve due to two mechanisms: the transfer of tensile forces generated in the nails due to frictional interaction between the ground and the nail, and the development of shear stress and bending stiffness in the nails as a result of deformation of soil mass (Figure 2.2). In addition to these mechanisms, the soil-structure interaction between the facing and the soil helps to restrain displacement and produce nail head load at the connection between the nail and facing to develop the force along the nails (Byrne et al, 1996). 


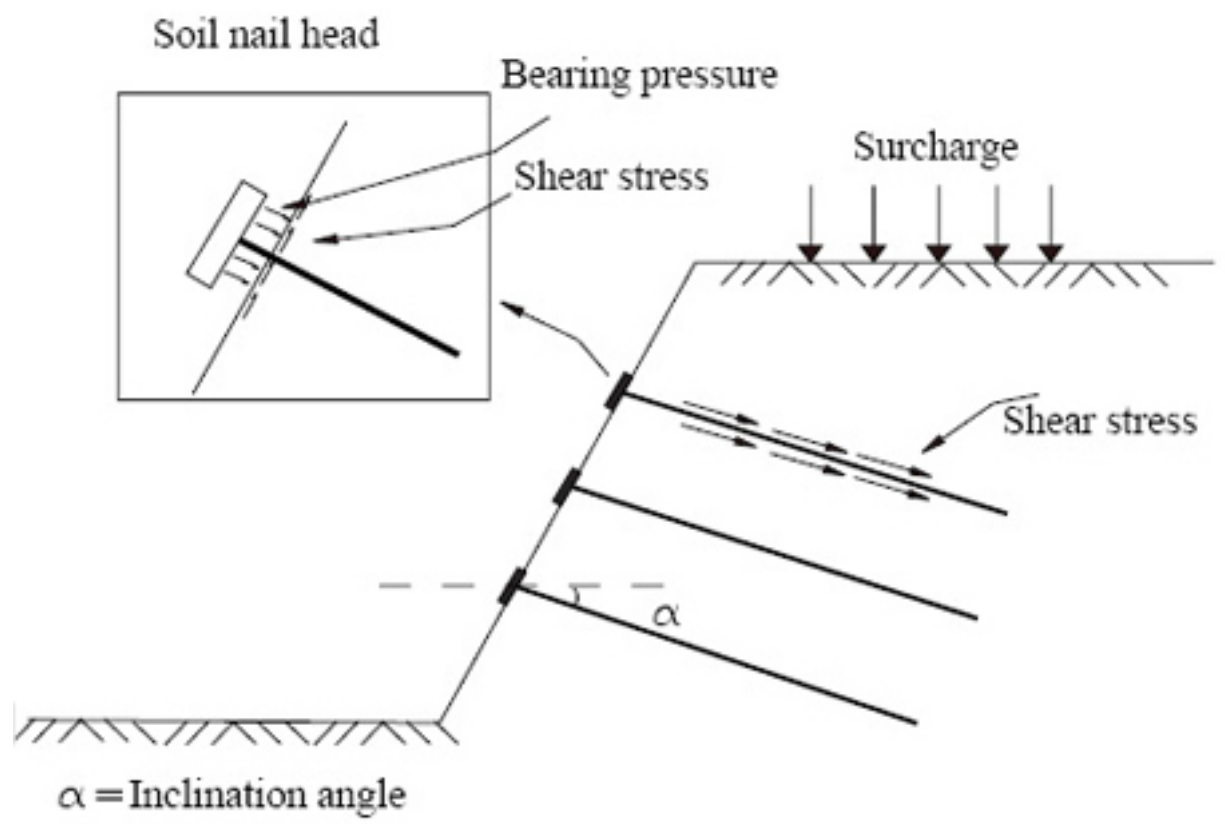

Figure 2.2: Load transfer mechanism of soil nail structure, (Shiu and Chang, 2004)

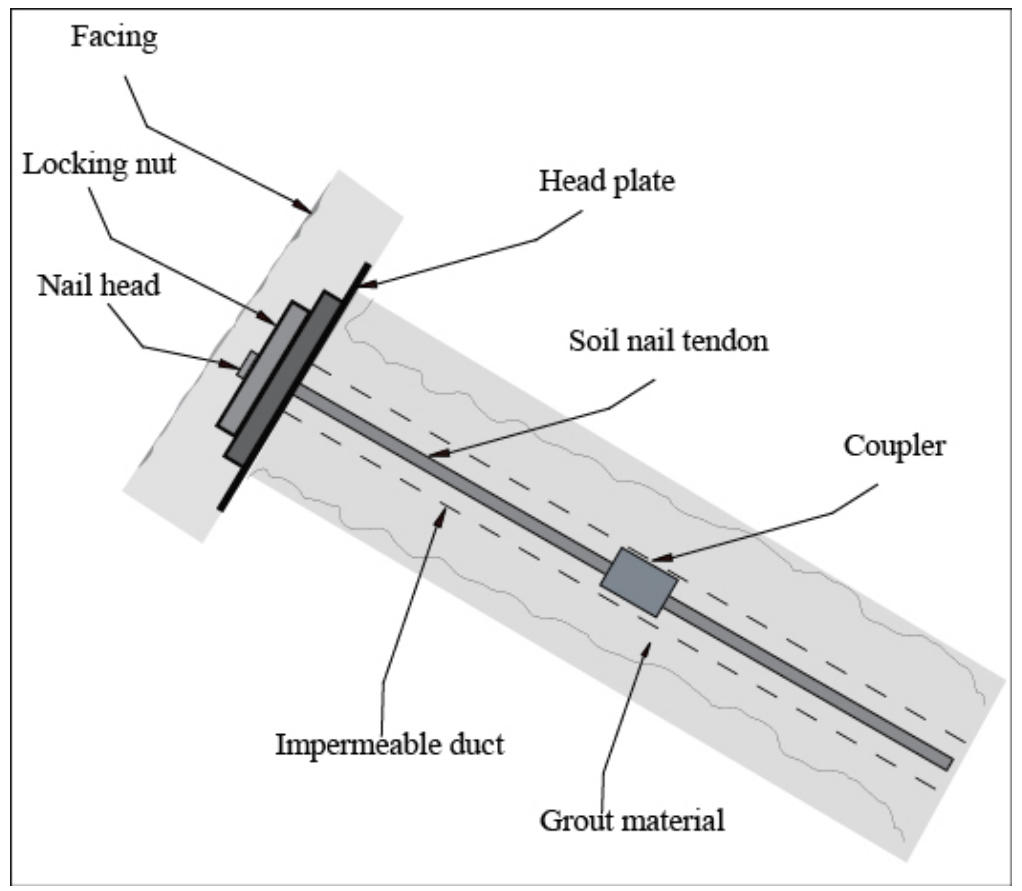

Figure 2.3: A typical soil nail detail, (Shiu and Chang, 2004) 


\subsubsection{Soil Nail Installation}

Soil nails are installed in a pattern designed to ensure both internal and external stability of a wall. A fairly large number of nails are placed so they can resist the tensile, compressive, and shear stresses within the wall and transfer them into the ground (Figure 2.3).

Steel reinforcing bars used for soil nails are commonly threaded and may be either solid or hollow. Bars generally have a nominal tensile strength of $420 \mathrm{MPa}[60$ kips per square inch (ksi) or Grade 60] or $520 \mathrm{MPa}$ (75 ksi or Grade 75). The common U.S. practice of soil nailing involves the use of solid steel bars of 420 or $520 \mathrm{MPa}$ (Grade 60 or 75$)$ (FWHA, 1999).

Threaded bars are generally used in practice. The two commonly used threaded soil nail sections shown in Figure 2.4. Reinforcing steel properties for Grade 60 and 75 (ASTM A615), can be seen in Table 2.1.
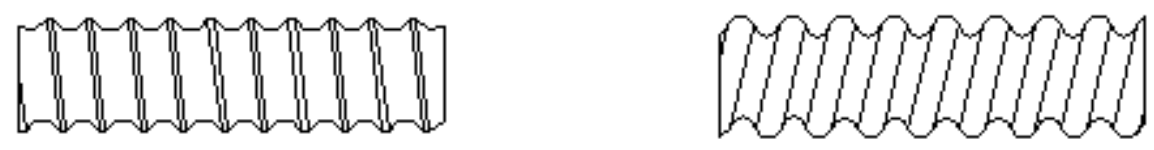

Figure 2.4: Two commonly used soil nail section; Threaded Form (Williams Form Engineering Corp., 2006) 
Table 2.1: Reinforcing steel properties ASTM A615 (Grade 60\& 75), (FWHA, 1999).

\begin{tabular}{|c|c|c|c|c|c|c|c|c|c|c|c|c|}
\hline Grade & \multicolumn{2}{|c|}{$\begin{array}{c}\text { Threadbar } \\
\text { Designation }\end{array}$} & \multicolumn{2}{c|}{$\begin{array}{c}\text { Yield } \\
\text { Stress }\end{array}$} & \multicolumn{2}{c|}{$\begin{array}{c}\text { Cross } \\
\text { Sectional } \\
\text { Area }\end{array}$} & \multicolumn{2}{c|}{$\begin{array}{c}\text { Yield } \\
\text { Strength }\end{array}$} & \multicolumn{2}{c|}{$\begin{array}{c}\text { Nominal } \\
\text { Weight }\end{array}$} & \multicolumn{2}{c|}{$\begin{array}{c}\text { Max.Threadbar } \\
\text { Diameter }\end{array}$} \\
\hline & $\begin{array}{c}\text { in- } \\
\text { lb }\end{array}$ & $\mathrm{mm}$ & $\mathrm{ksi}$ & $\mathrm{Mpa}$ & $\mathrm{in}^{2}$ & $\mathrm{~mm}^{2}$ & $\mathrm{kips}$ & $\mathrm{kN}$ & $\mathrm{lbs} / \mathrm{lf}$ & $\mathrm{kg} / \mathrm{m}$ & in & $\mathrm{mm}$ \\
\hline 60 & $\# 6$ & 19 & 60 & 414 & 0.44 & 284 & 26.4 & 118 & 1.50 & 2.24 & 0.86 & 21.8 \\
\hline 60 & $\# 7$ & 22 & 60 & 414 & 0.60 & 387 & 36.0 & 160 & 2.04 & 3.04 & 0.99 & 25.1 \\
\hline 60 & $\# 8$ & 25 & 60 & 414 & 0.79 & 510 & 47.4 & 211 & 2.67 & 3.98 & 1.12 & 28.4 \\
\hline 75 & $\# 6$ & 19 & 75 & 517 & 0.44 & 284 & 33.0 & 147 & 1.50 & 2.24 & 0.86 & 21.8 \\
\hline 75 & $\# 7$ & 22 & 75 & 517 & 0.60 & 387 & 45.0 & 200 & 2.04 & 3.04 & 0.99 & 25.1 \\
\hline 75 & $\# 8$ & 25 & 75 & 517 & 0.79 & 510 & 59.3 & 264 & 2.67 & 3.98 & 1.12 & 28.4 \\
\hline 75 & $\# 9$ & 29 & 75 & 517 & 1.00 & 645 & 75.0 & 334 & 3.40 & 5.06 & 1.26 & 32.0 \\
\hline 75 & $\# 10$ & 32 & 75 & 517 & 1.27 & 819 & 95.3 & 424 & 4.30 & 6.41 & 1.43 & 36.3 \\
\hline 75 & $\# 11$ & 36 & 75 & 517 & 1.56 & 1006 & 117.0 & 520 & 5.31 & 7.91 & 1.61 & 40.9 \\
\hline 75 & $\# 14$ & 43 & 75 & 517 & 2.25 & 1452 & 168.8 & 751 & 7.65 & 11.39 & 1.86 & 47.2 \\
\hline
\end{tabular}

There are five types of soil nails: Driven nails, grouted nails, corrosion-protected nails, jet grouted nails, and launched nails (Goldstein, 2001).

Driven nails are generally small-diameter nails $(15-46 \mathrm{~mm})$ with a relatively limited length (to about $20 \mathrm{~m}$ ) made of mild steel (about $50 \mathrm{ksi}$ ) that are closely spaced in the wall (two to four nails per square meter). Nails with an axial channel can be used to permit the addition of grout sealing. This installation method is the quickest (four to six per hour) and most economical to establish with a pneumatic or hydraulic hammer.

Grouted nails are generally steel bars, with diameters ranging from 15 to $46 \mathrm{~mm}$, stronger than driven nails (about $60 \mathrm{ksi}$ ). Grouted nails are inserted into boreholes of $10-15 \mathrm{~cm}$ and then cement-grouted by gravity and under low pressure. Ribbed bars are also used to increase soil adhesion. 
Corrosion-protected nails are generally used for aggressive soils as well as for permanent structures. Corrosion control is necessary for long-term temporary and/or permanent works and can be prevented by using one of these methods: epoxy coatings, polyethylene sheathing, or chatodic protection.

Jet-grouted nails are composite inclusions made of grouted soil and a central steel rod that can be as thick as 30 to $40 \mathrm{~cm}$ thick. During installation, nails are installed using a high-frequency vibropercussion hammer, and cement grouting is injected. The jetgrouted installation technique has been shown to increase the pullout resistance of the composite, and the nails are corrosion-resistant.

Launched nails are between 25 and $38 \mathrm{~mm}$ in diameter and up to $6 \mathrm{~m}$ or longer are fired directly into the soil, using a compressed-air launcher. During installation, the ground around the nail is displaced and compressed. This installation technique involves the least site disturbance.

\subsubsection{Nail Heads}

The strength of nail head is one of the parameters used in design of soil-nailing practice (Shiu and Chang, 2004). The strength of the nail head determines the stability of the nailed structure against failure involving the facing element. A typical facing system is shown in Figure 2.5. Design of the nail head is out of scope of this study, but it should be noted that the nail head plays an important role in the design of the soil-nail system. 


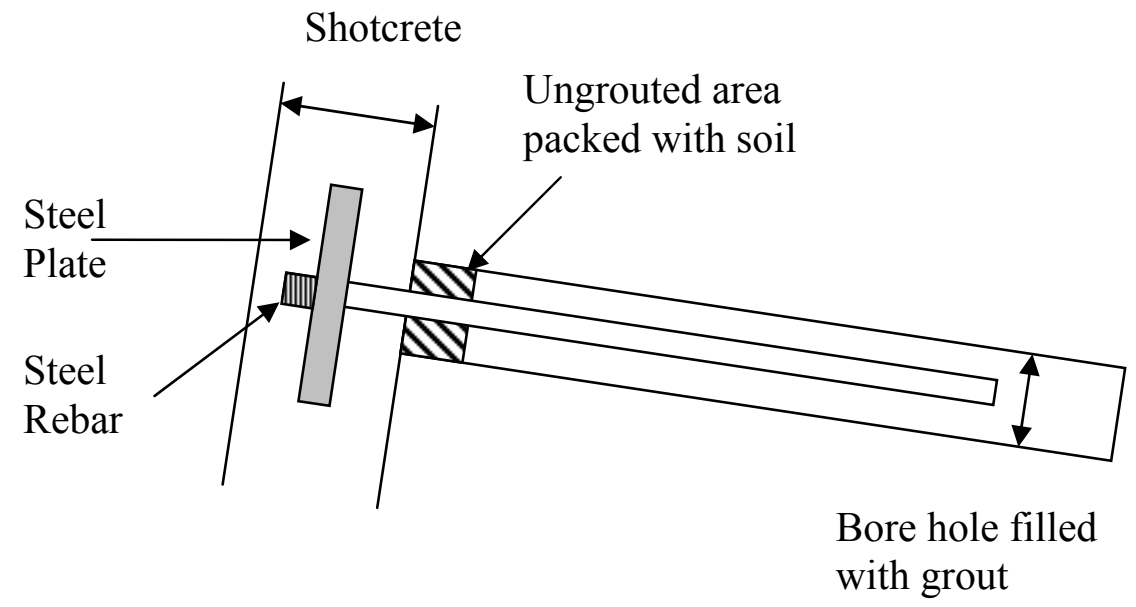

Figure 2.5: Typical soil nail, and nail head detail (Broms and Wong, 1991)

Strength of nail head is primarily governed by the flexure and/or punching shear of the facings, and nail head connection (Shong, 2005).

The flexural strength of the proposed facing system for a soil nail wall must be analyzed to assure that the loads generated by the non-uniform earth pressure between the nails can be resisted without flexural failure of the facing (Chance, 1999). A typical facing system is shown in Figure 2.6. The structural capacity of the facing can, therefore, be determined using standard reinforced concrete design procedures for singlyreinforced, rectangular concrete beams (Shong, 2005). 


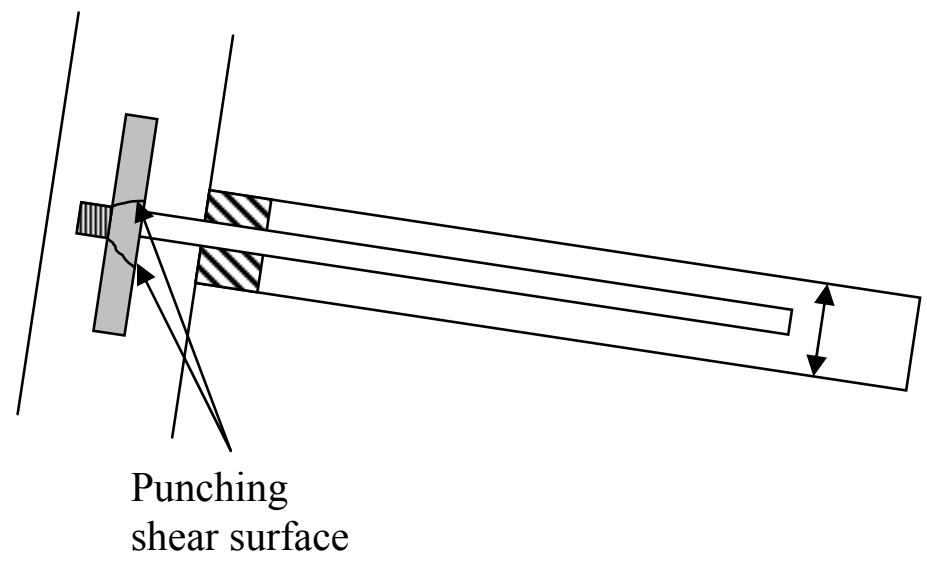

Figure 2.6: Typical punching shear of bearing plate (Broms and Wong, 1991)

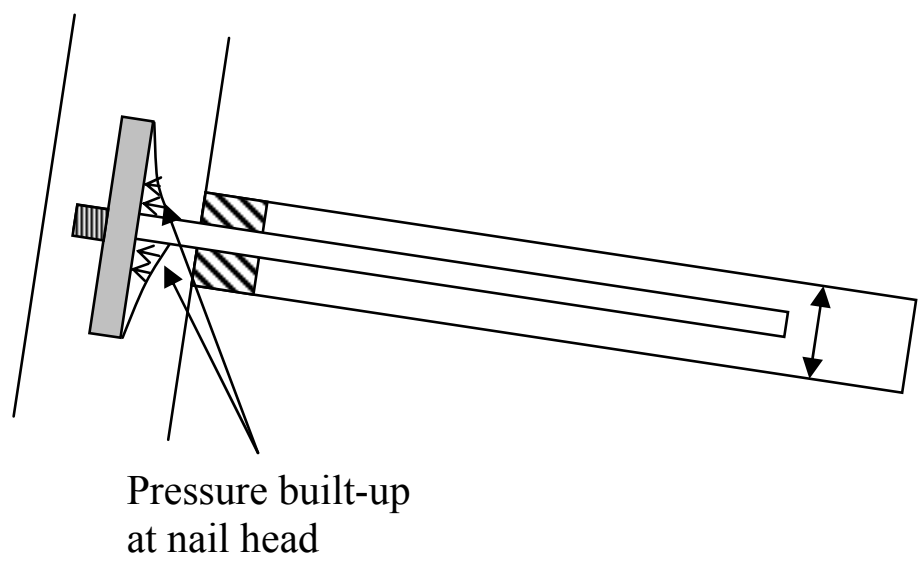

Figure 2.7: Typical facing pressure distribution on nail head detail (Broms and Wong, 1991, Shong 2005)

Punching shear failure of the connection of a soil nail system is shown in Figure 2.7, and involves punching a cone of shotcrete centered about the nail head through the facing (Chance, 1999). There are two components of the resistance of the system to punching shear; the resistance provided by the facing (shotcrete and reinforcing steel); and the resistance provided by the soil behind the facing. The analysis procedure presented herein ignores the contribution of the soil in determining the punching shear 
strength because the soil at the face of the wall is generally disturbed by the installation of the anchor and may provide little or no bearing resistance (Shong, 2005). It also assumes that the square bearing plate may be represented by a circular plate with a diameter equal to the width of the plate and that welded wire mesh steel reinforcement does not provide any shear capacity reinforcement (Chance, 1999). 


\section{CHAPTER 3 \\ NUMERICAL METHODOLOGY}

\subsection{Introduction}

Finite element method (FEM) is a powerful numerical tool for solving many engineering problems dealing with mechanical behavior of solids. With recent advancements in computer technology, the finite element method has become a popular alternative to traditional methods in geotechnical engineering. In this research, a finite element method was used to numerically obtain the factor of safety for both reinforced and unreinforced slopes. The factors of safety obtained from different theories and previous research work are compared with the numerical results from the present study to evaluate soil slope failures. Factor of safety was determined by using the shear strength reduction (SSR) technique, which was described in Chapter 2.

\subsection{Finite Element Method (FEM)}

Finite element method (FEM), also called finite element analysis (FEA), is a numerical method for solution of complex problems. Individual finite elements can be visualized as small pieces of a structure. The first step of a finite element analysis is to divide the actual geometry of a structure using a collection of discrete portions called "finite elements". Elements are connected at points called nodes. The collection of the nodes and finite elements is called the mesh. The number and the type of the elements need to be carefully chosen to effectively approximate the variables over the region of interest. The governing equations for each finite element are determined and assembled to analyze the behavior of the solid body (Cook et al. 2003), which is subjected to external loads and boundary conditions. 
The governing equation for the discritized domain can be written as:

$$
[K]\{r\}=\{R\}
$$

where,

$$
\begin{aligned}
& {[K]=\text { global stiffness matrix }} \\
& \{\mathrm{r}\}=\text { global displacement vector } \\
& \{\mathrm{R}\}=\text { global load vector }
\end{aligned}
$$

In the present study, the constitutive model used for soils was the Mohr-Coulomb criteria with non-associative plastic flow (Griffiths and Lane, 1999). Therefore, the resulting $[\mathrm{K}]$ matrix is non-symmetric (Abaqus, 2006), and the equations solved by using a non-symmetric solver (Abaqus, 2006).

\subsection{Geometry}

A number of soil problems including reinforced soil slopes were solved in this research. The novelty of this research is the analysis of reinforced slopes. However, as a first step, a number of previously solved soil slopes were re-analyzed to calibrate the present computational model. Details of some of these problems can be found elsewhere in the literature (Griffiths and Lane, 1999; Ann et al, 2004; Shiu and Chang, 2004). Two different soil slope models are presented in this paper as shown in Figure 3.5 and Figure 3.6. These models are: (a) a benchmark problem with no base, and (b) a benchmark with base (foundation soil).

The analysis of a reinforced soil slope includes three different parts: (a) soil, (b) soil nail, and (c) nail head. These parts are described below. 


\subsection{Soil Model}

The soil is considered as a non-linear elasto-plastic material in this research. In general, soils do not behave like a linear-elastic material ( $\mathrm{Yu}, 2000)$. The analysis for the soil is based upon the Mohr-Coulomb failure criterion.

The Mohr-Coulomb criterion can be expressed as (Das, 2002):

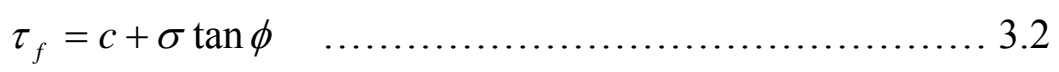

where:

$$
\begin{aligned}
& c=\text { cohesion } \\
& \phi=\text { angle of internal friction } \\
& \sigma=\text { normal stress } \\
& \tau_{\mathrm{f}}=\text { shear stress }
\end{aligned}
$$

In this paper, the soil was modeled as a homogeneous, two-dimensional, plane strain medium. It was assumed that the soil properties do not depend on temperature. In description of the material properties of soil, non-associated Mohr-Coulomb plasticity model is used. The soil model included six parameters:

$$
\begin{aligned}
& \phi^{\prime}: \text { Angle of friction (degree) } \\
& \mathrm{c}^{\prime}: \text { Cohesion } \\
& \psi: \text { Dilation angle (degree) } \\
& v: \text { Poisson's ratio } \\
& \text { E: Young's modulus }\left(\mathrm{kN} / \mathrm{m}^{2}, \mathrm{psi}\right) \\
& \gamma: \text { Unit weight }\left(\mathrm{kN} / \mathrm{m}^{3}, \mathrm{pcf}\right)
\end{aligned}
$$

The relationship between the dilation angle $\psi$, and the angle of friction $\phi^{\prime}$, determines whether the soil dilates or compacts upon plastic deformation (Fenton, 1990). 
If the ratio of dilation angle to the angle of friction $\left(\psi / \phi^{\prime}>1.0\right)$ exceeds 1.0 , then only compaction occurs. Otherwise initial compaction is followed by dilation (Fenton, 1990). Dilation is a measure of how much volume change takes place when the material undergoes shearing (Griffiths and Lane, 1999). For a Mohr-Coulomb material, dilation is an angle that generally varies between zero and the friction angle. If $\psi=\phi^{\prime}$, the plastic flow occurs according to "associative flow rule". If, $\psi=0$, then the plasticity corresponds to a "non-associated flow rule" (Griffiths and Lane, 1999). Previous studies on soil dilatancy were mostly concentrated on the theoretical analysis of the dilation angle, and its influence on soil strength (Chen et al, 2003). Very few actual test data of dilation angles were reported (Chen et al, 2003). In this study, the volume change in soil during the failure was not considered. Therefore, dilation angle, $\psi$, was taken as zero.

Poisson's ratio, $v$, and Young's ratio, E, are the elastic parameters of the soil. Although, these parameters have a significant influence on the computed deformations prior to failure, they have very little influence on the predictions of factor of safety of slopes (Griffiths and Lane, 1999). In this study, constant values for soil modeling were used for these two parameters, as given below:

$$
\begin{aligned}
\mathrm{E} & =10^{5} \mathrm{kN} / \mathrm{m}^{2} \\
v & =0.3
\end{aligned}
$$

The most important parameters in the finite element analysis of slope stability analysis are: angle of friction $\phi^{\prime}$, cohesion $c^{\prime}$, and unit weight $\gamma$, and geometry of the model (Griffiths and Lane, 1999). Different values of these parameters were used in the problems solved in this research. Details of the problems solved in this research can be found in the next chapter. 


\subsection{Nail and Nail Head Model}

Nail and nail head geometric parameters were taken published literature on a "reinforced slope model" (Abaqus, 2006). Although, designing nails and nail heads are not in the main focus of this research, selection of appropriate parameters is an important task. Pre-stressed nails can be used in soil-nailed slope models in order to evaluate their effects on the failure plane and the factor of safety of slopes (Abaqus, 2006). Based on published data (Abaqus, 2006), it was assumed that the nails and the nail heads have a density of $7,800 \mathrm{~kg} / \mathrm{m}^{3}$, and an elastic modulus of $200 \mathrm{GPa}$. The nails are considered as embedded, which means they are fully bonded to the surrounding soil. Tips of nails were coupled to the upper surface of the nail heads (Figure 3.2 (b)). Nail heads were tied to the upper face of the soil slope (Figures 3.2 (a) and 3.2 (b). Nail length was varied to investigate the influence of nail length on slope stability. The length was chosen as 20 meters in all other cases for consistency among each model used in this study. Nail head parameters were kept the same in all cases.

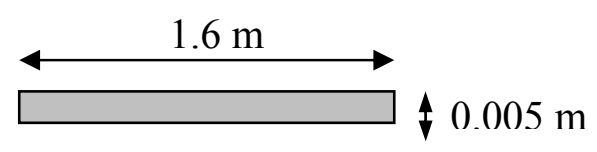

Figure 3.1: Nail head cross section used in the analysis (Abaqus, 2006)

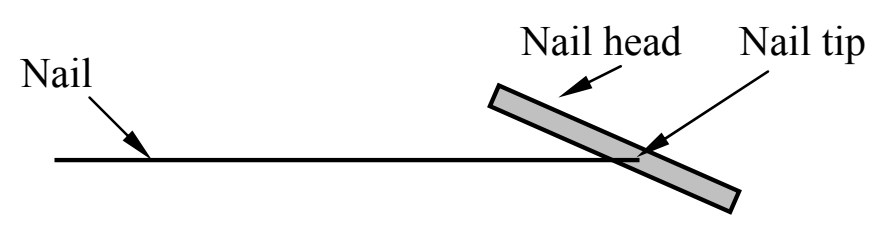

Figure 3.2 (a): Schematic detail of the connection of soil nail and the nail head 


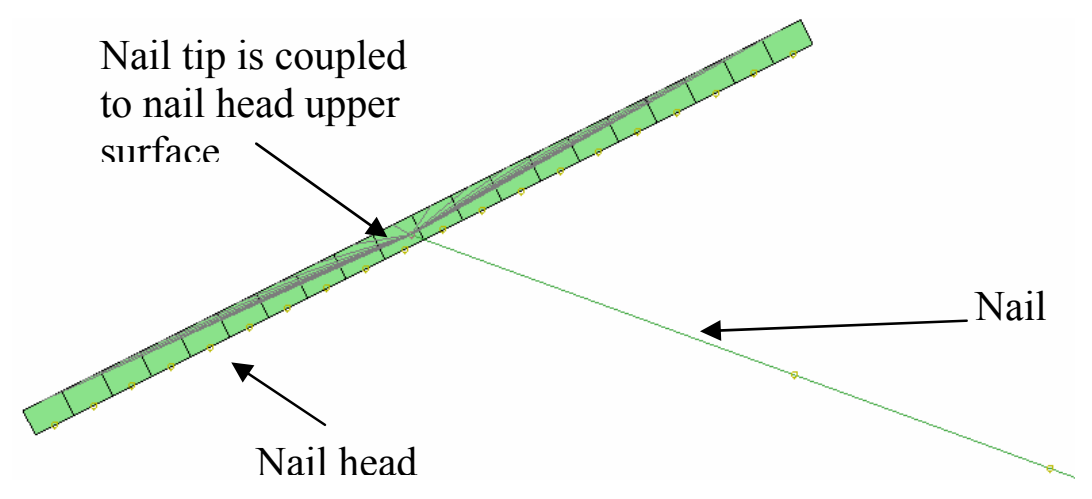

Figure 3.2 (b): Nail and nail head detail in FEA

\subsection{Element Type and Mesh Used in the Study}

Element type and mesh properties did not differ for each model in this study. The soil body (slope) was modeled by using 6-noded quadratic triangular plane strain (CPE6) elements (Figures 3.10, and 3.12). Moreover, 8-noded quadrilateral plane strain (CPE8) elements (Figures 3.11, and 3.13) were also used in the benchmark model with no base to investigate the effects of element type on computed factor of safety. Soil nails were modeled by using 2-noded linear beam (B21) in this study. Nail head was modeled by using 8-noded biquadratic plane strain (CPE8) elements. Typical finite element meshes for nail and nail head used in the study are shown in Figure 3.3. 


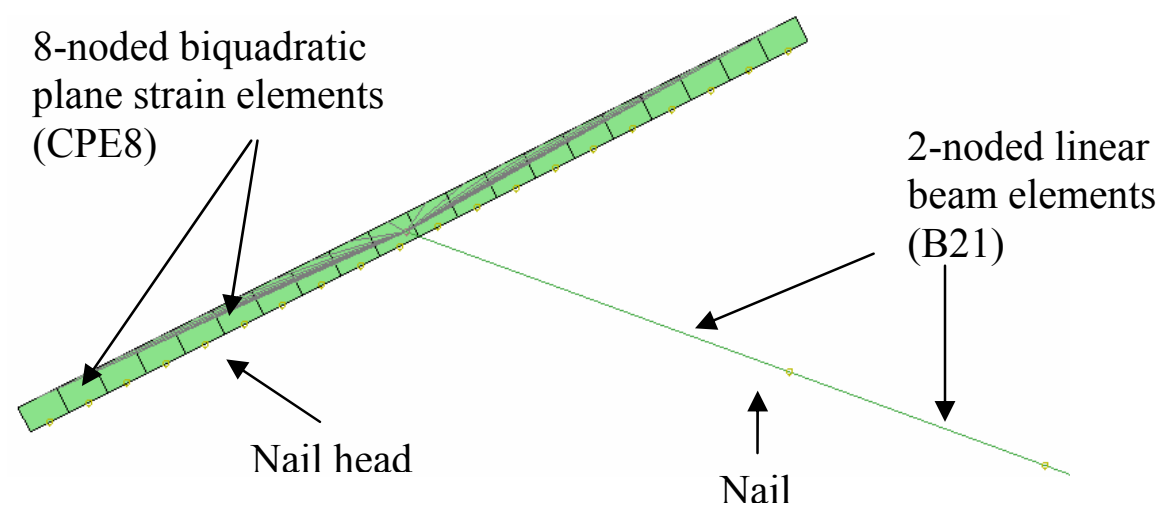

Figure 3.3: Nail and nail head element mesh details

\subsubsection{Mathematical Details of Triangular Elements (CPE6)}

A quadratic triangle has side nodes in addition to corner nodes as shown in Figure 3.4. For stress analysis, nodal unknowns (degree of freedom) are $u_{i}$ and $v_{i}$ at each node $\mathrm{i}=1,2, \ldots, 6$, can be expressed as (Cook, et al. 2003):

$$
\begin{aligned}
& \mathrm{u}=\mathrm{N}_{1} U_{1}+N_{2} U_{2}+\ldots+N_{6} U_{6} \ldots \ldots \ldots \ldots \ldots \ldots \ldots \ldots \ldots \ldots \ldots \ldots \ldots \ldots .3 \\
& v=\mathrm{N}_{1} V_{1}+N_{2} V_{2}+\ldots+N_{6} V_{6} \quad \ldots \ldots \ldots \ldots \ldots \ldots \ldots \ldots \ldots
\end{aligned}
$$

where,

$\mathrm{u}, v$ represent the nodal displacements in the $\mathrm{x}-$ and $\mathrm{y}$ - directions $\mathrm{N}_{\mathrm{i}}$, represents interpolation function. 


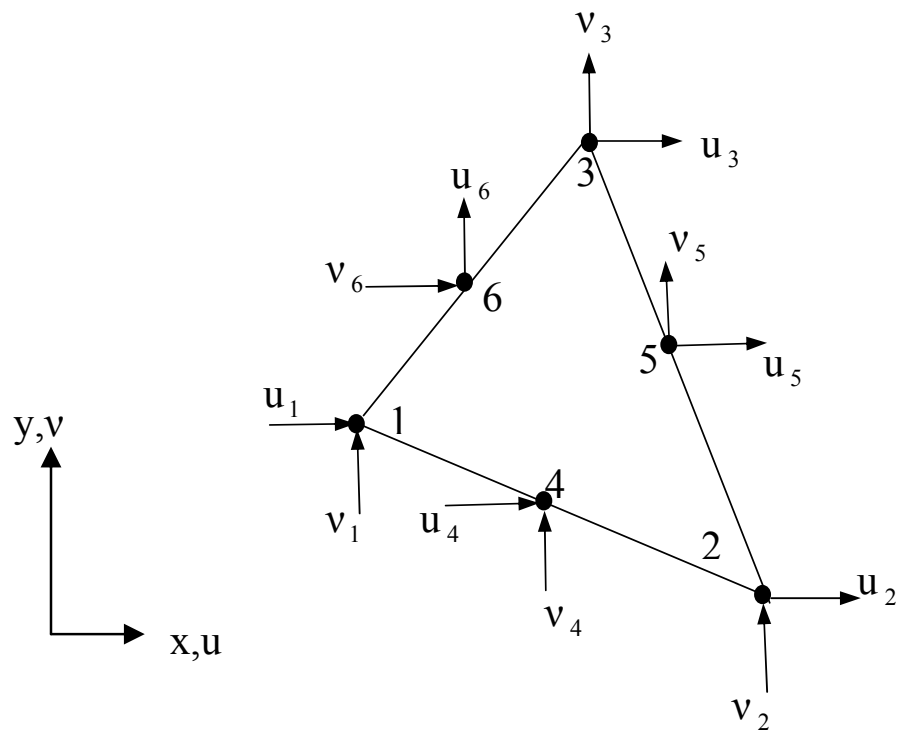

Figure 3.4: Quadratic triangle (Cook, et al. 2003)

Element strains can be expressed in terms of displacements as (Cook, et al. 2003):

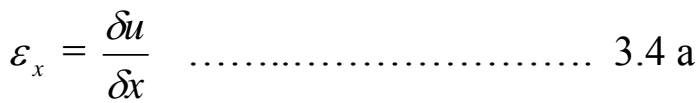

$$
\begin{aligned}
& \varepsilon_{y}=\frac{\delta v}{\delta y} \quad \ldots \ldots \ldots \ldots \ldots \ldots \ldots \ldots . . . \ldots \ldots \\
& \gamma_{x y}=\frac{\delta u}{\delta y}+\frac{\delta v}{\delta x} \quad \ldots \ldots \ldots \ldots \ldots \ldots . . .4 \mathrm{c}
\end{aligned}
$$




\subsubsection{Mathematical Details of Quadrilateral Elements (CPE8)}

A quadratic rectangle can be achieved by adding additional side notes to the linear rectangle. There are 8 nodes in quadrilateral elements as shown in Figure 3.5. The displacement field of the element can be expressed as (Cook, et al. 2003):

$$
\begin{aligned}
& \mathrm{u}=\mathrm{N}_{1} U_{1}+N_{2} U_{2}+\ldots+N_{8} U_{8} \quad \ldots \ldots \ldots \ldots \ldots \ldots \ldots \ldots . .5 .5 \\
& v=\mathrm{N}_{1} V_{1}+N_{2} V_{2}+\ldots+N_{8} V_{8} \quad \ldots \ldots \ldots \ldots \ldots \ldots \ldots \ldots \ldots .6
\end{aligned}
$$

where,

$\mathrm{u}, v$ represent the nodal displacements in the $\mathrm{x}$ - and $\mathrm{y}$ - directions

$\mathrm{N}_{\mathrm{i}}$, represents interpolation function.

Strains in the element can be expressed as:

$$
\begin{aligned}
& \varepsilon_{x}=\frac{\partial N_{1}}{\partial N_{x}} U_{1}+\frac{\partial N_{2}}{\partial N_{x}} U_{2}+\ldots+\frac{\partial N_{8}}{\partial N_{x}} U_{8} \\
& \varepsilon_{y}=\frac{\partial N_{1}}{\partial N_{y}} V_{1}+\frac{\partial N_{2}}{\partial N_{y}} V_{2}+\ldots+\frac{\partial N_{8}}{\partial N_{y}} V_{8} \\
& \gamma_{x y}=\frac{\partial N_{1}}{\partial N_{y}} U_{1}+\frac{\partial N_{2}}{\partial N_{y}} U_{2}+\ldots+\frac{\partial N_{8}}{\partial N_{y}} U_{8}+\frac{\partial N_{1}}{\partial N_{x}} V_{1}+\frac{\partial N_{2}}{\partial N_{x}} V_{2}+\ldots+\frac{\partial N_{8}}{\partial N_{x}} V_{8} . .3 .7 \mathrm{c}
\end{aligned}
$$




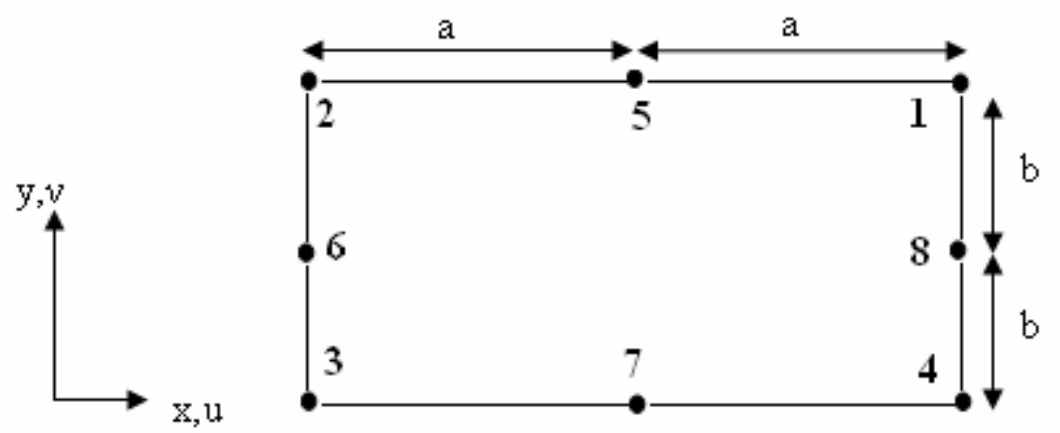

Figure 3.5: An 8-node quadrilateral element

\subsubsection{Mathematical Details of 2-noded Beam Element}

A 2-noded beam element has a node at each end and each node has two degree of freedom as shown in Figure 3.6. The stiffness matrix of a $2 \mathrm{D}$ beam element is 4 by 4 , and the load vector contains moments and forces.

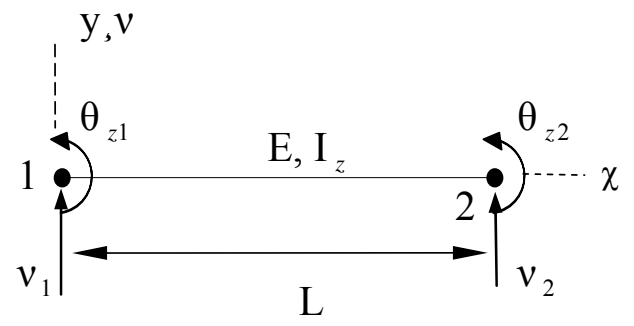

(a)

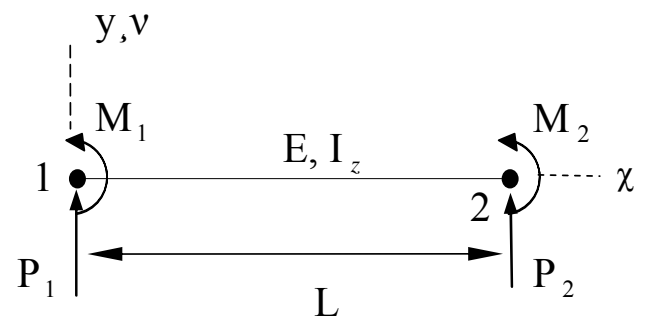

(b)

Figure 3.6: 2-noded beam element 
The complete 2-noded beam element stiffness matrix can be written as (Cook, et al. 2003):

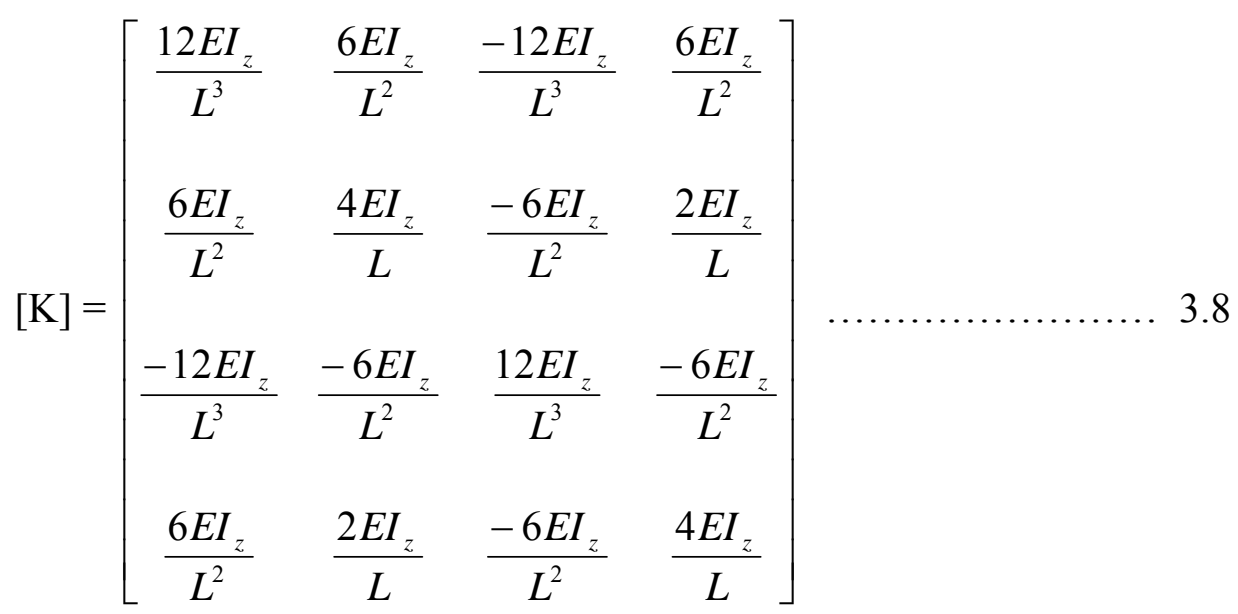

Where,

$$
\mathrm{E}=\text { elastic modulus }
$$

$\mathrm{I}_{z}=$ moment of inertia of the beam cross-sectional area about a centroidal axis parallel to the $\mathrm{z}$ axis.

$v_{1}, v_{2}=$ lateral translations

$\theta_{z 1}, \theta_{z 2}=$ rotations of the beam element

The governing equation can be expressed as:

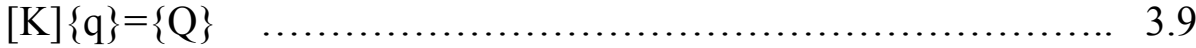

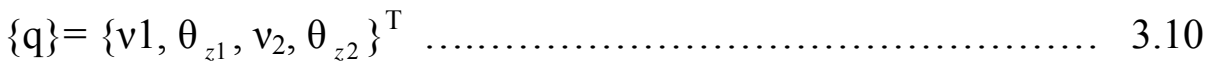

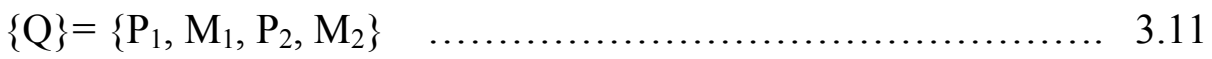

where,

$$
\begin{aligned}
& {[K]=\text { stiffness matrix }} \\
& \{\mathrm{q}\}=\text { displacement vector } \\
& \{\mathrm{Q}\}=\text { load vector }
\end{aligned}
$$




\subsection{Material Properties}

Table 3.1 and Table 3.2 shows the material properties used for this analysis. Soil\#1 is used in the modeling of benchmark problem with no base soil (see Figure 3.7), and Soil\#2 is used in the benchmark with base soil (see Figure 3.7). These two models are shown in Figure 3.7 and Figure 3.8.

Table 3.1: Soil properties

\begin{tabular}{|l|c|c|c|c|c|}
\hline Material & $\begin{array}{c}\text { Unit weight } \\
\left(\mathrm{kN} / \mathrm{m}^{3}\right)\end{array}$ & $\begin{array}{c}\text { Friction angle } \\
(\text { degree })\end{array}$ & Cohesion & $\begin{array}{c}\text { Young's Modulus } \\
\left(\mathrm{kN} / \mathrm{m}^{2}\right)\end{array}$ & Poisson's Ratio \\
\hline Soil\#1 & 20 & 20 & 10 & $10^{5}$ & 0.3 \\
\hline Soil\#2 & 20.2 & 19.6 & 3 & $10^{5}$ & 0.3 \\
\hline
\end{tabular}

Table 3.2: Reinforcement properties

\begin{tabular}{|l|c|c|c|}
\hline Reinforcement & $\begin{array}{c}\text { Unit weight, } \gamma \\
\left(\mathrm{kg} / \mathrm{m}^{3}\right)\end{array}$ & $\begin{array}{c}\text { Young's Modulus, E } \\
(\mathrm{GPa})\end{array}$ & Poisson's Ratio, $v$ \\
\hline Nail & 7,800 & 200 & 0.3 \\
\hline Nail head & 7,800 & 200 & 0.3 \\
\hline
\end{tabular}

\subsection{Loading, and Boundary Conditions}

\subsubsection{Loading}

In all cases, it was assumed that there is no external load other than the gravitational forces (i.e. body force). A negative (downward) $1 \mathrm{kN}$ gravity force is applied to the whole embankment to replicate the gravity load. 


\subsubsection{Boundary Conditions}

Two different geometries were used in this study: A benchmark embankment with no base (or foundation), and a benchmark embankment with base. On the benchmark (with no base), the bottom of the embankment is fixed and the left side to the vertical, rollers was used as shown in Figure 3.7.

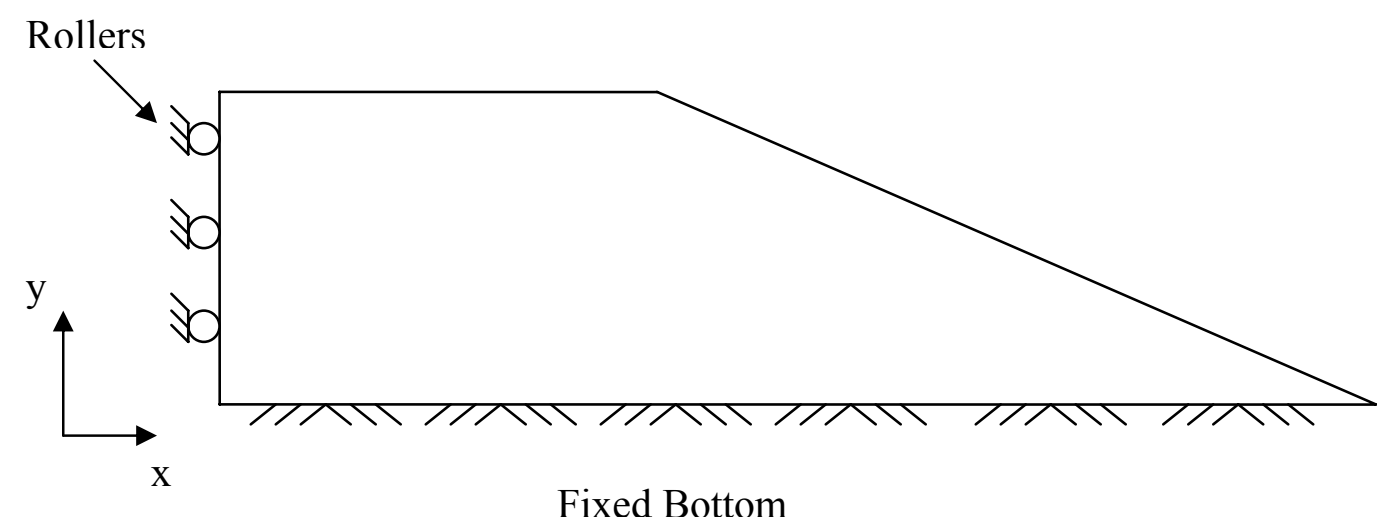

Figure 3.7: Boundary conditions used in benchmark model with no base soil

On the second model (benchmark with base soil), the bottom of the embankment is fixed and the two sides to the vertical, rollers was used as seen in Figure 3.8.

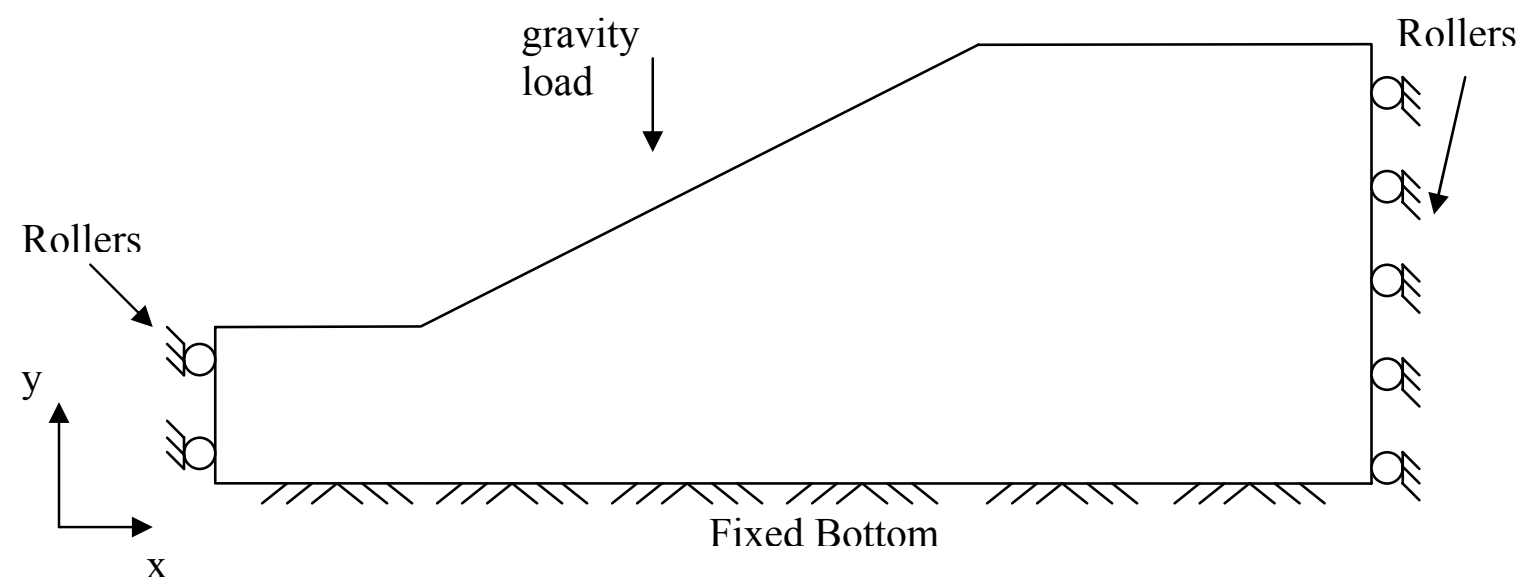

Figure 3.8: Boundary conditions on benchmark model with base soil 


\subsection{Case Studies: Numerical Modeling of Unreinforced Slopes}

There are two cases in this section: (a) a homogenous benchmark with no base, and (b) a homogenous benchmark with base. The purpose of this section was to study the effects of mesh refinement by using both linear triangular and linear quadrilateral elements in these two cases. The mesh refinement is determined by the selection of approximate global size.

\subsubsection{Case 1: A Homogenous Slope with No Base}

In the present study, a slope stability benchmark example has been considered. This benchmark problem was solved by using different theories as explained in the literature (Griffiths et al, 1999; Ann et al, 2004; Shiu et al, 2004) and earlier chapters. The benchmark problem considers a uniform soil with homogeneous slope. The factors of safety obtained from different theories are compared with the numerical results to assess how close or far the slopes are from failure. Figure 3.9 shows the geometry of the embankment used in the benchmark problem. In the present study, the slope of the embankment is inclined at 26.565 degrees to the horizontal and is raised to $10 \mathrm{~m}$ above the ground.

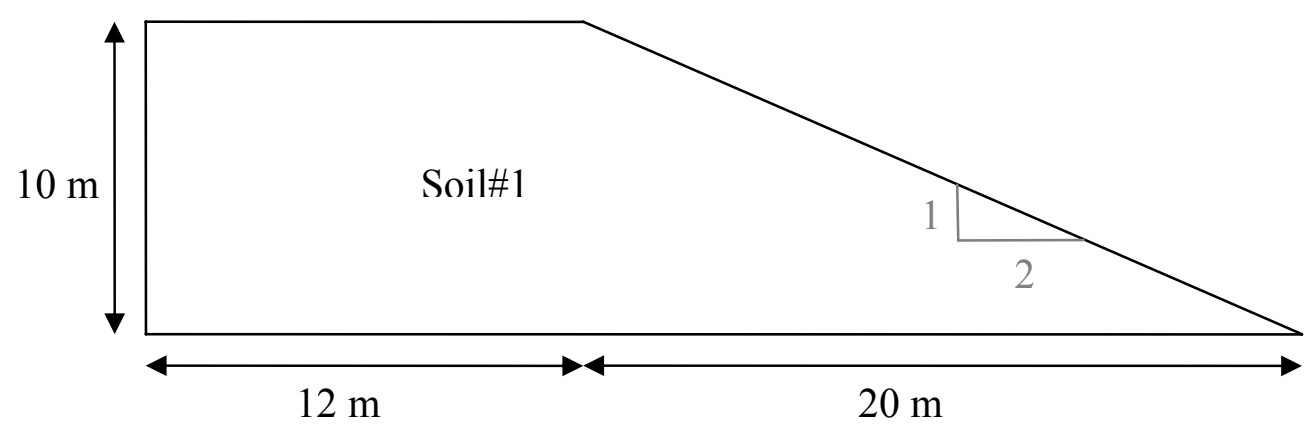

Figure 3.9: Geometry of the benchmark model with no base model 
In this example, four different mesh configurations were used to study the effects of mesh refinement on factor of safety (see Figures 3.10, 3.11, 3.12 and 3.13).

\section{Analysis 1}

6-node quadratic plane strain triangle elements were used for meshing. There were 790 active elements and 1677 active nodes on the mesh body (see Figure 3.10).

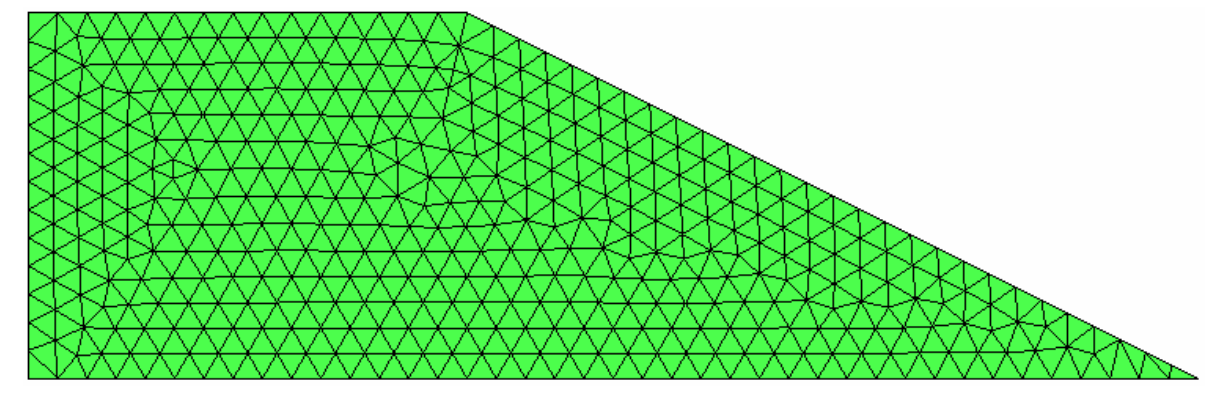

Figure 3.10: 6-node quadratic plane strain triangle elements with approximate global size of 0.8 .

\section{Analysis 2}

8-node biquadratic plane strain quadrilateral elements were used for meshing. There were 353 active elements and 1152 active nodes on the mesh body (see Figure $3.11)$.

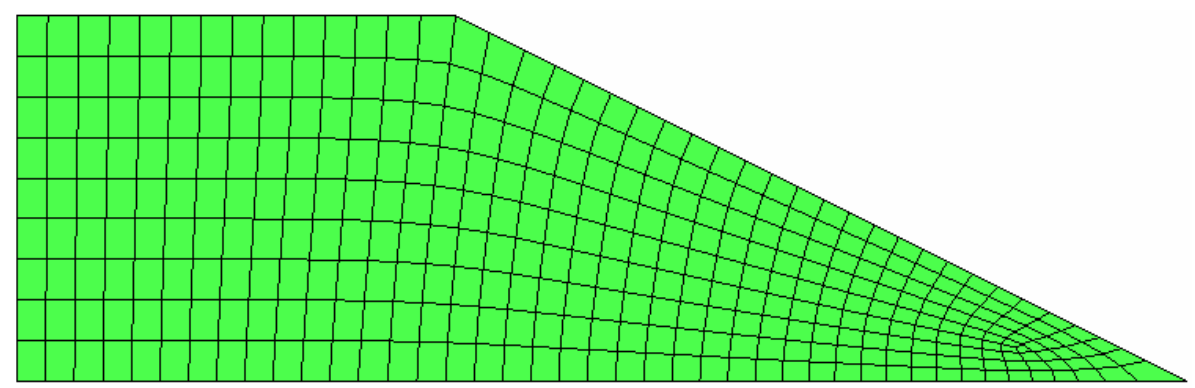

Figure 3.11: 8-node biquadratic plane strain quadrilateral elements with approximate global size of 0.8 


\section{Analysis 3}

6-node quadratic plane strain triangle elements were used for meshing. There were 2781 active elements and 5754 active nodes on the mesh body (see Figure 3.12).

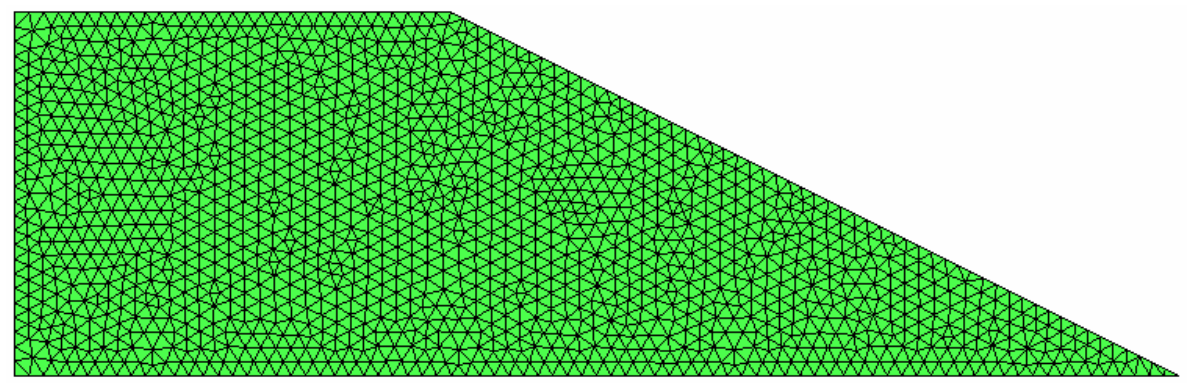

Figure 3.12: 6-node quadratic plane strain triangle elements with approximate global size of 0.4

\section{Analysis 4}

8-node biquadratic plane strain quadrilateral elements were used for meshing. There were 1496 active elements and 7495 active nodes on the mesh body (see Figure $3.13)$.

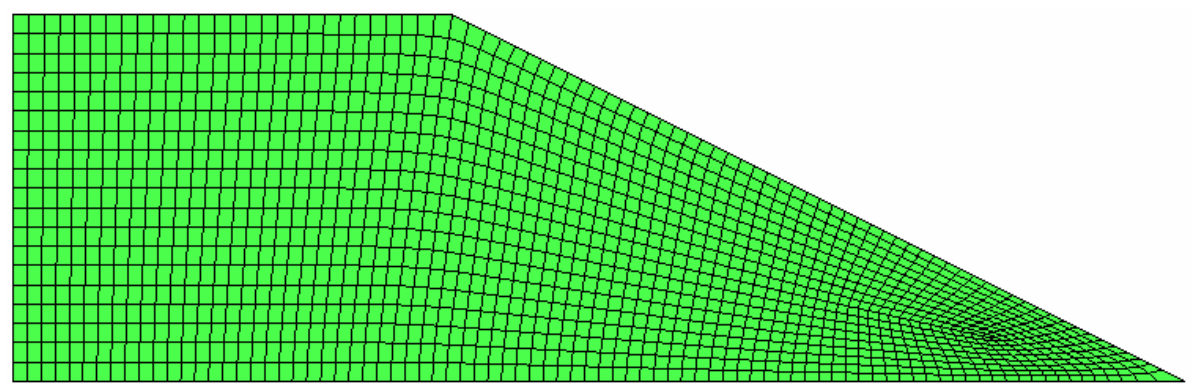

Figure 3.13: 8-node biquadratic plane strain quadrilateral elements with approximate global size of 0.4

In the analyses 1 and 2, approximate global size of 0.8 was used for meshing. And, approximate global size of 0.4 was used in analysis 3 and 4 . The value of 0.4 produces finer mesh then the size value of 0.8 . 


\subsubsection{Case 2: A Homogenous Slope with Base}

The second model has the same dimensions with the previous example except a $5 \mathrm{~m}$ deep base part is added to the bottom as shown in Figure 3.14. Soil\#2 properties were used in this analysis. The geometry of the embankment is shown in Figure 3.14 below. In this model, material properties were kept same in order to have an accurate comparison among cases that have the same geometry. The factor of safety was computed when there was no reinforcement in the embankment. It was compared with factor of safety with reinforcement later in this chapter.

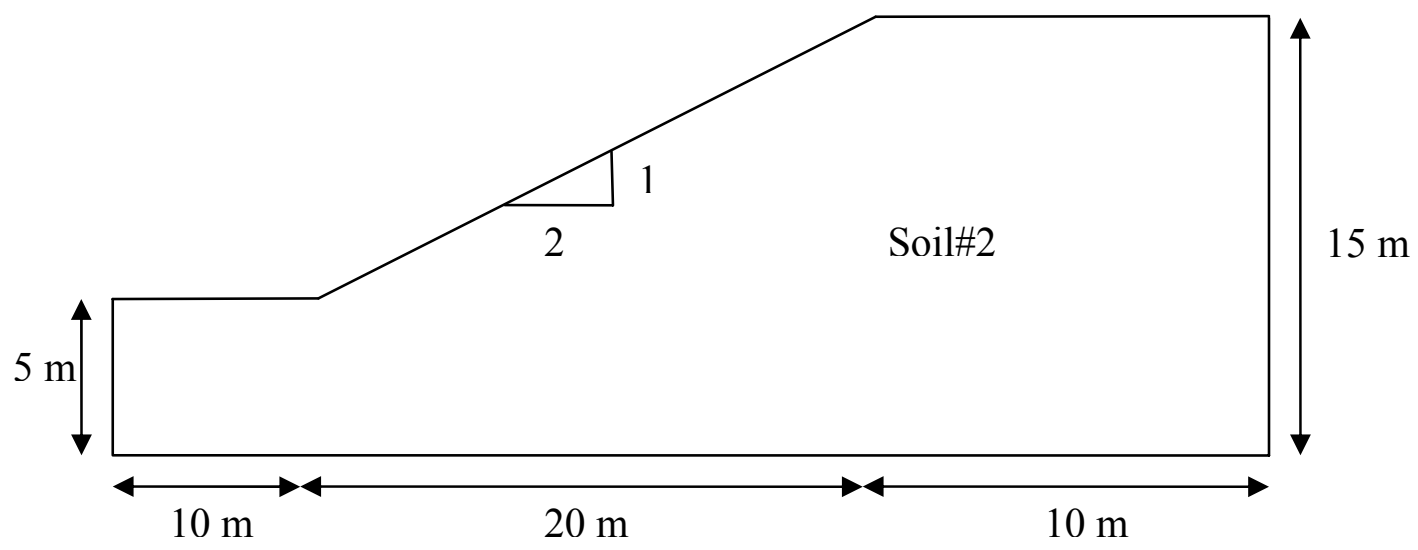

Figure 3.14: Geometry of the benchmark model with base soil

In this case, three different meshing systems were used to study the influence of finite element mesh on the factor of safety. Approximate global size for mesh refinement was varied from 0.8 to 1.5 for each analysis. Finite element meshes used in this study are shown in Figures 3.15, 3.16, and 3.17. 


\section{Analysis 1}

6-node quadratic plane strain triangle elements (CPE6) were used for meshing. There were 728 active elements and 541 active nodes on the mesh body (see Figure 3.15). Approximate global size of discretization was 1.5.

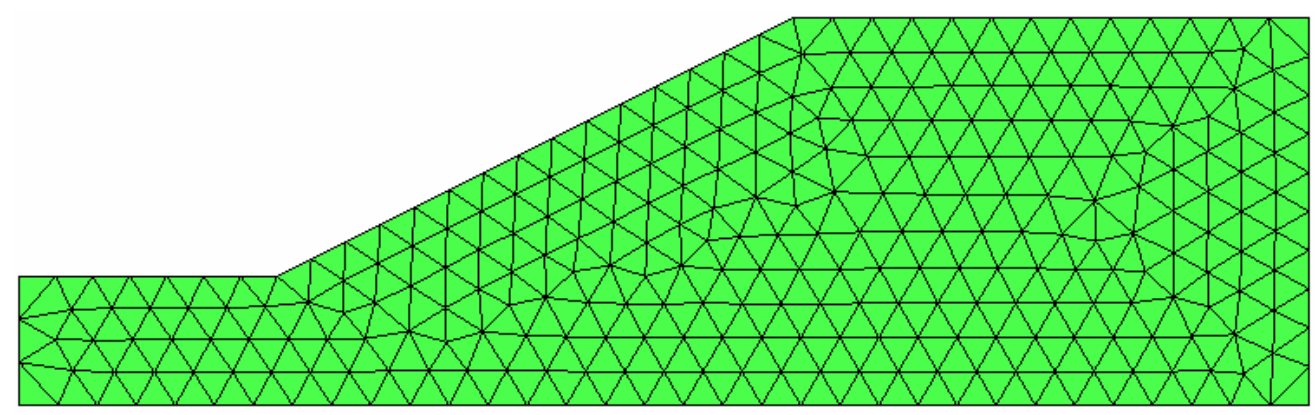

Figure 3.15: 6-node quadratic plane strain triangle elements (CPE6)

\section{Analysis 2}

6-node quadratic plane strain triangle elements (CPE6) were used for meshing. There were 1174 active elements and 1551 active nodes on the mesh body (see Figure 3.16). Approximate global size of discretization was 1.3.

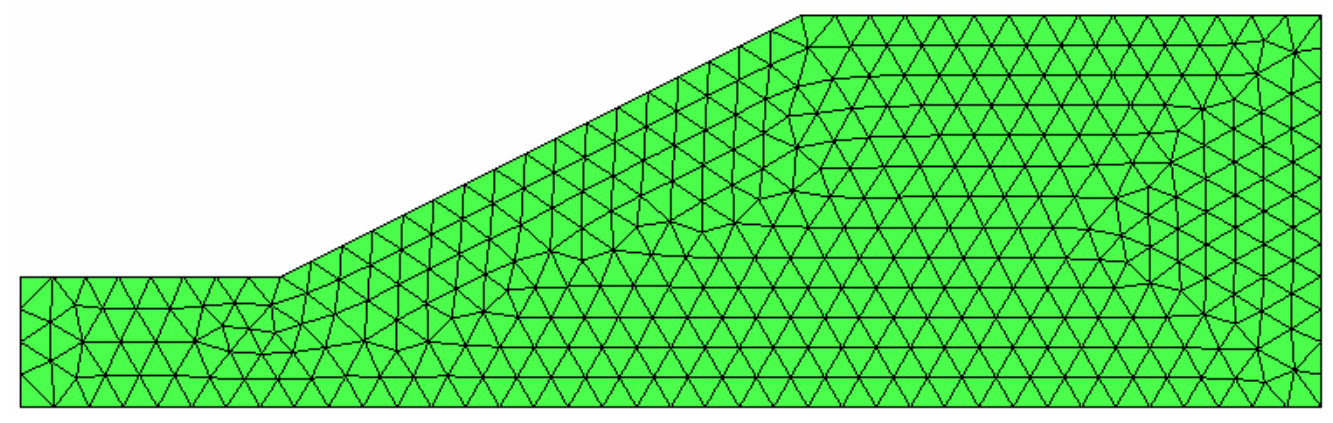

Figure 3.16: 6-node quadratic plane strain triangle elements (CPE6) 


\section{Analysis 3}

6-node quadratic plane strain triangle elements (CPE6) were used for meshing. There were 1397 active elements and 2932 active nodes on the mesh body (see Figure 3.17). Approximate global size of discretization was 0.9 .

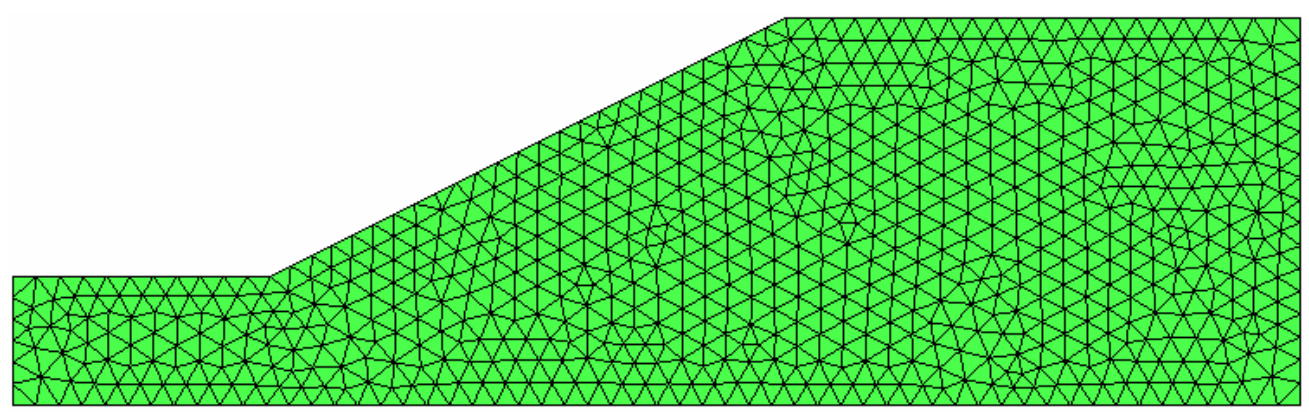

Figure 3.17: 6-node quadratic plane strain triangle elements (CPE6)

\subsection{Numerical Modeling of Reinforced Slopes}

In this section, numerical modeling of reinforced slopes was studied on a homogenous benchmark model with no base soil, and a homogenous benchmark with base soil.

\subsubsection{Influence of Soil Nail Length}

Two models are analyzed in this section: a) benchmark with no soil base with one nail and b) benchmark with soil base with one nail.

\section{a) Benchmark with No Soil Base with One Nail}

In this section, the influence of nails on stability of slopes was examined. The factor of safety of the unreinforced slope was obtained from the previous benchmark example. The geometry of the benchmark model and the material parameters were kept the same in this section, in order to evaluate the soil nail influence on the factor of safety. Deformation contours were compared and presented with and without soil nails. A nail was placed $2 \mathrm{~m}$ above vertically from the toe. Figure 3.18 shows the geometry of the 
benchmark model used in this study. Nail length, L, was varied as $10 \mathrm{~m} ., 15 \mathrm{~m}$., and $20 \mathrm{~m}$. Effects of the length of the nail were studied in this example.

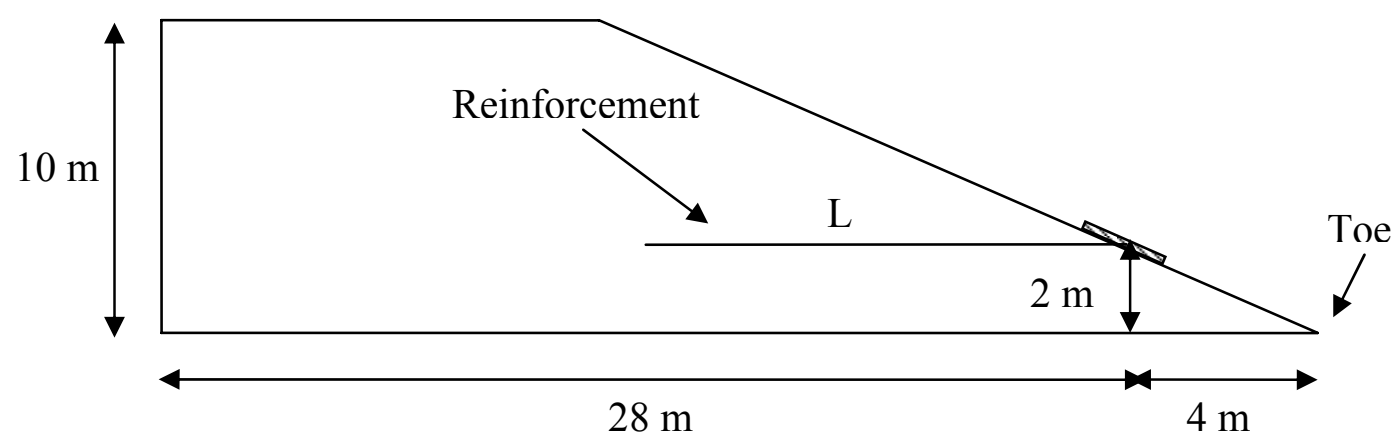

Figure 3.18: Geometry of the benchmark with one soil nail.

\section{b) Benchmark with Soil Base with One Nail}

This section will examine the effects of the nail length. Similar to the previous analysis, all the variables were kept constant except for the nail length. Nail inclination $\alpha$, was chosen as 20 degrees. A nail was placed $5 \mathrm{~m}$ above vertically from the toe as shown in Figure 3.18. The factor of safety was obtained when there was only one nail with varying length. Nail length, L, was varied as $4 \mathrm{~m}$ to $15 \mathrm{~m}$ (see Figure 3.19). 


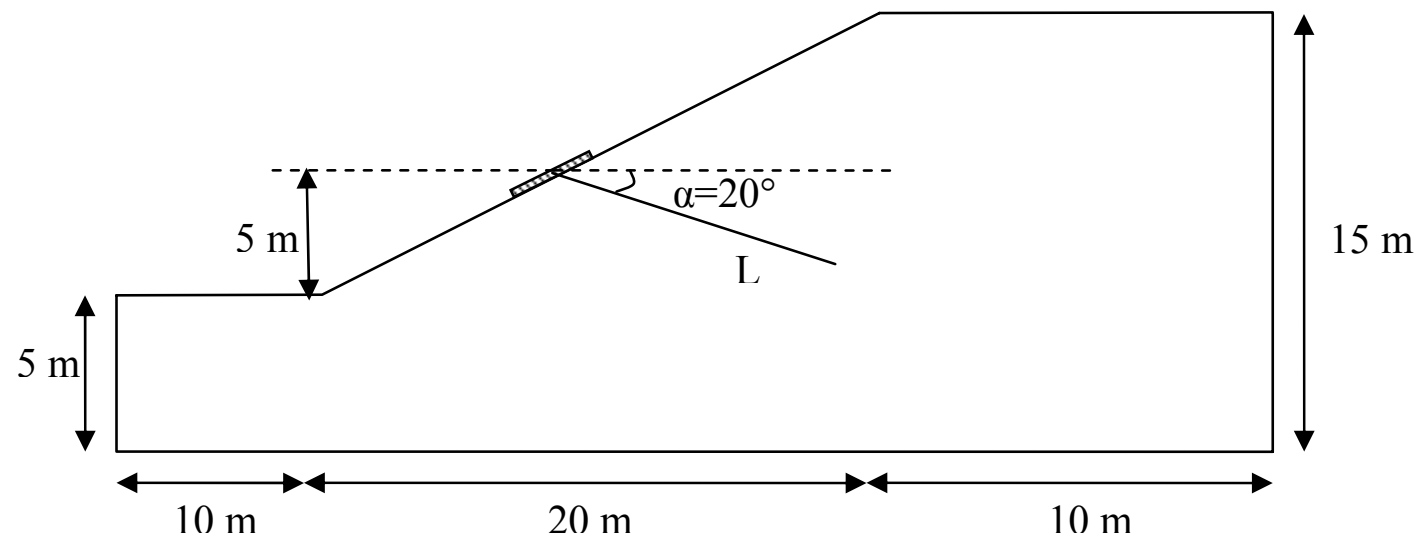

Figure 3.19: Geometry of the benchmark with base with one soil nail.

\subsubsection{Influence of Soil Nail Inclination}

The study on the influence of nail inclination is presented in this section. Similar to analysis procedure followed in previous sections, all the variables were kept constant except the inclination angle, $\alpha$. A $10 \mathrm{~m}$ long nail was placed $5 \mathrm{~m}$ above vertically from the toe. Inclination was changed in two directions: clockwise inclination and counterclockwise inclination (upward direction). The counter clockwise direction is not very common in the field practice. In order to measure the numerical effects of soil nail inclination, this direction was studied. Nail inclination was varied from 0 degree to 20 degree in clockwise direction and from 0 degree to 45 degree in upward direction (see Figure 3.20). 


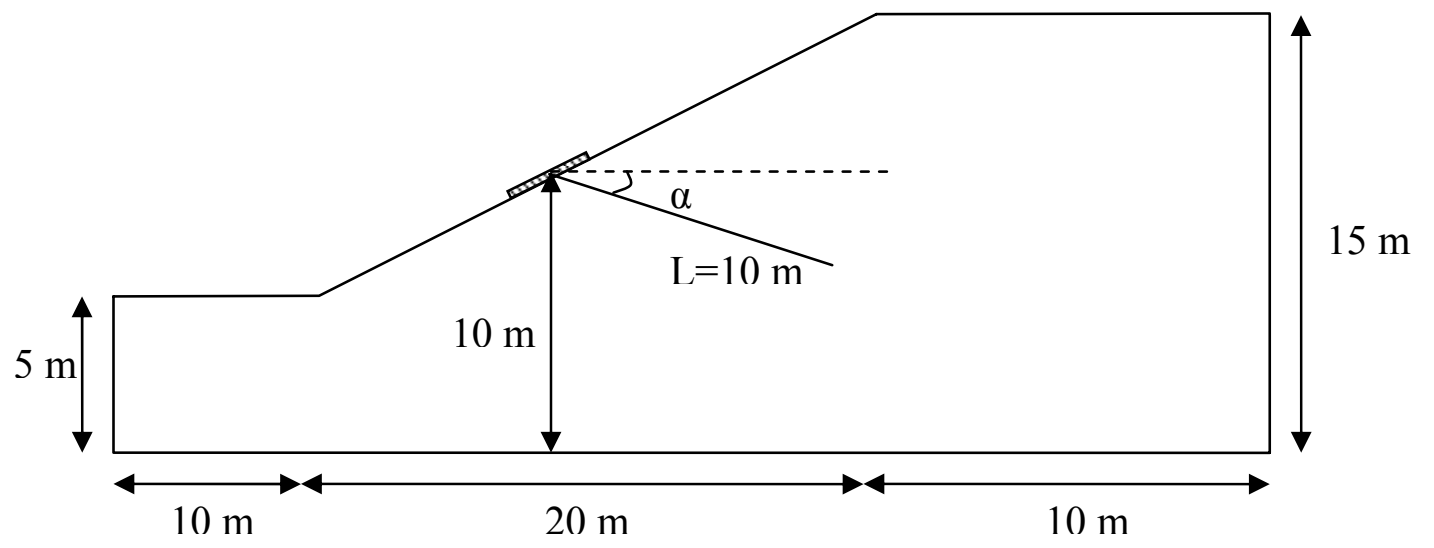

Figure 3.20: Geometry of the benchmark with base with inclined nail

\subsubsection{Influence of Soil Nail Location}

In this section the effects of location of soil nail is examined. A $10 \mathrm{~m}$ long nail was placed at different locations (Figure 3.21) to study the effects of the nail location. One nail was used in each simulation. Along with small increments, the nail was placed starting from the toe level of the slope to $9 \mathrm{~m}$ above vertically from toe. Similar to the previous examples, all the variables were kept constant except the location of the nail.

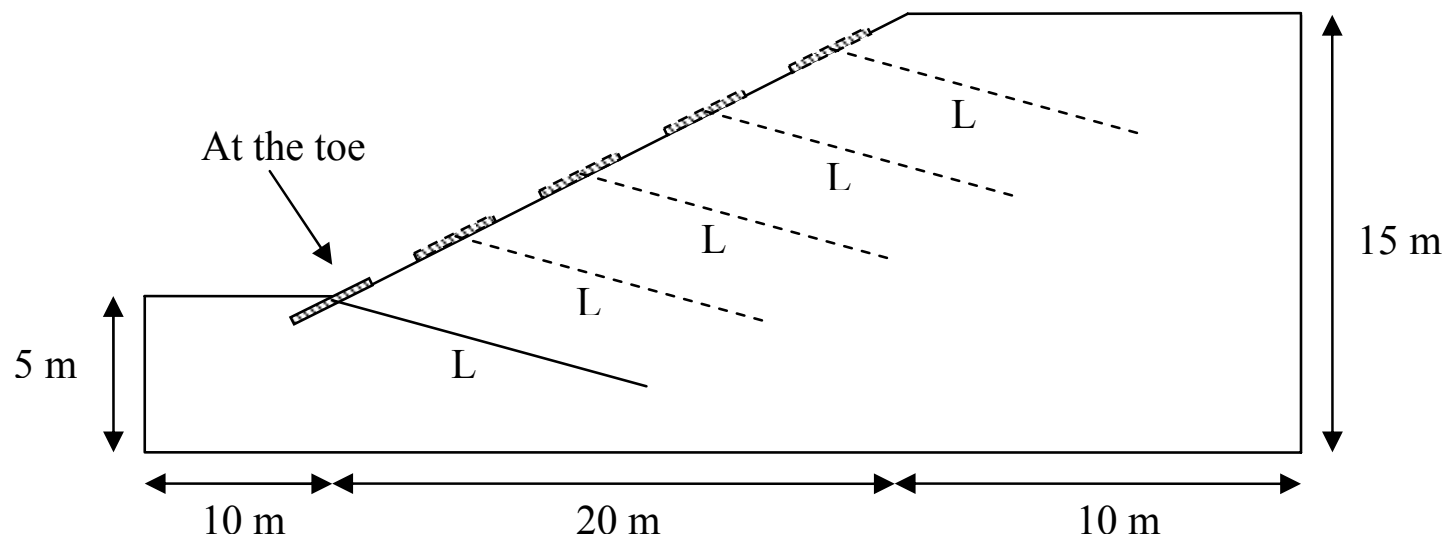

Figure 3.21: Geometry of the benchmark with base with different locations 


\subsubsection{Influence of Multiple Nails}

In addition to the single nail study, multiple nails were placed into the slope surface as shown in Figure 3.22. In this section, the number of nails was increased from one to three to examine the effects of multiple nails. The length of the nails was chosen as $10 \mathrm{~m}$. The vertical spacing of the nails was $2 \mathrm{~m}$ and the horizontal spacing was $4 \mathrm{~m}$ (see Figure 3.22). The material properties of soil, nails and nail heads were the same as previous examples. Single nail case was compared with two-nail and three-nail case in terms of the factor of safety values.

Results from all these cases are shown in the next chapter.

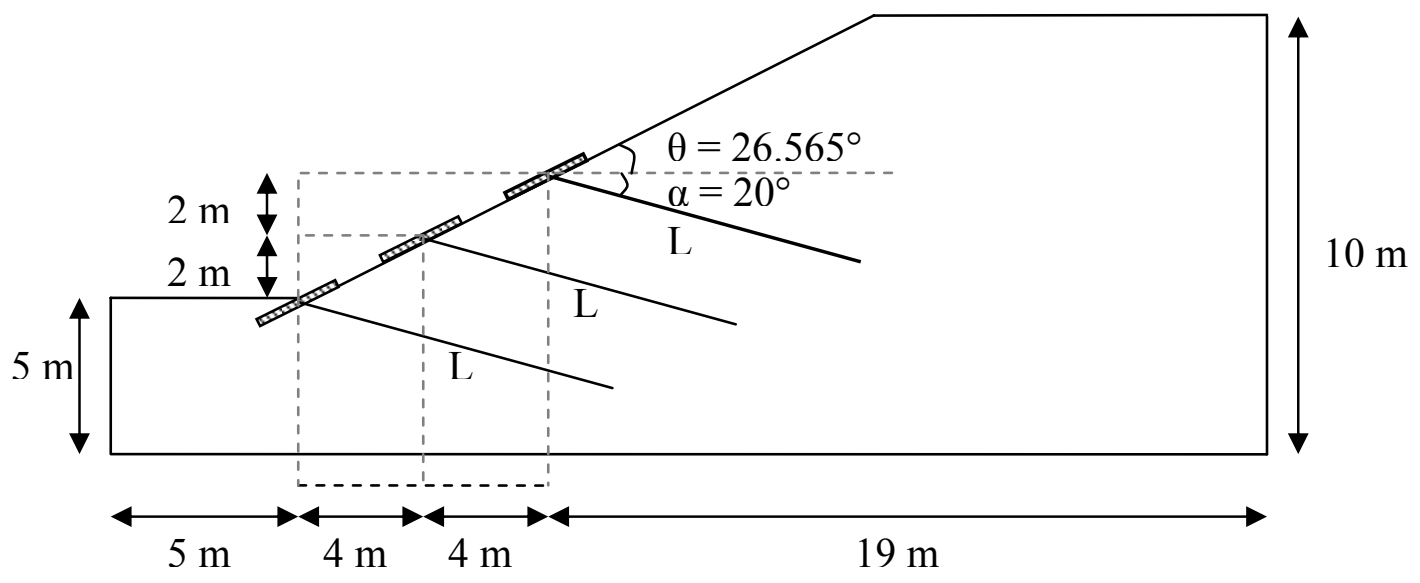

Figure 3.22: Geometry of the benchmark with base with multiple nails 


\section{CHAPTER 4}

\section{RESULTS and DISCUSSIONS}

\subsection{Introduction}

In the present study, two-dimensional finite element analyses were performed using ABAQUS to evaluate stability of slopes with and without reinforcement. Analyses were performed on two different slopes (geometric models) with several different cases as described in the previous chapter. The factors of safety for each analysis were obtained from different theories and previous research work reported in the literature (Griffiths and Lane, 1999; Ann et al, 2004; Shiu and Chang, 2004). The results are compared with the numerical results to evaluate the suitability of numerical methods to analyze slope failures. Also, the results obtained from ABAQUS are compared with results obtained from other finite element schemes reported in the literature (Griffiths and Lane, 1999). In finite element analyses, the factor of safety is determined by using the Shear Strength Reduction (SSR) technique which was explained in previous chapters.

\subsection{Results for Unreinforced Slopes}

The results are shown for the following cases in this section: a homogenous slope model with no base soil, and a homogenous slope with base soil.

\subsubsection{Case 1: A Homogenous Slope with No Base}

In this example, four different meshing systems were used to study the effects of concentration of mesh refinement on factor of safety. The results are shown in Table 4.1 from the analyses $1,2,3$, and 4 . The computed factor of safety ranged from 1.32 to 1.401 as shown in Table 4.1. These minimum and maximum values are less than $3 \%$ away from those obtained from limit equilibrium methods. However, the difference of computed factor of safety using CPE6 and CPE8 elements are slightly larger than 5\%. As would be expected, the finer mesh gives more conservative results than the coarser mesh. The factor of safety using CPE6 and CPE8 from Analyses 1 and 2, are very close to the results reported by Griffiths (Griffiths et. al. 1999). 
The deformed finite element meshes corresponding to these cases are shown in Figures 4.1(a), 4.2 (a), 4.3 (a), and 4.4(a). The equivalent plastic strain measure in finite element analysis can be used to assess the accumulation of plastic strain in the soil region (Abaqus, 2006). Figures 4.1 (b), 4.2 (b), 4.3 (b), and 4.4 (b) show contours of the equivalent plastic strain for Case 1. Additionally, a $5 \mathrm{~m}$ base was added to this slope to investigate the influence of soil base on the factor of safety (see Appendix A). The computed factor of safety was found as 1.395 .

Table 4.1: Computed Factor of safety for Case 1

\begin{tabular}{|l|c|c|c|c|}
\hline Case 1 & $\begin{array}{c}\text { Metho } \\
\mathrm{d}\end{array}$ & Mesh & $\begin{array}{c}\text { Factor of } \\
\text { Safety }\end{array}$ & $\begin{array}{c}\text { Percentage difference in } \\
\text { FS compared to Griffiths' } \\
\text { results }\end{array}$ \\
\hline Analysis 1 (790 elements) & FE & CPE6 & 1.401 & $-0.07 \%$ \\
\hline Analysis 2 (353 elements) & FE & CPE8 & 1.385 & $1.07 \%$ \\
\hline Analysis 3 (2781 elements) & FE & CPE6 & 1.341 & $4.21 \%$ \\
\hline Analysis 4 (1496 elements) & FE & CPE8 & 1.329 & $5.07 \%$ \\
\hline Griffiths' (1999) & FE & Q8 & 1.400 & - \\
\hline Janbu (Slope/W) & LEM & - & 1.390 & $0.71 \%$ \\
\hline Bishop (Slope/W) & LEM & - & 1.382 & $1.29 \%$ \\
\hline M-P (Slope/W) & LEM & - & 1.392 & $0.57 \%$ \\
\hline
\end{tabular}

*FS $=$ Factor of Safety

*M-P= Morgenstern-Price Method

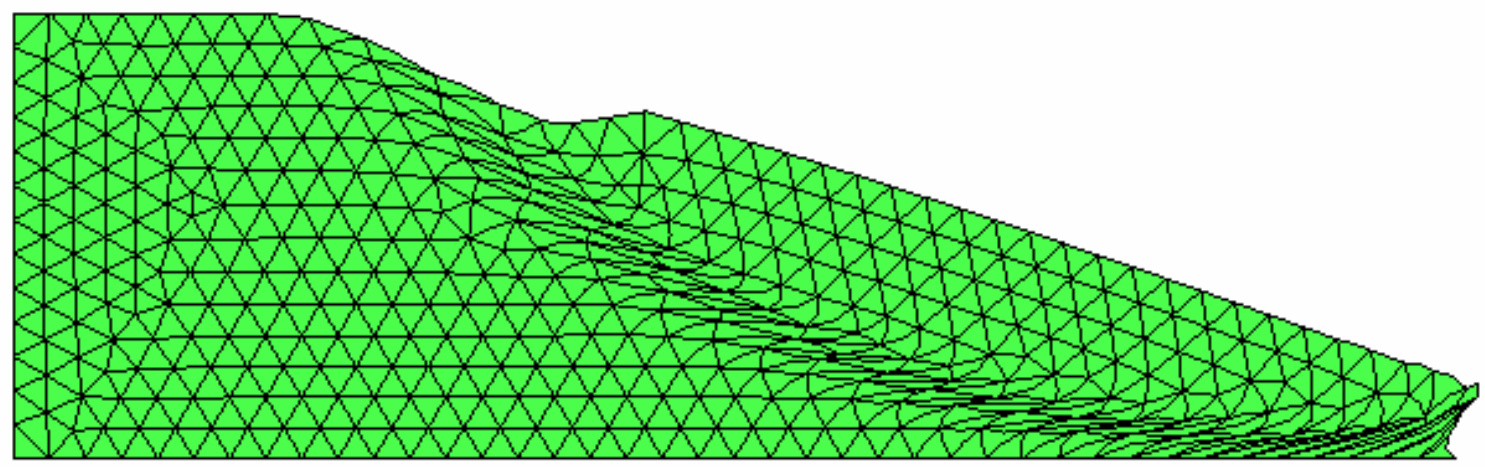

Figure 4.1 (a): Deformed mesh with CPE6 elements (Analysis 1) 


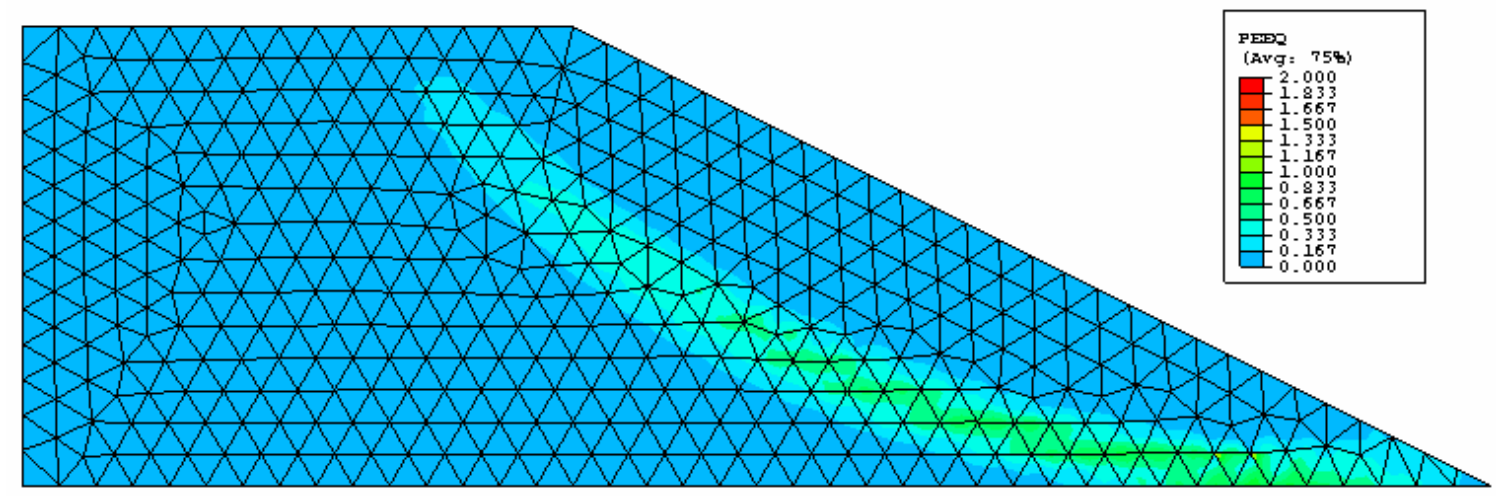

Figure 4.1 (b): The equivalent plastic strain contour for Analysis 1

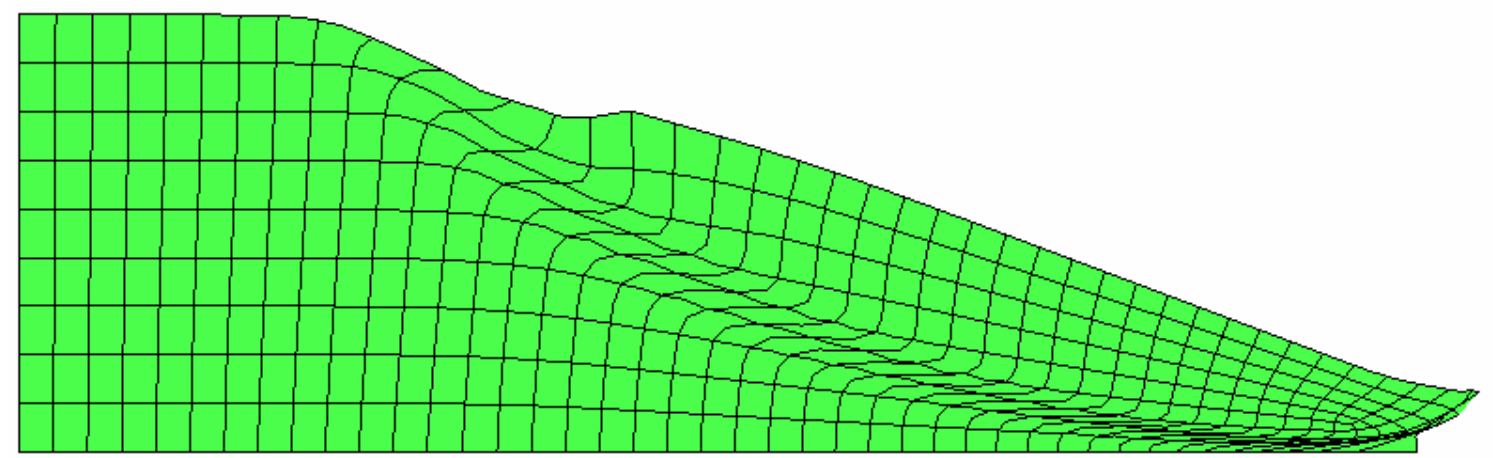

Figure 4.2 (a): Deformed mesh with CPE8 elements (Analysis 2)

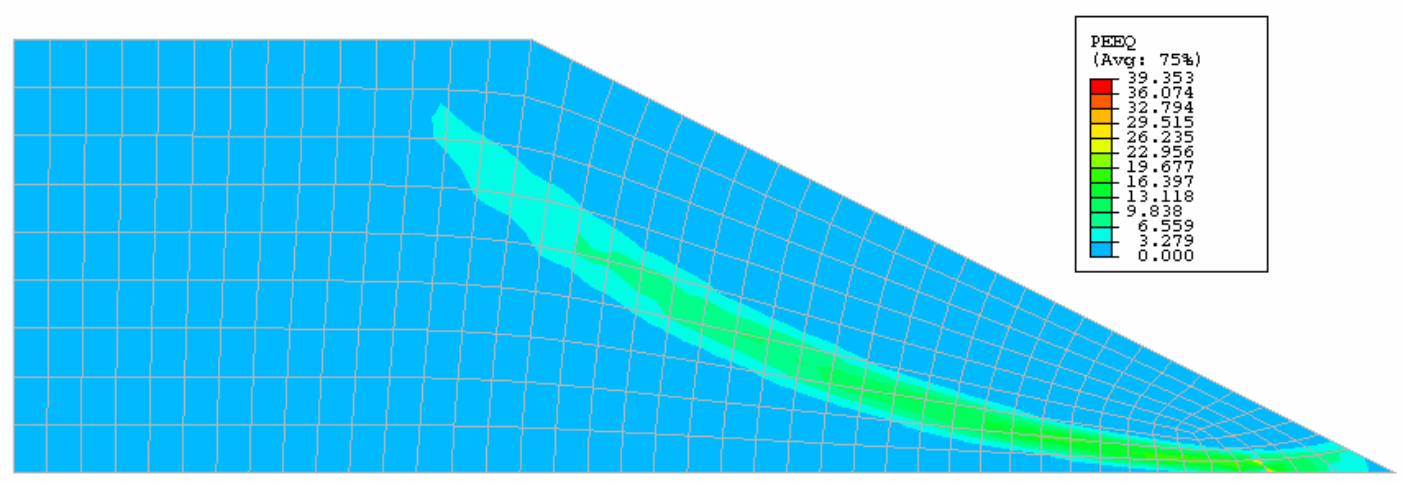

Figure 4.2 (b): The equivalent plastic strain contour for Analysis 2 


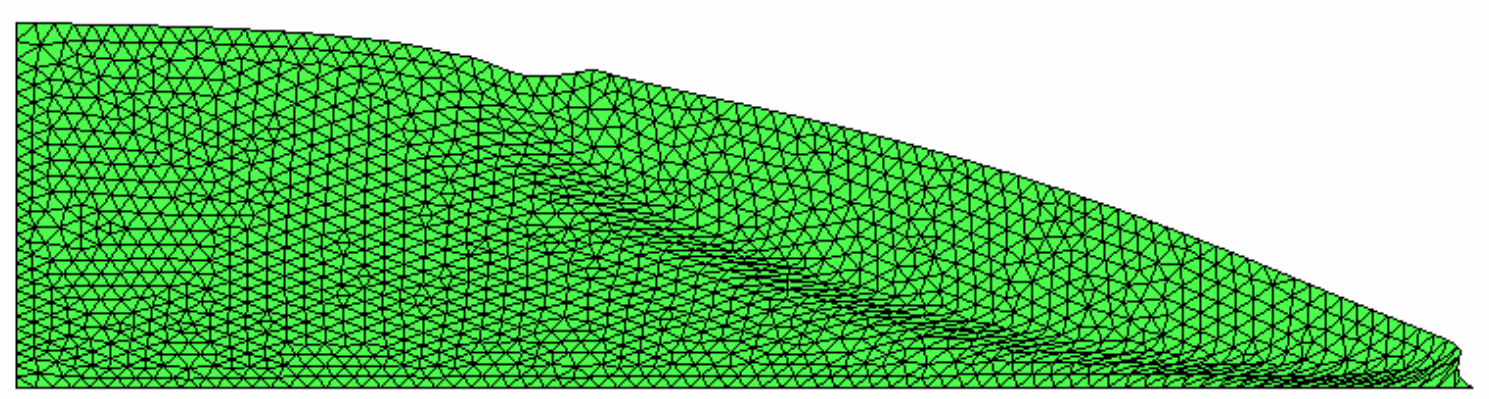

Figure 4.3 (a): Deformed mesh with CPE6 elements (Analysis 3)

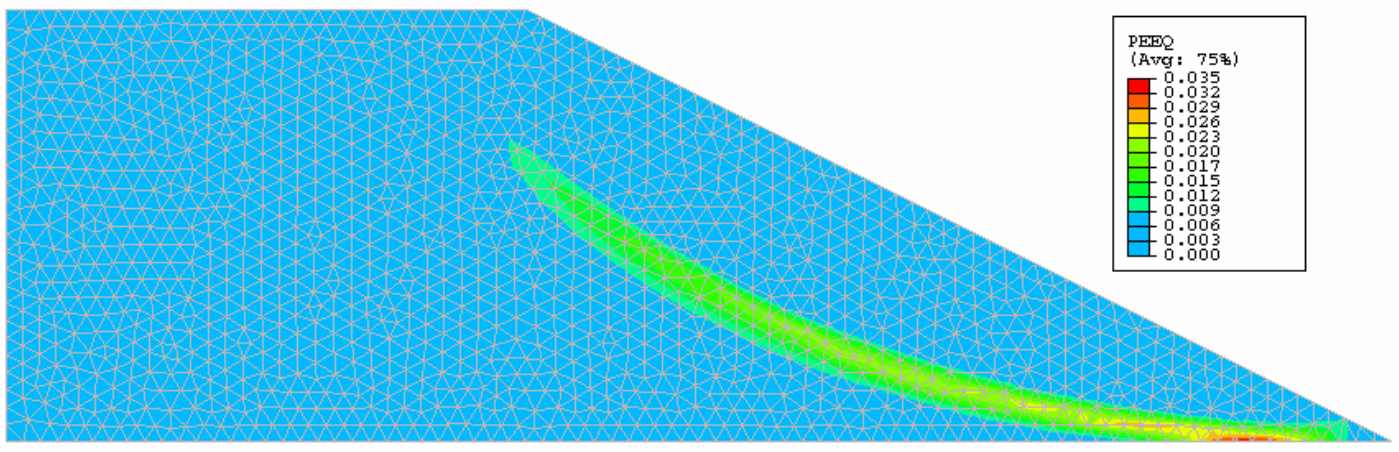

Figure 4.3 (b): The equivalent plastic strain contour for Analysis 3

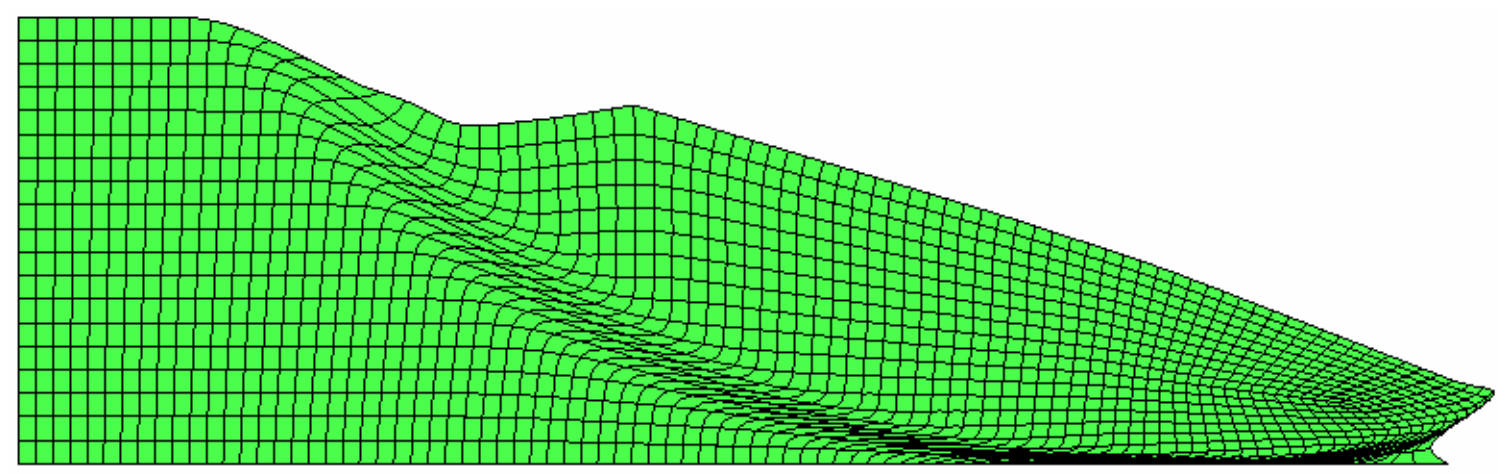

Figure 4.4 (a): Deformed mesh with CPE8 elements (Analysis 4) 


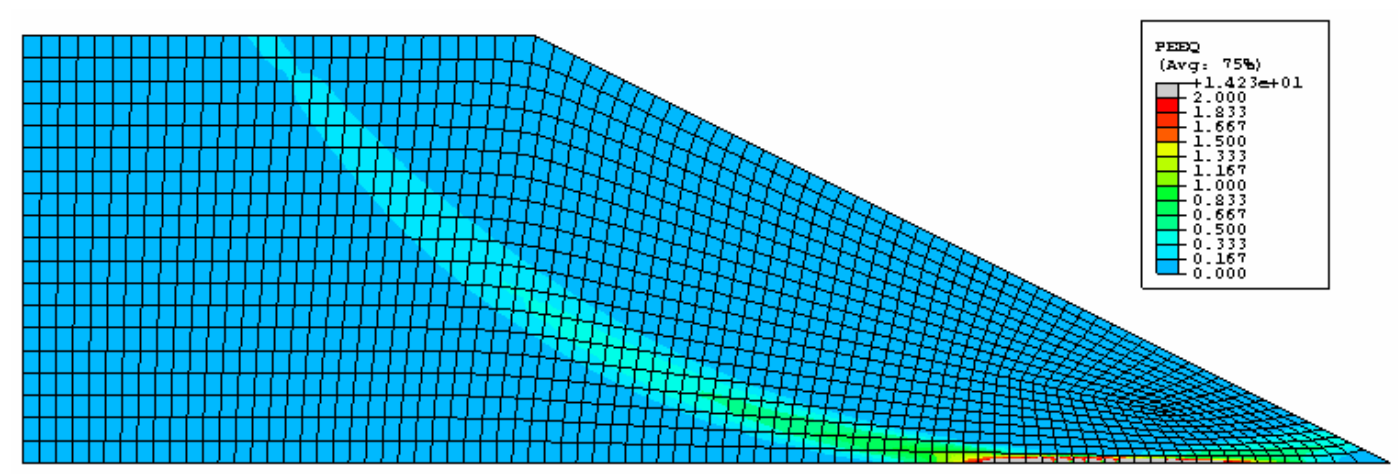

Figure 4.4 (b): The equivalent plastic strain contour for Analysis 4

The computed factors of safety were close to limit equilibrium values $(<5 \%)$, finer mesh with CPE8 elements performed well on replicating the failure surface on deformed mesh (Figure 4.4 a). Moreover, CPE6 elements performed better than CPE8 elements on the shape of failure plane. However, more research is needed to confirm this observation. The effects of the proper element selection for slope stability analyses can be a research topic itself.

\subsubsection{Case 2: A Homogenous Slope with Base}

Finite element analysis of a slope with a base was performed by using three different mesh refinements were used to study the effects of meshing on the factor of safety. In this example, only CPE6 elements were used in all three cases. Three meshes used in example had following properties: analysis 1 with 728 active elements (Figure 4.5), analysis 2 with 1164 active elements (Figure 4.6), and analysis 3 with 1397 active elements (Figure 4.7). The results on the computed factor of safety are shown in Table 4.2. Consistently, the finer mesh gave more conservative results than the coarser mesh.

The factor of safety ranged from 0.98 to 1.03 in this case. These minimum and maximum values are less than 5\% away from the values based on limit equilibrium methods (Bishop's Modified Method (Bishop, 1955), Janbu's Modified Method (Janbu, 1968), Morgenstern and Price's Method (Morgenstern and Price, 1965), and Spencer's Method (Spencer, 1967)). However, the difference in computed factor of safety using 728 elements (Analysis 1) and 1397 elements (Analysis 3) elements is slightly larger than 5\%. 
Table 4.2: Computed Factor of safety results for Case 2

\begin{tabular}{|l|c|c|c|c|}
\hline & Method & Mesh & $\begin{array}{c}\text { Factor of } \\
\text { Safety }\end{array}$ & $\begin{array}{c}\text { Percentage difference } \\
\text { in FS compared to min. } \\
\text { LEM results (0.989) }\end{array}$ \\
\hline Analysis 1 (728 Elements) & FEM & CPE6 & 1.03 & $4.15 \%$ \\
\hline Analysis 2 (1,164 Elements) & FEM & CPE6 & 0.995 & $0.61 \%$ \\
\hline Analysis 3 (1,397 Elements) & FEM & CPE6 & 0.98 & $-0.91 \%$ \\
\hline Spencer (Slope/W) & LEM & - & 0.989 & - \\
\hline Bishop (Slope/W) & LEM & - & 0.99 & - \\
\hline Morgenstern-Price (Slope/W) & LEM & - & 0.999 & - \\
\hline
\end{tabular}

The deformed finite element meshes corresponding to these three cases are shown in Figures 4.5 (a), 4.6 (a), and 4.7 (a). The deformed mesh shows the shape of the sliding block as shown in figures. The equivalent plastic strain measure in finite element analysis can be used to assess the accumulation of plastic strain in the soil region (Abaqus, 2006). Figures 4.5 (b), 4.6 (b), and 4.7 (b) show contours of the equivalent plastic strain for the one-nail case.

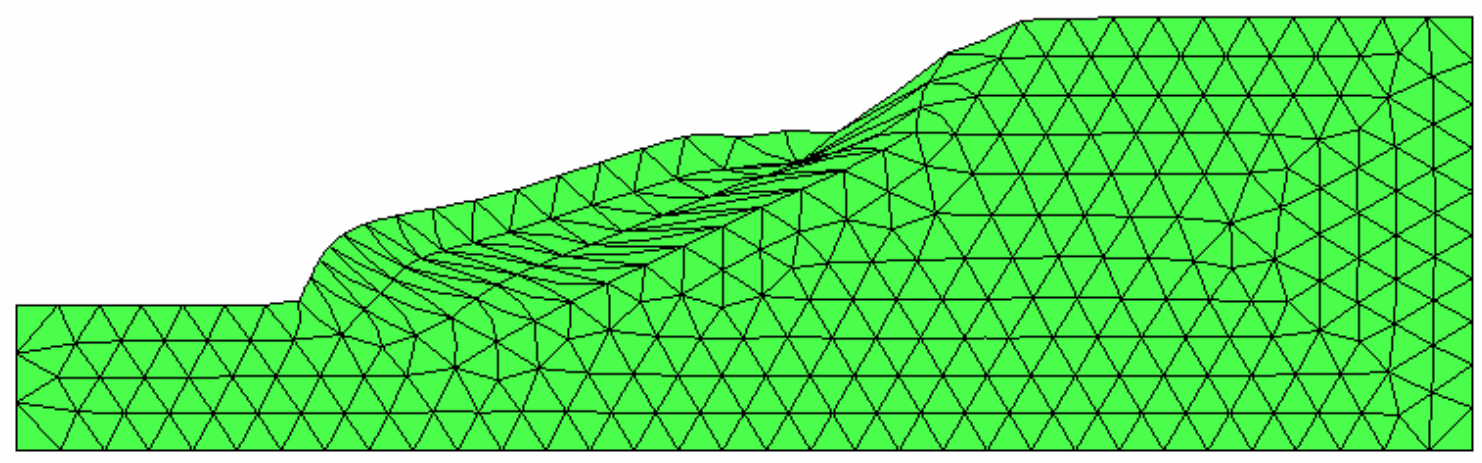

Figure 4.5 (a): Deformed mesh with 728 elements (Analysis 1) 


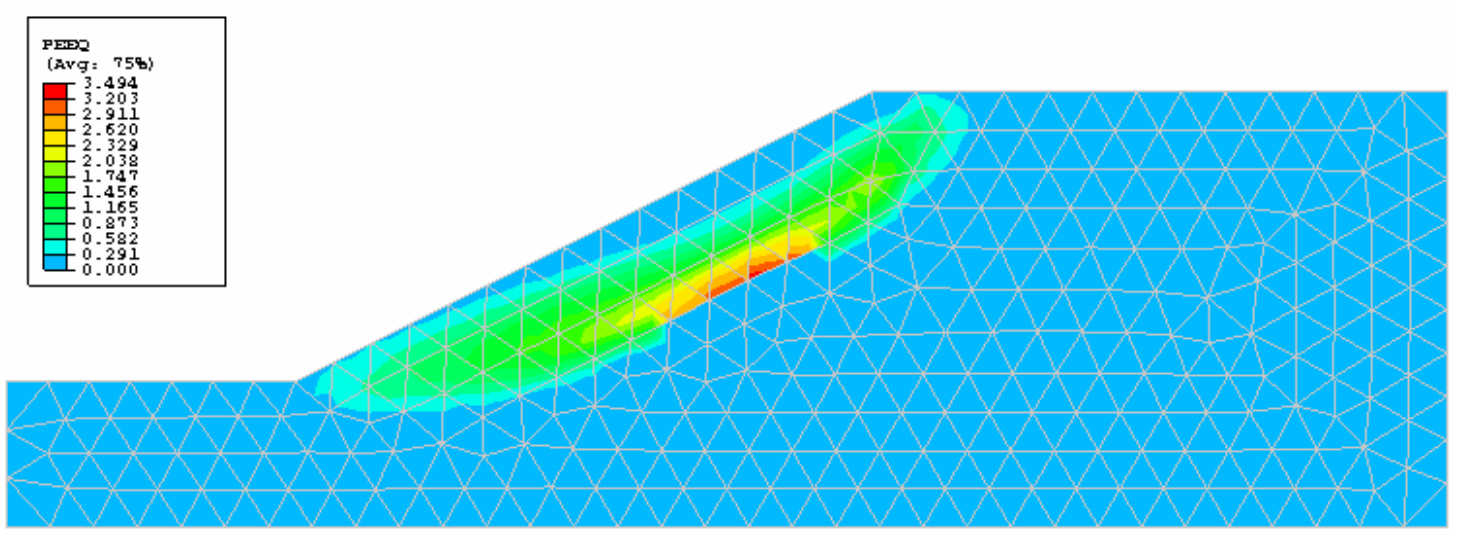

Figure 4.5 (b): The equivalent plastic strain contour for Analysis 1

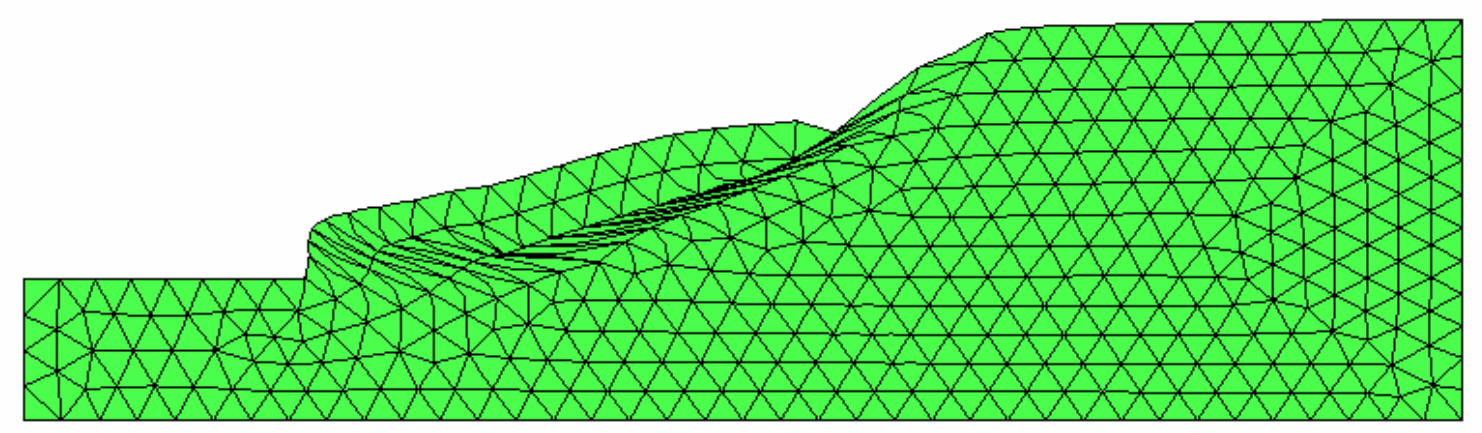

Figure 4.6 (a): Deformed mesh with 1164 elements (Analysis 2)

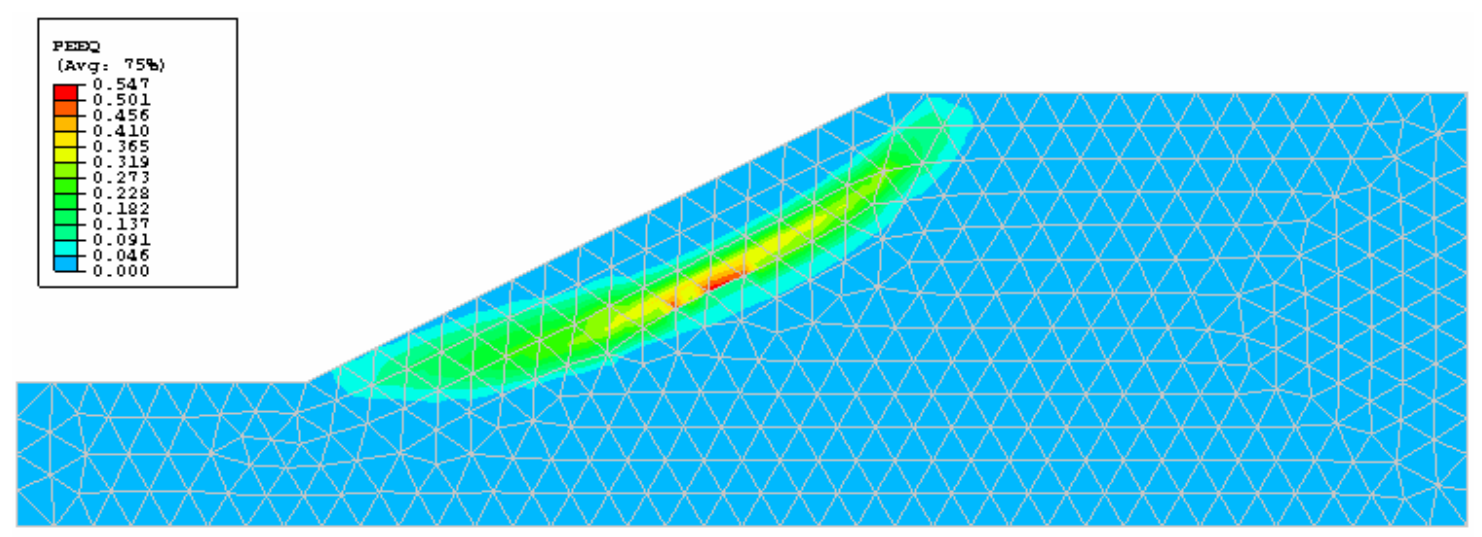

Figure 4.6 (b): The equivalent plastic strain contour for Analysis 2 


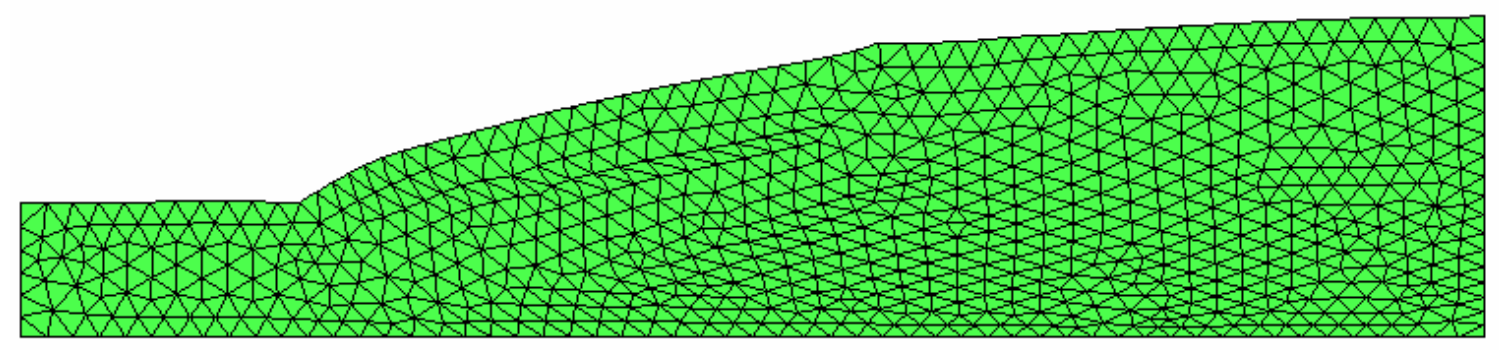

Figure 4.7 (a): Deformed mesh with 1397 elements (Analysis 3)

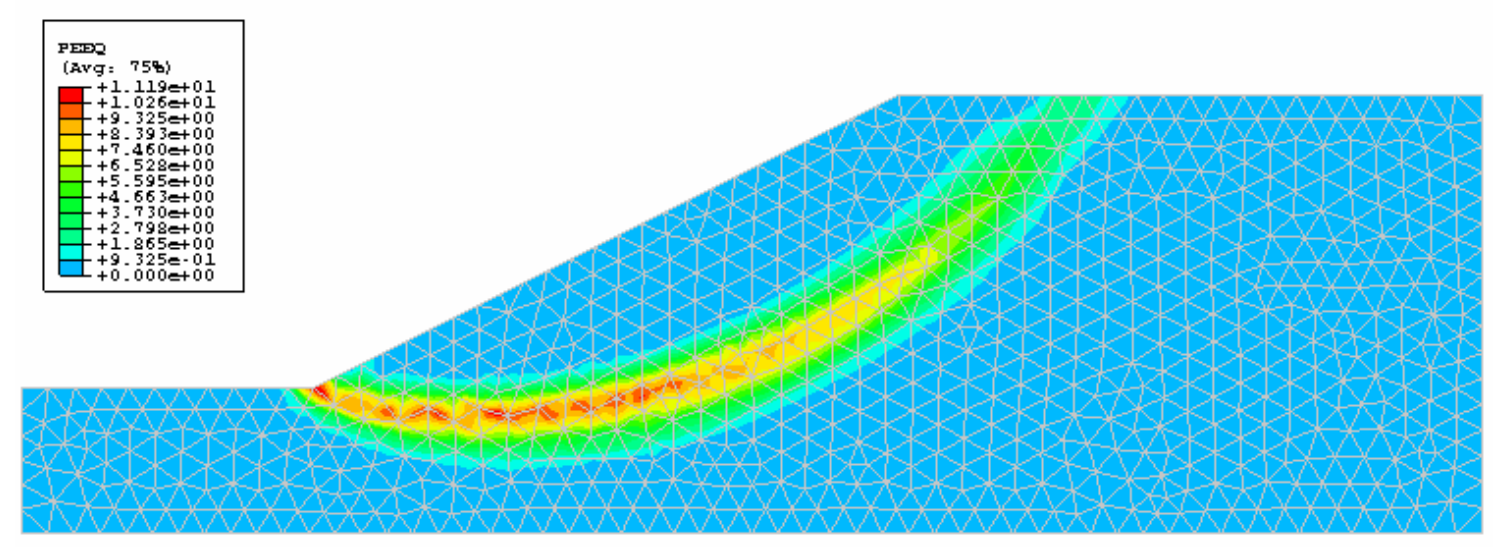

Figure 4.7 (b): The equivalent plastic strain contour for Analysis 3

\subsubsection{The Radius of failure circle compare with Limit Equilibrium Method}

For this analysis, same slope from the Analysis 1 in Section 4.2.1 example has been considered. The benchmark problem considers a uniform soil with homogeneous slope. The computer software package GeoStudio 2004-SLOPE/W developed by GEOSLOPE was used in determining the factor of safety values are obtained from the limit equilibrium methods that were mentioned in Chapter 2.

The finite element result of failure circle of the slope for Analysis 1 in this section was compared with the limit equilibrium method results. The radius point was obtained by using Geo-Slope (Figure 4.8). For this example, the radius was $20.33 \mathrm{~m}$, and the coordinates were found to be $x=27.34 \mathrm{~m}$ and $y=20.16 \mathrm{~m}$. The same coordinates were 
sketched on the finite element analysis of slope displacement contours (Figure 4.9 (a) and the equivalent plastic strain contours (Figure 4.9 (b)).

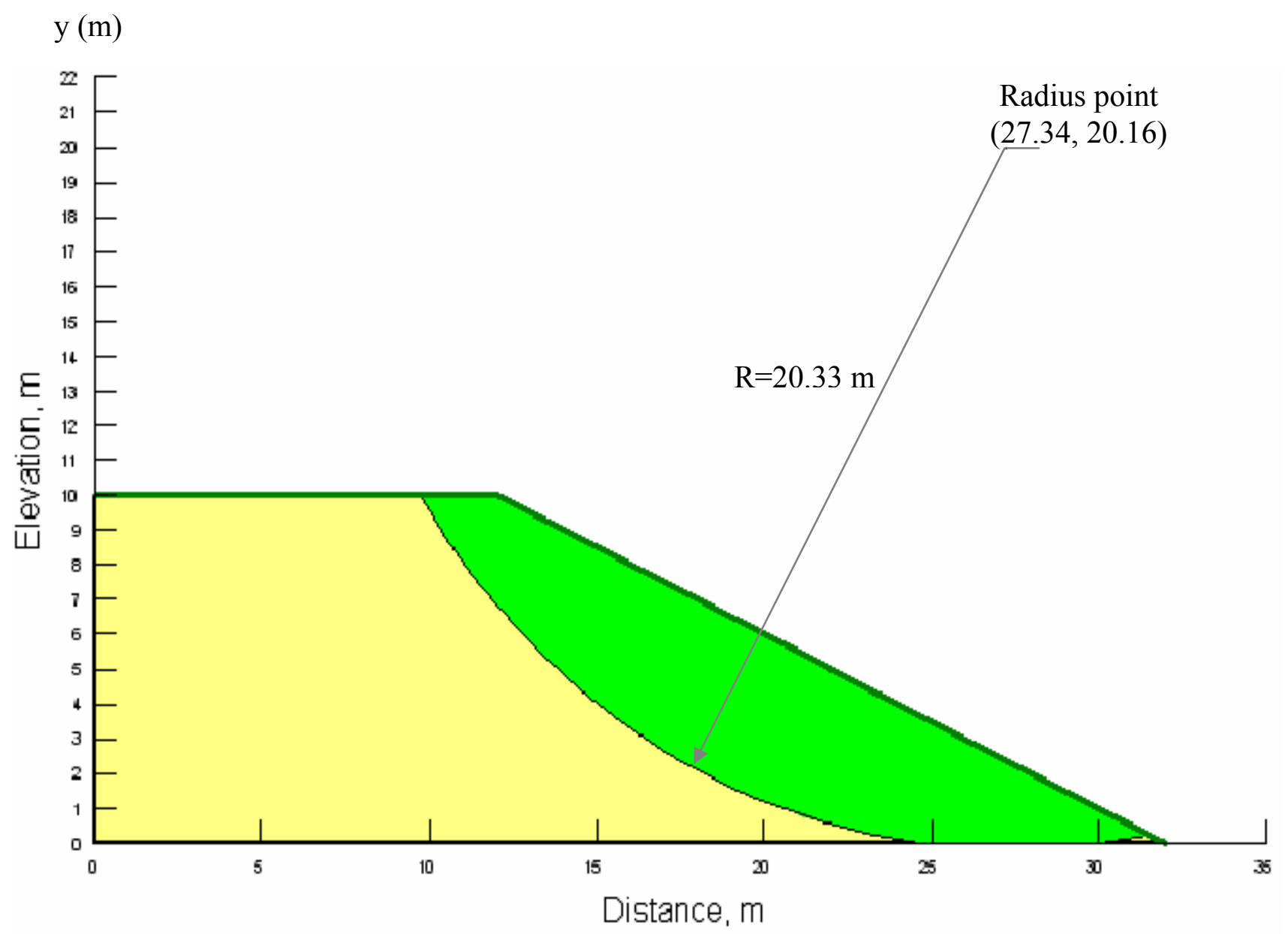

Figure 4. 8: Limit equilibrium solution for Analysis 1 generated with Geo Studio, Slope/W (Geo-Studio, 2004) 


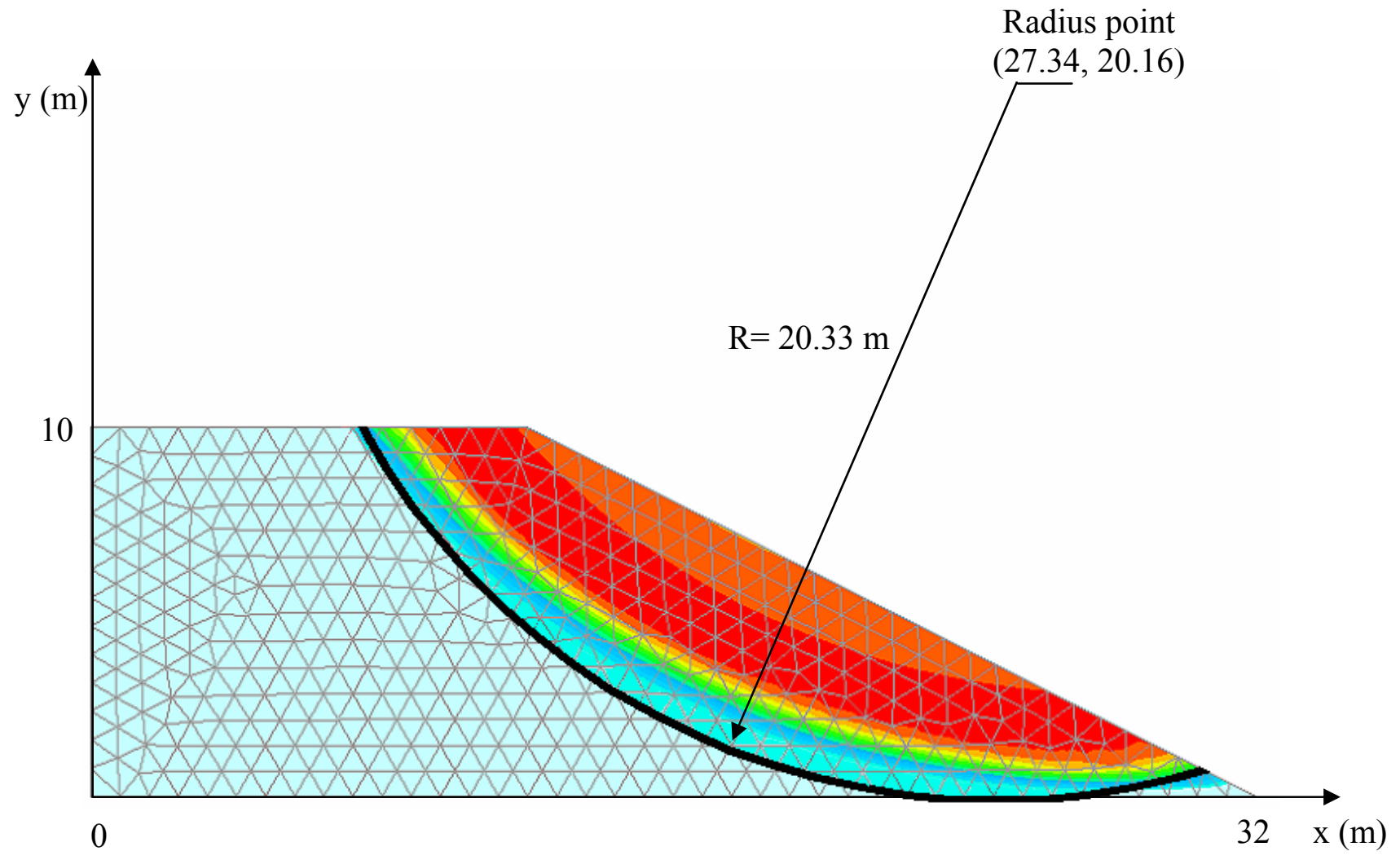

Figure 4.9 (a): Displacement contours for Analysis 1 


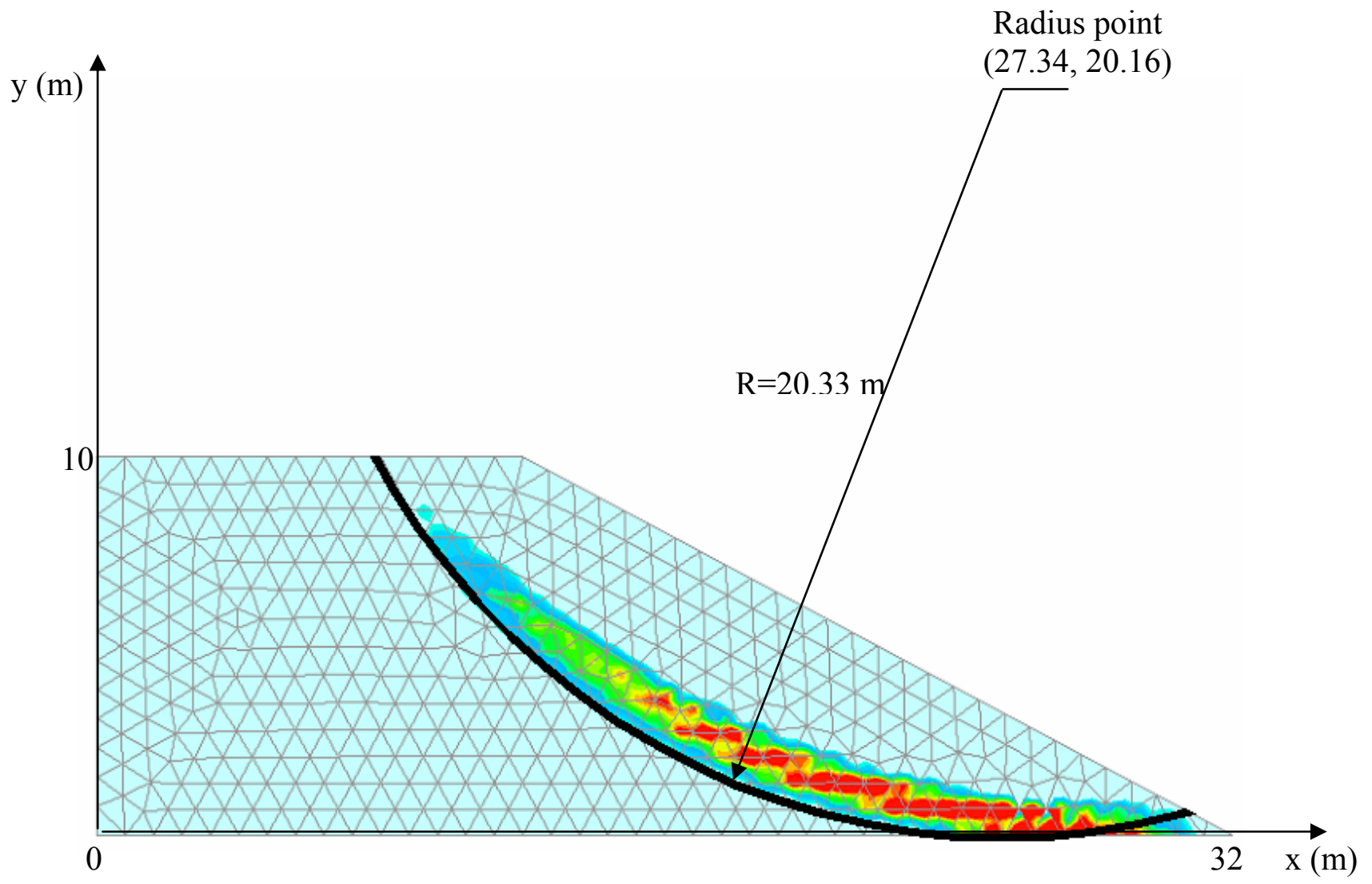

Figure 4.9 (b): The equivalent plastic strain contours for Analysis 1

The finite element analysis displacement and the equivalent plastic strain contours of the homogeneous slope replicated the radius of failure circle of the limit equilibrium method results. The finite element method was able to predict the failure plane (slip surface) on both displacement contours (Figure 4.9 (a)) and the equivalent plastic strain contours (Figure 4.9 (b)). In addition, the finite element analysis in this example did not require an arbitrary partitioning of the critical surface selection prior to calculations.

\subsection{Results for Reinforced Slopes}

The results are shown for the following cases in this section: a homogenous benchmark model with no base soil, and a homogenous benchmark with base soil. 


\subsubsection{Influence of Soil Nail Length}

The effects of the length of a nail were studied in this section: a) benchmark with no soil base with one nail and b) benchmark with soil base with one nail.

\section{a) Benchmark with No Soil Base with One Nail}

In this case, the effect of the length of a nail was studied on three models as described in section 3.10.1 in the previous chapter. The length of the nail affected the slope deformation significantly. Increasing the nail length beyond a certain length did not change the displacements significantly. For the case with a $10 \mathrm{~m}$ long nail, the nail was not long enough to pass the failure plane, and therefore it did not improve the deformation as much (Figure 4.10 (a)). When the slope did not have any reinforcement the obtained factor of safety was 1.40. After the addition of the $10 \mathrm{~m}$ long nail, the factor of safety was increased by about $4.3 \%$ and it was determined as 1.46 . In the second case, a $15 \mathrm{~m}$ long nail was used. This nail resulted in a significantly higher factor of safety, 1.58. This is about $12.86 \%$ increase comparing to the case of an unreinforced slope. The results are shown in Table 4.3. Deformed meshes corresponding to different nail lengths are shown in Figures 4.10, 4.11, and 4.12. As can be seen from these figures, the failure surface is different for reinforced cases in comparison to the unreinforced case.

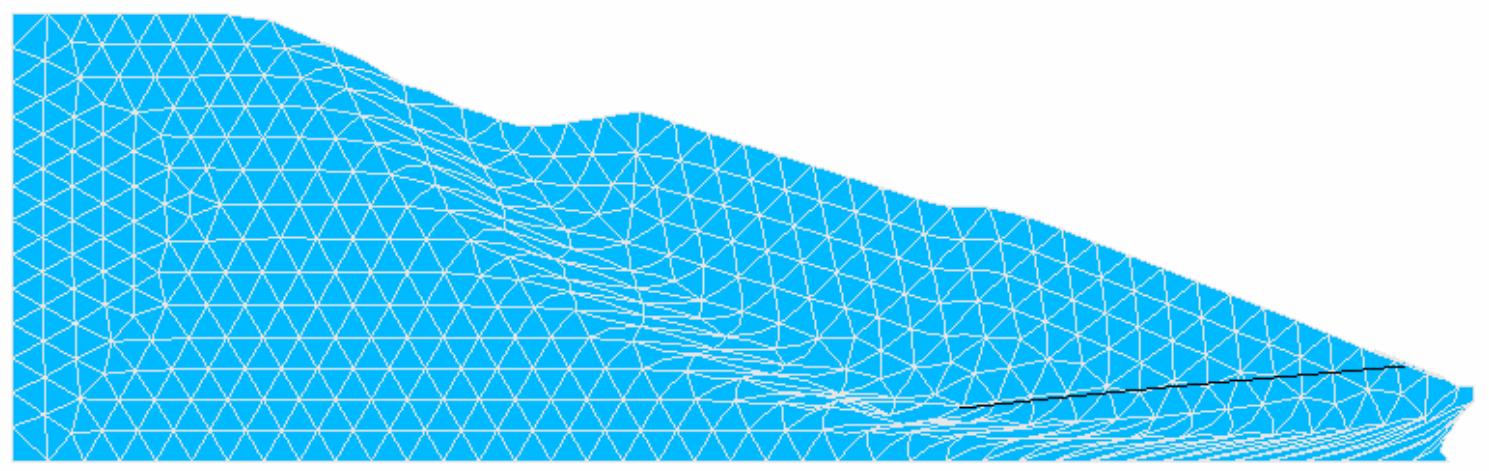

Figure 4.10 (a): Deformed mesh for the case with a $10 \mathrm{~m}$ long nail 


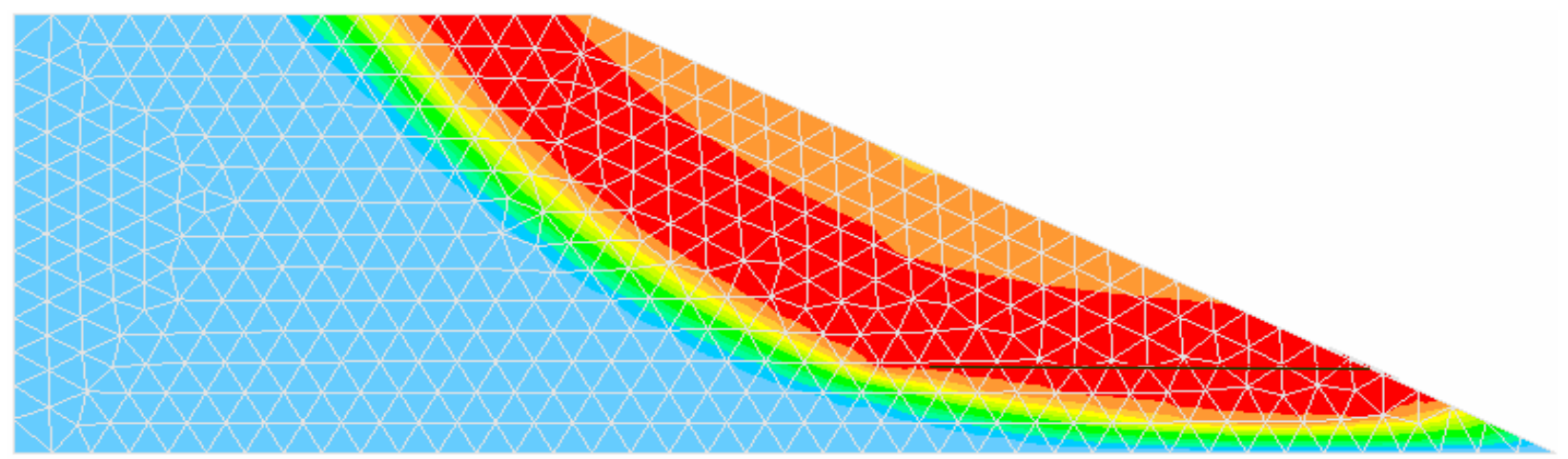

Figure 4.10 (b): Displacement contours for the case with a $10 \mathrm{~m}$ long nail

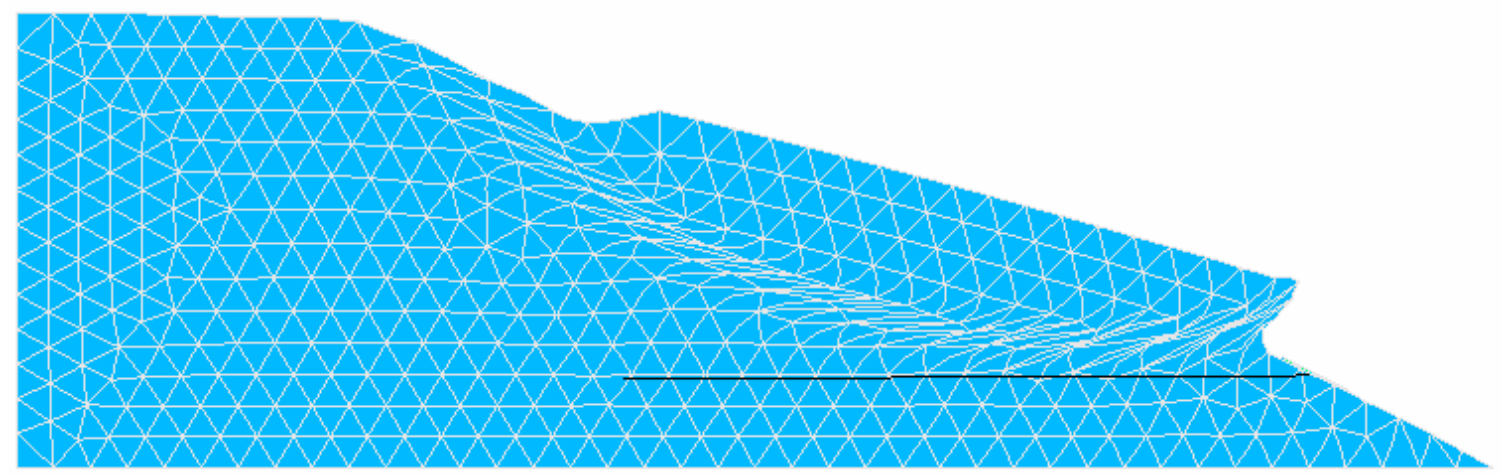

Figure 4.11 (a): Deformed mesh for the case with a $15 \mathrm{~m}$ long nail

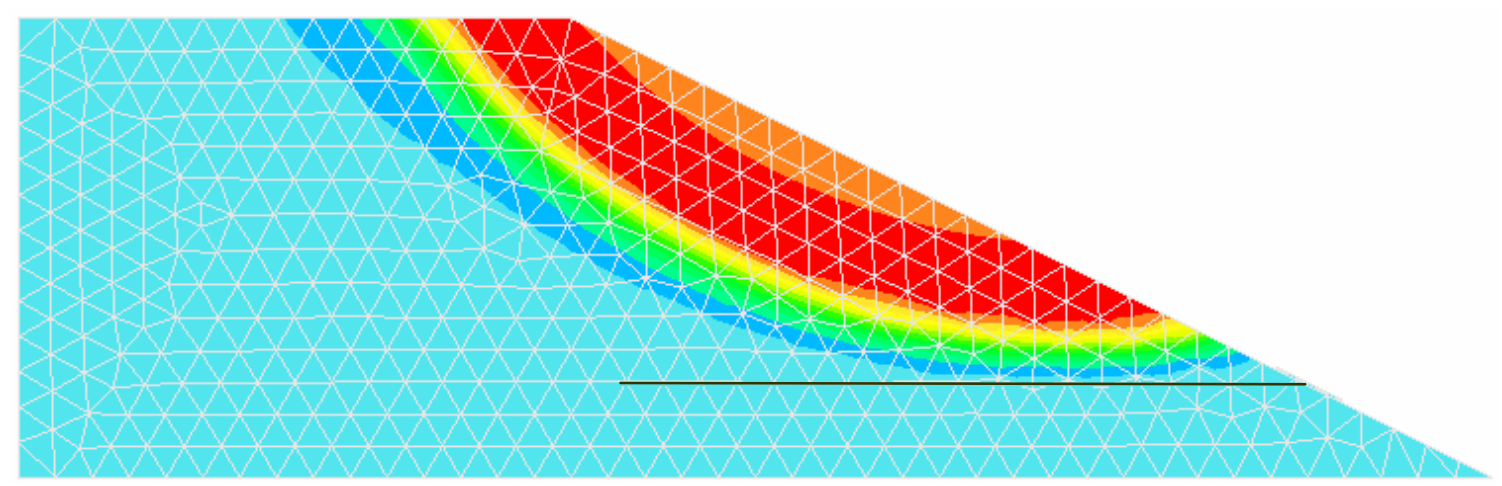

Figure 4.11 (b): Displacement contours for the case with a $15 \mathrm{~m}$ long nail 


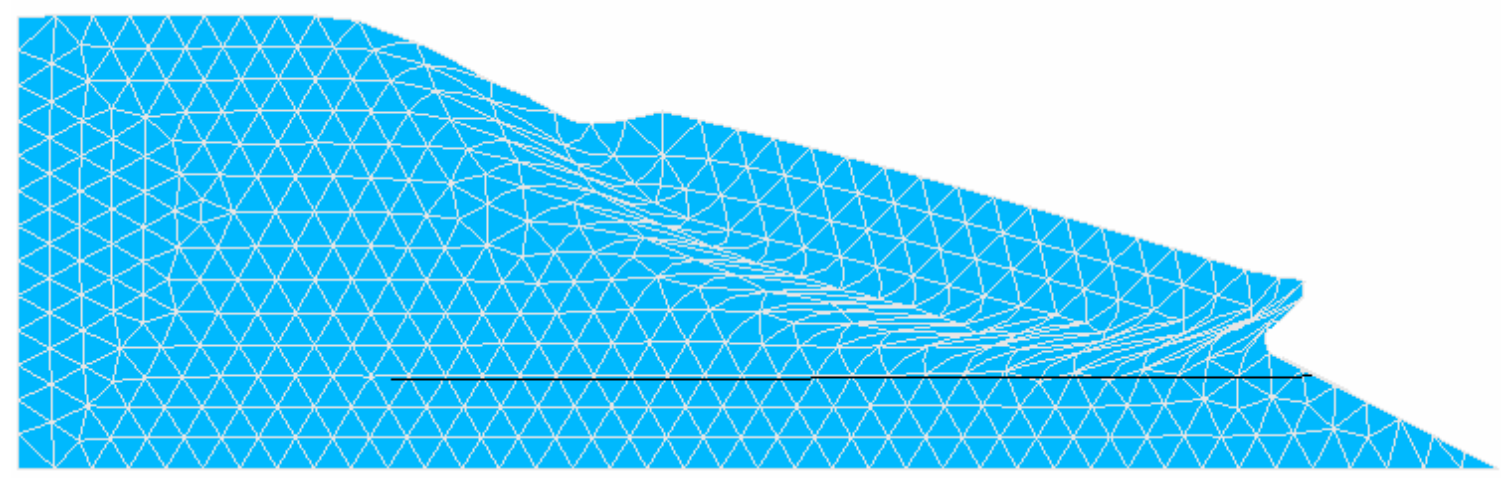

Figure 4.12 (a): Deformed mesh for the case with a $20 \mathrm{~m}$ long nail

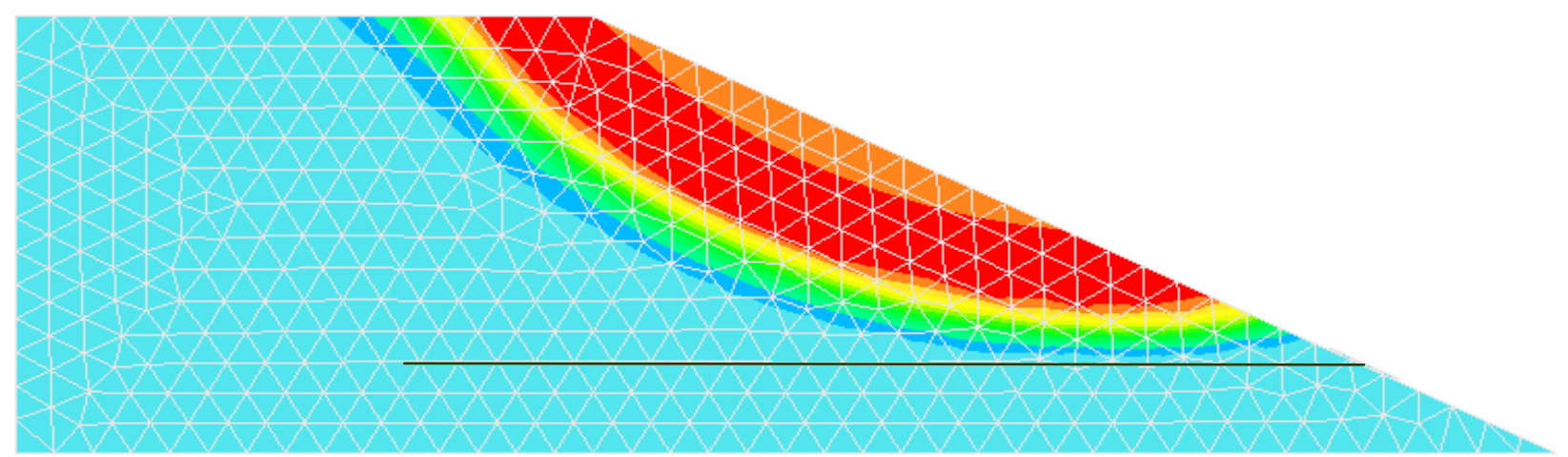

Figure 4.12 (b): Displacement contours for the case with a $20 \mathrm{~m}$ long nail

Table 4.3: Computed Factor of safety for unreinforced slope and one-nail case

\begin{tabular}{|c|c|c|c|}
\hline \multirow{2}{*}{$\begin{array}{c}\text { Unreinforced } \\
\text { Slope }\end{array}$} & \multicolumn{3}{|c|}{$\begin{array}{c}\text { Case 1 with one nail } \\
\text { Nail Length (m) }\end{array}$} \\
\cline { 2 - 4 } & $10 \mathrm{~m}$ & $15 \mathrm{~m}$ & $20 \mathrm{~m}$ \\
\hline 1.40 & 1.46 & 1.52 & 1.59 \\
\hline
\end{tabular}




\section{b) Benchmark with Soil Base with One Nail}

In this case, the influence of the nail length was examined as described in Section 3.10.1. All the variables were kept constant except for the nail length. Nail inclination $\alpha$, was chosen as $20^{\circ}$ with respect to the geometry defined earlier (see Figure 3.20). A nail was placed $5 \mathrm{~m}$ vertically above the toe. The factor of safety was obtained when there was only one nail, but with varying length. Nail length, $\mathrm{L}$, was varied as $4 \mathrm{~m}$ to $15 \mathrm{~m}$. The greatest factor of safety of 1.33 was obtained when the soil nail length had a length of $12 \mathrm{~m}$. Variation of factor of safety with nail length is shown in Figure 4.13. As can be seen from this Figure, the critical length of the nail appears to be about $10 \mathrm{~m}$. Beyond this length, no improvements were observed.

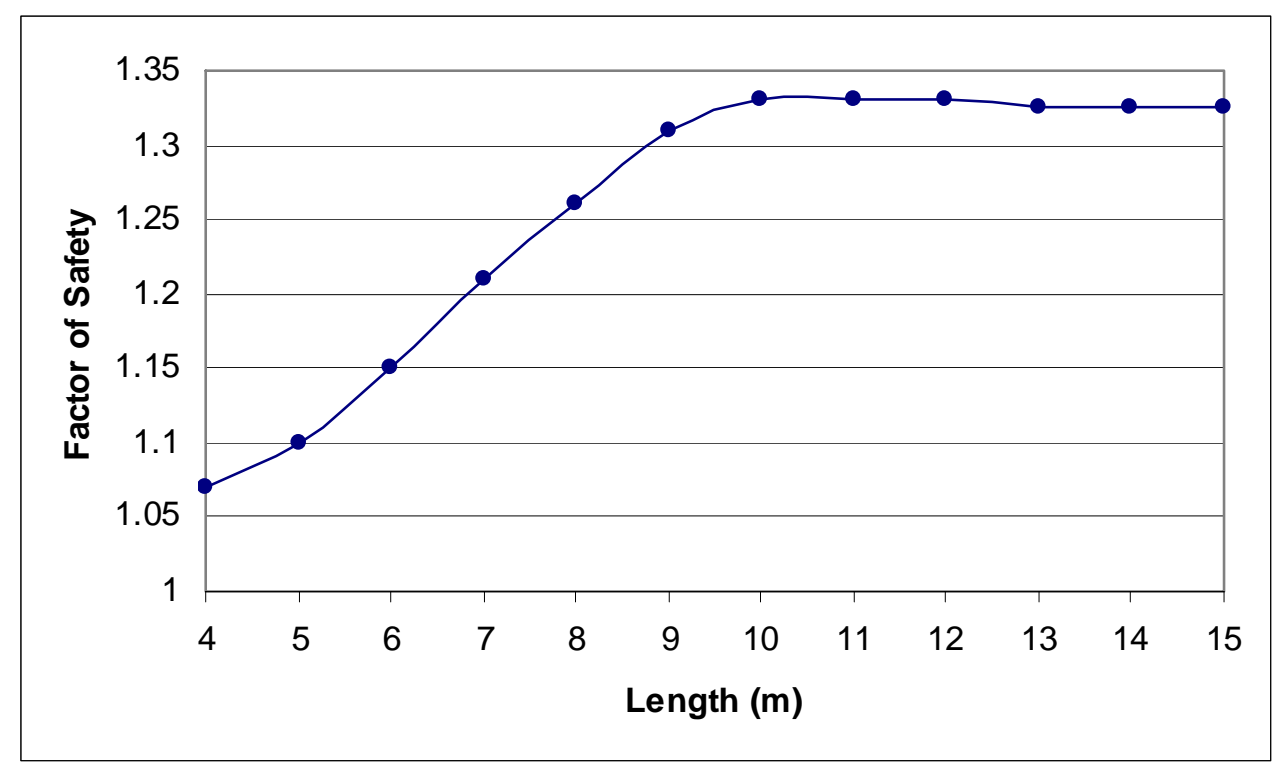

Figure 4.13: Variation of factor of safety against length of the soil nail

The resultant displacement was determined at point " $\mathrm{A}$ " for different nail length as shown in Figure 4.12 to investigate the relationship between nodal displacement and the factor of safety value. Variation of displacement at point 'A' against length of the soil nail is shown in Figure 4.14. The results show that the decrease in displacement values correlate with increase in the nail length values. This figure shows that there was 
significant difference in displacement when the length of the nail falls between $5 \mathrm{~m}$ and $9 \mathrm{~m}$. Figure 4.15 shows that the factor of safety starts to become stable after the nail length exceeded $9 \mathrm{~m}$.

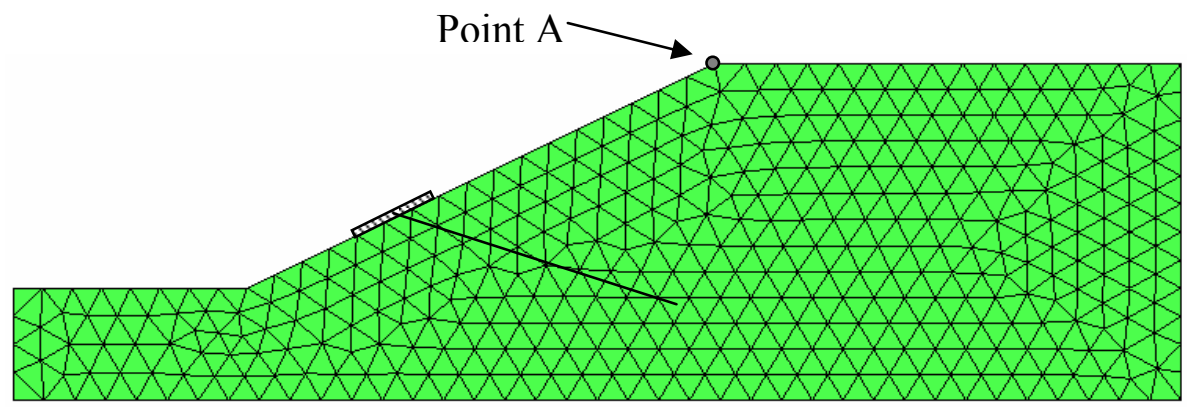

Figure 4.14: Schematic location of point "A"

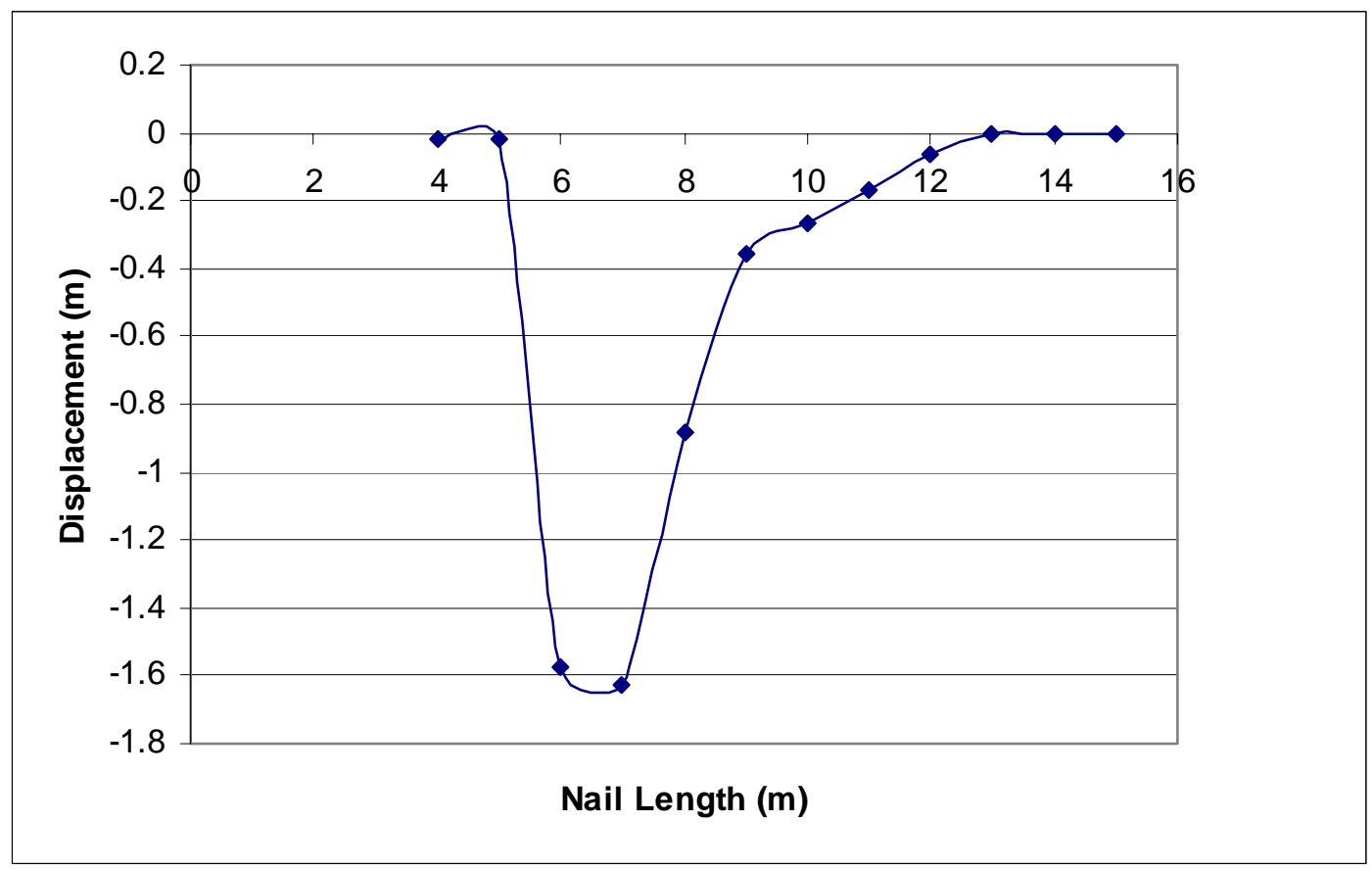

Figure 4.15: Variation of displacement at point ' $A$ ' with the length of soil nail 
Plastic strain contours corresponding to different values of nail length are shown in Figures 4.16 to 4.19. The plastic strain values in different regions in the soil and additional information on the proximity of the existing shear stress to the maximum shear strength that can be generated in those regions can be helpful in improving designs for reinforced soil slopes (Abaqus, 2006). Slope failures can occur when adjacent regions of the soil mass yield simultaneously in shear. The equivalent plastic strain measure in finite element analysis can be used to assess the accumulation of plastic strain in the soil region (Abaqus, 2006). Figures 4.16, 4.17, 4.18, and 4.19 show contours of the equivalent plastic strain for the one-nail case.

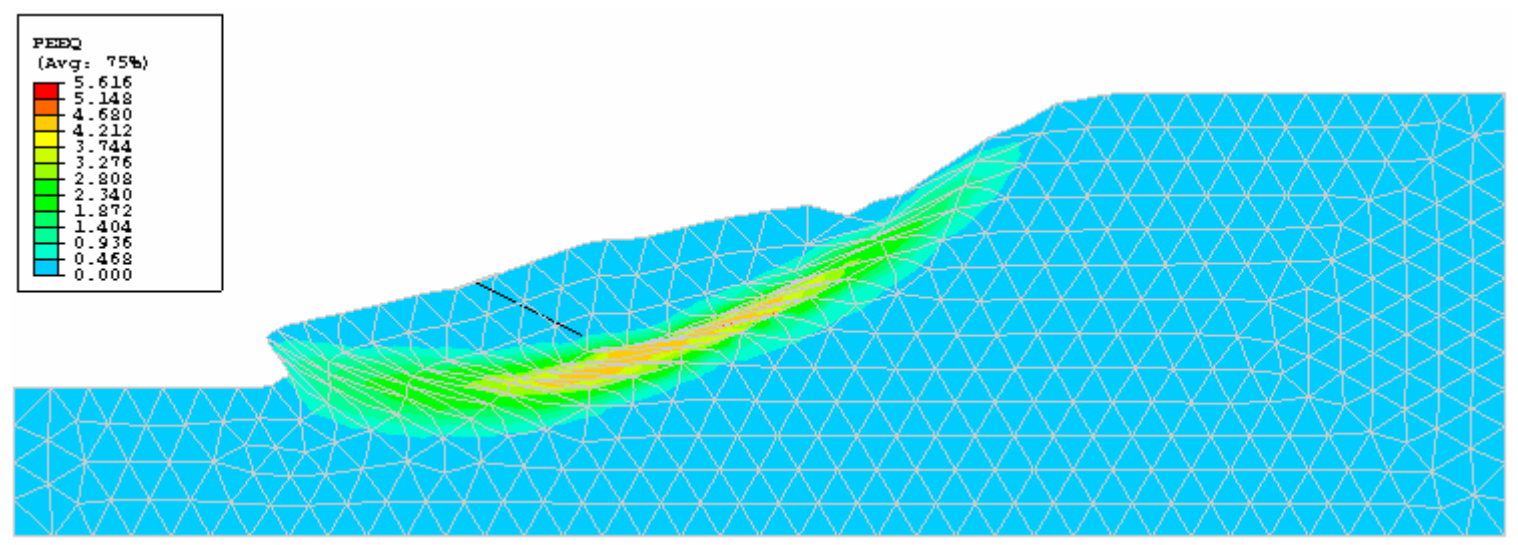

Figure 4.16: The equivalent plastic strain contour for $4 \mathrm{~m}$ long nail 


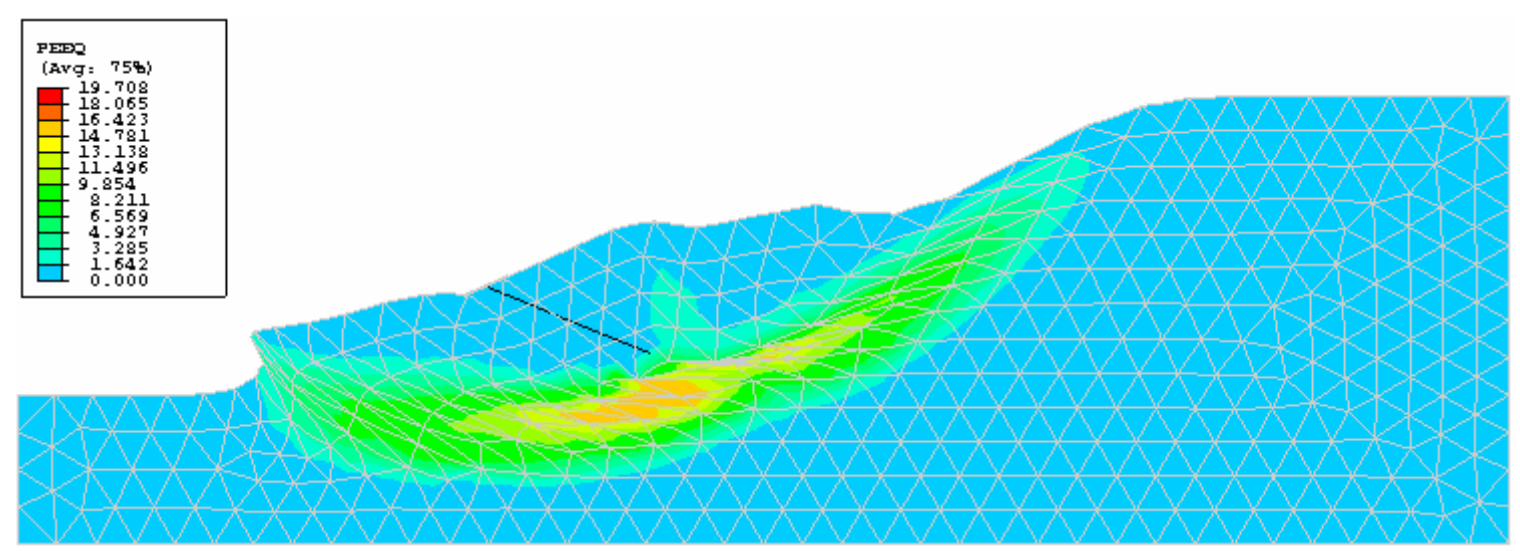

Figure 4.17: The equivalent plastic strain contour for $6 \mathrm{~m}$ long nail

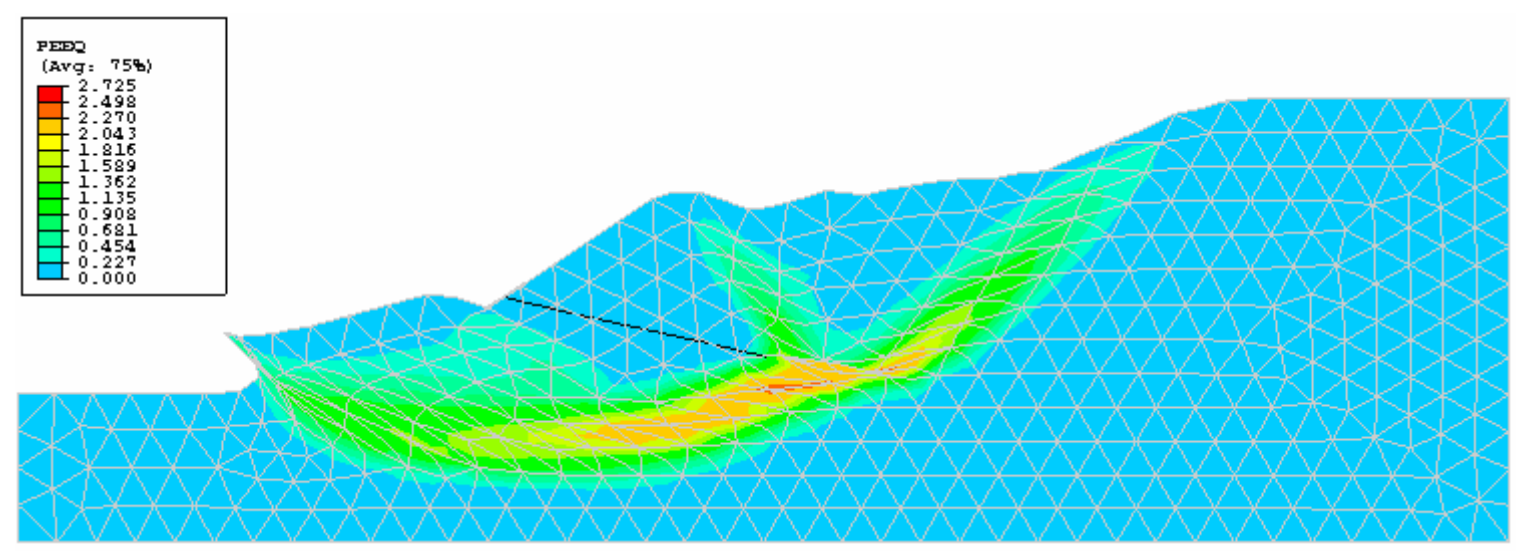

Figure 4.18: The equivalent plastic strain contour for $8 \mathrm{~m}$ long nail 


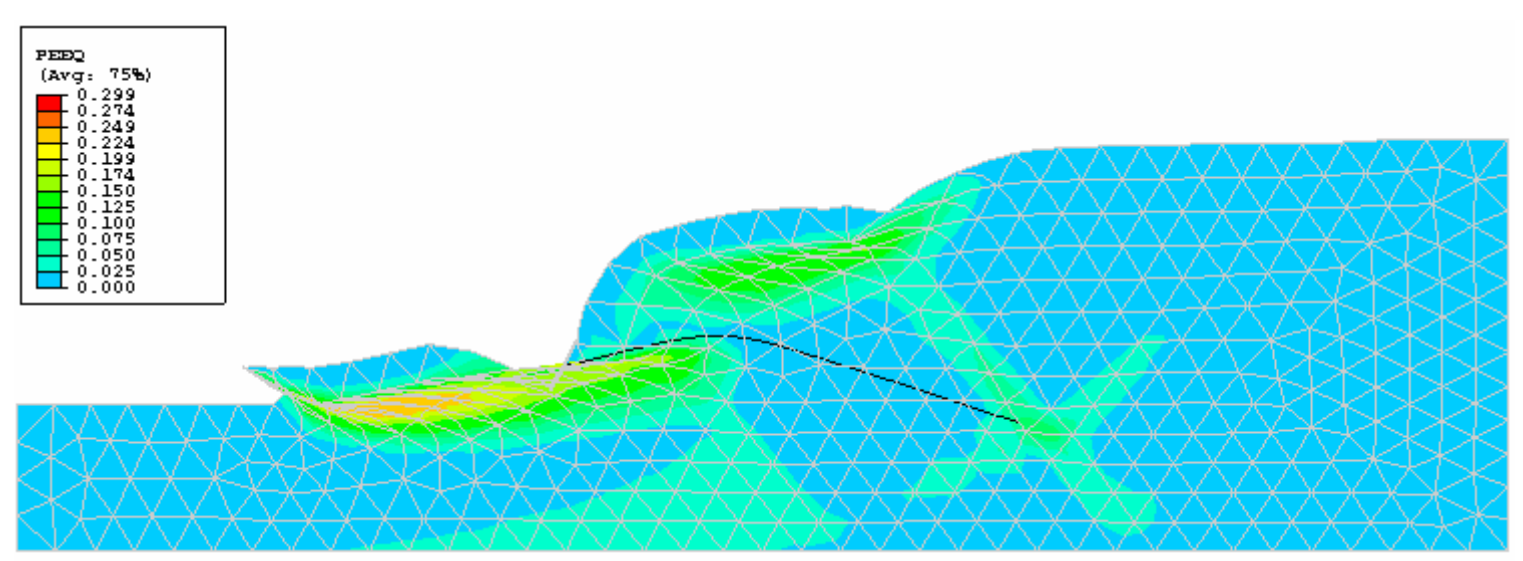

Figure 4.19: The equivalent plastic strain contour for $15 \mathrm{~m}$ long nail

\subsubsection{Influence of Nail Inclination}

Nail inclination was varied from $0^{\circ}$ to $26^{\circ}$ degree in clockwise (positive) direction and from $0^{\circ}$ degree to $45^{\circ}$ degree in counterclockwise (negative) direction. A $10 \mathrm{~m}$ long nail was placed $5 \mathrm{~m}$ vertically above from the toe as shown in Figure 4.19. Similar to the previous examples, all the variables were kept constant except for the nail inclination angle. The highest calculated factor of safety value of 1.33 was obtained when the inclination angle was at $20^{\circ}$ in clockwise direction. Nail length, L, was varied from $4 \mathrm{~m}$ to $15 \mathrm{~m}$. The relationship between the calculated factor of safety and the inclination angle $\alpha$ is presented in Figure 4.20. The factor of safety is close to 1.30 with small variations for the range of $\alpha$ between $0^{\circ}$ and $20^{\circ}$ in the clockwise direction. The factor of safety decreased considerably as the inclination angle $\alpha$ increased beyond $20^{\circ}$. 


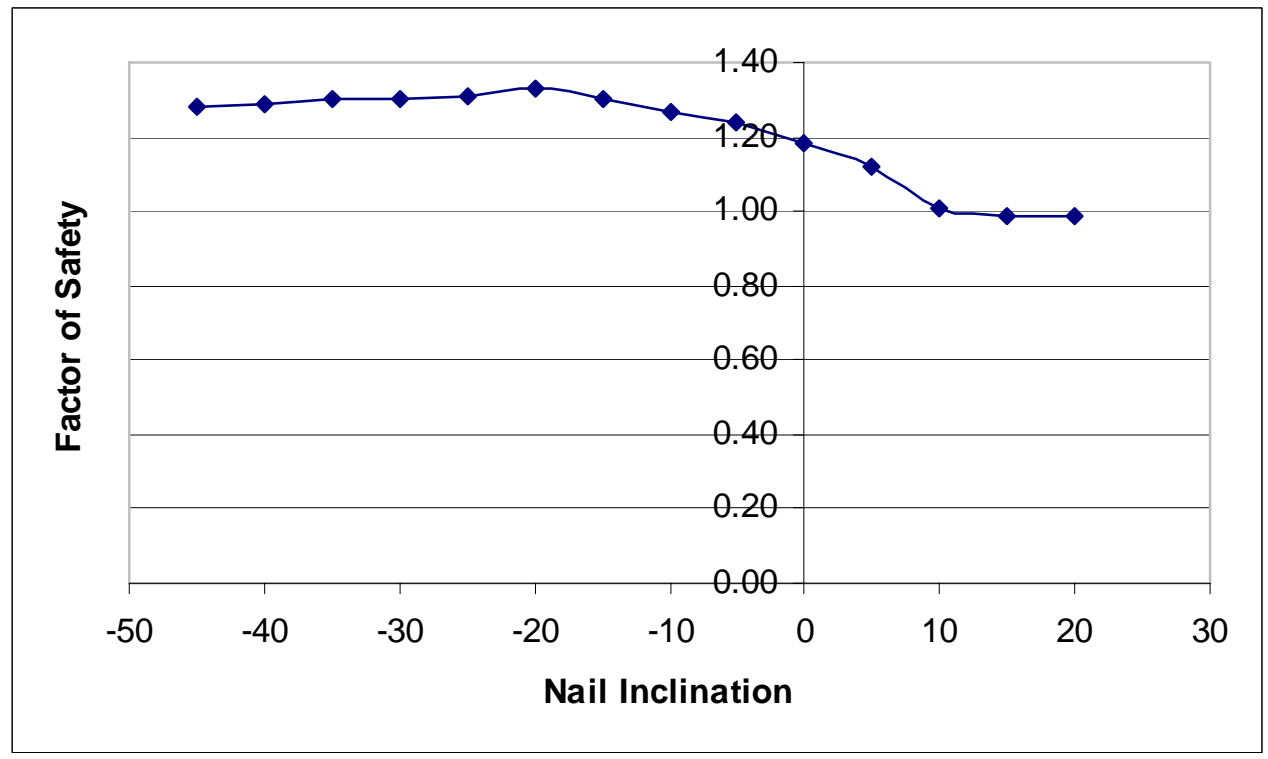

Figure 4.20: Variation of factor of safety with inclination angle of a soil nail

Figures 4.21 to 4.23 show the failure mechanism of the slope for different values of nail inclination angle.

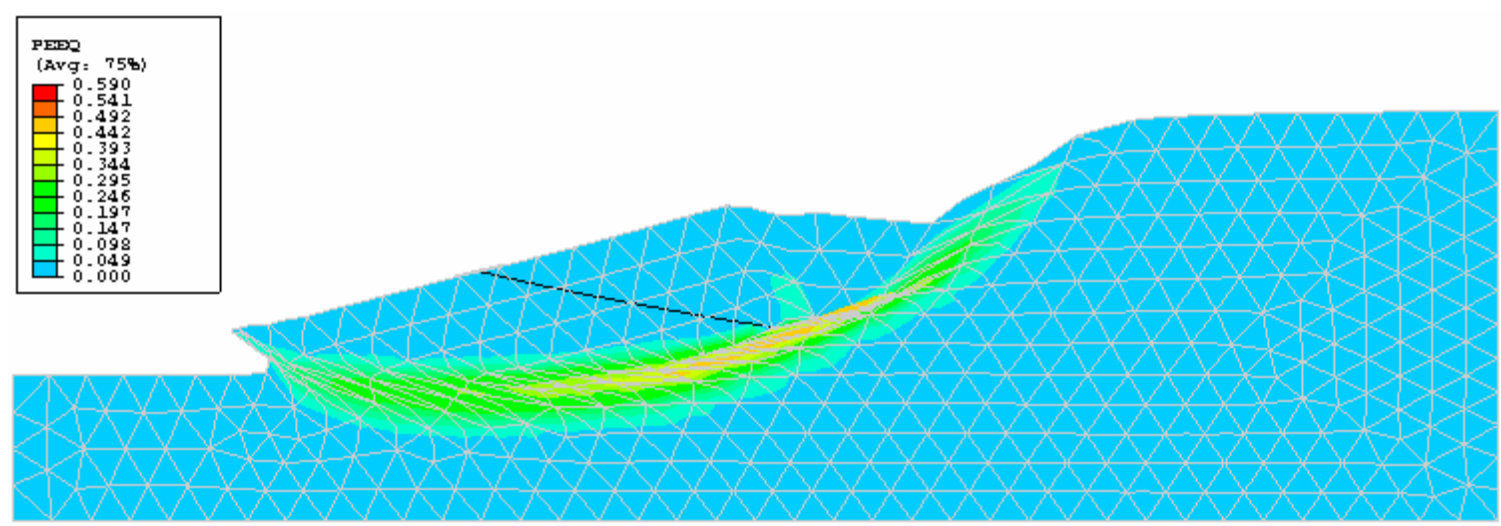

Figure 4.21: The equivalent plastic strain contours for nail inclination of zero degrees 


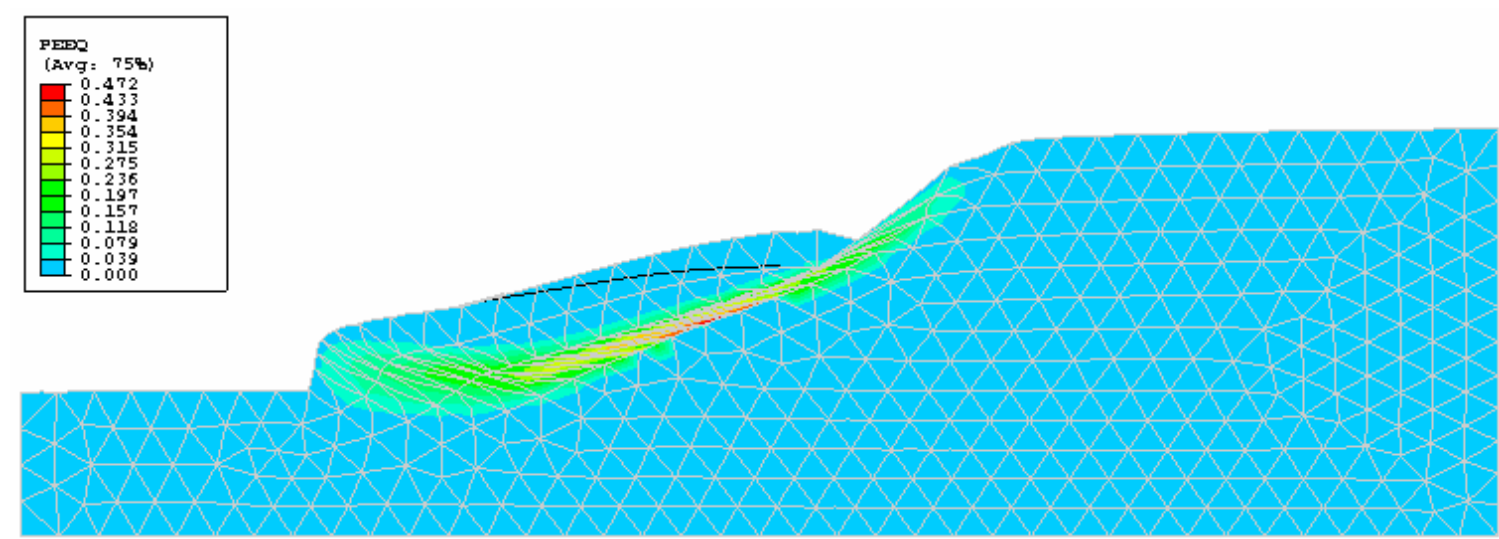

Figure 4.22: The equivalent plastic strain contours for nail inclination of 20 degrees (counterclockwise)

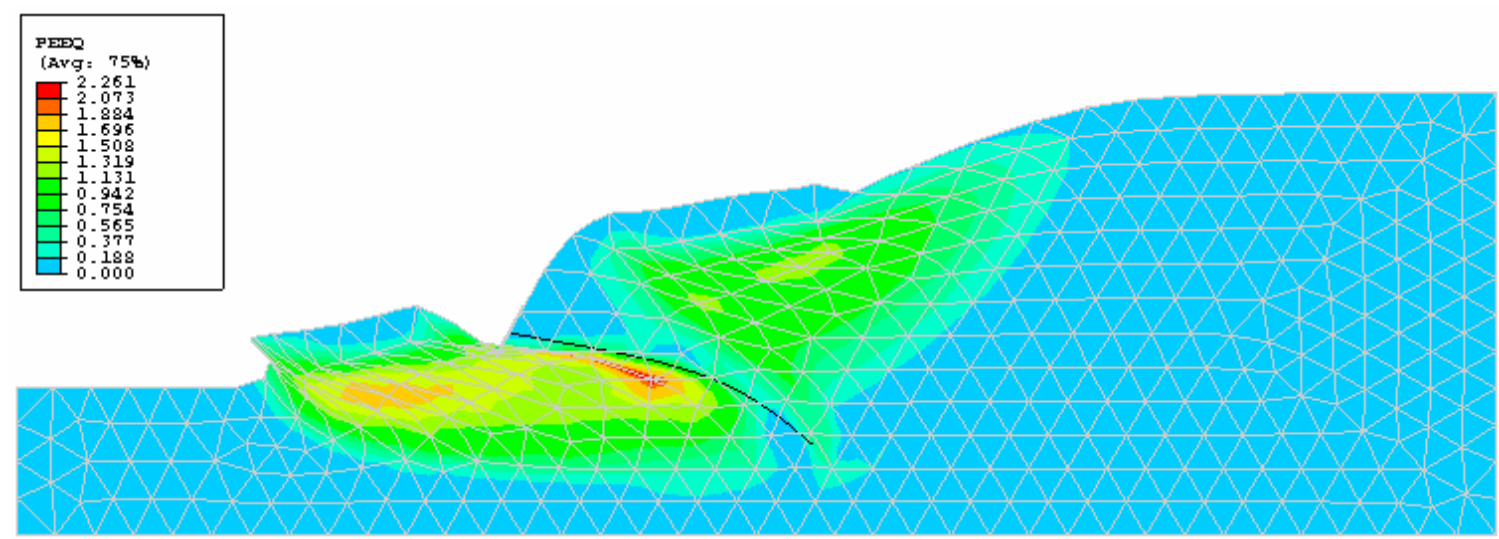

Figure 4.23: The equivalent plastic strain contours for nail inclination of 45 degrees 


\subsubsection{Influence of Nail Location}

In this section, the influence of location of soil nail is presented as described in Section 3.10.3. A $10 \mathrm{~m}$ long nail was placed in different locations to study the effects of the nail location. One nail was used in each simulation. The nail location was changed from the toe level of the slope to $9 \mathrm{~m}$ vertically above from toe (Figure 4.26). The results are shown in the Figure 4.24. The maximum factor of safety value of 1.28 was obtained when the nail was at $5.5 \mathrm{~m}$ above the toe level. The factor of safety values started to decrease beyond this position.

The failure envelope is clearly seen in Figure 4.25 which shows plastic strain contours; this figure corresponds to the case in which the nail was located at the toe of the slope. Figure 4.24 corresponds to the case in which the nail was located $8 \mathrm{~m}$ above the toe. Both these figures show that plastic strain contours can be used to identify the failure surface.

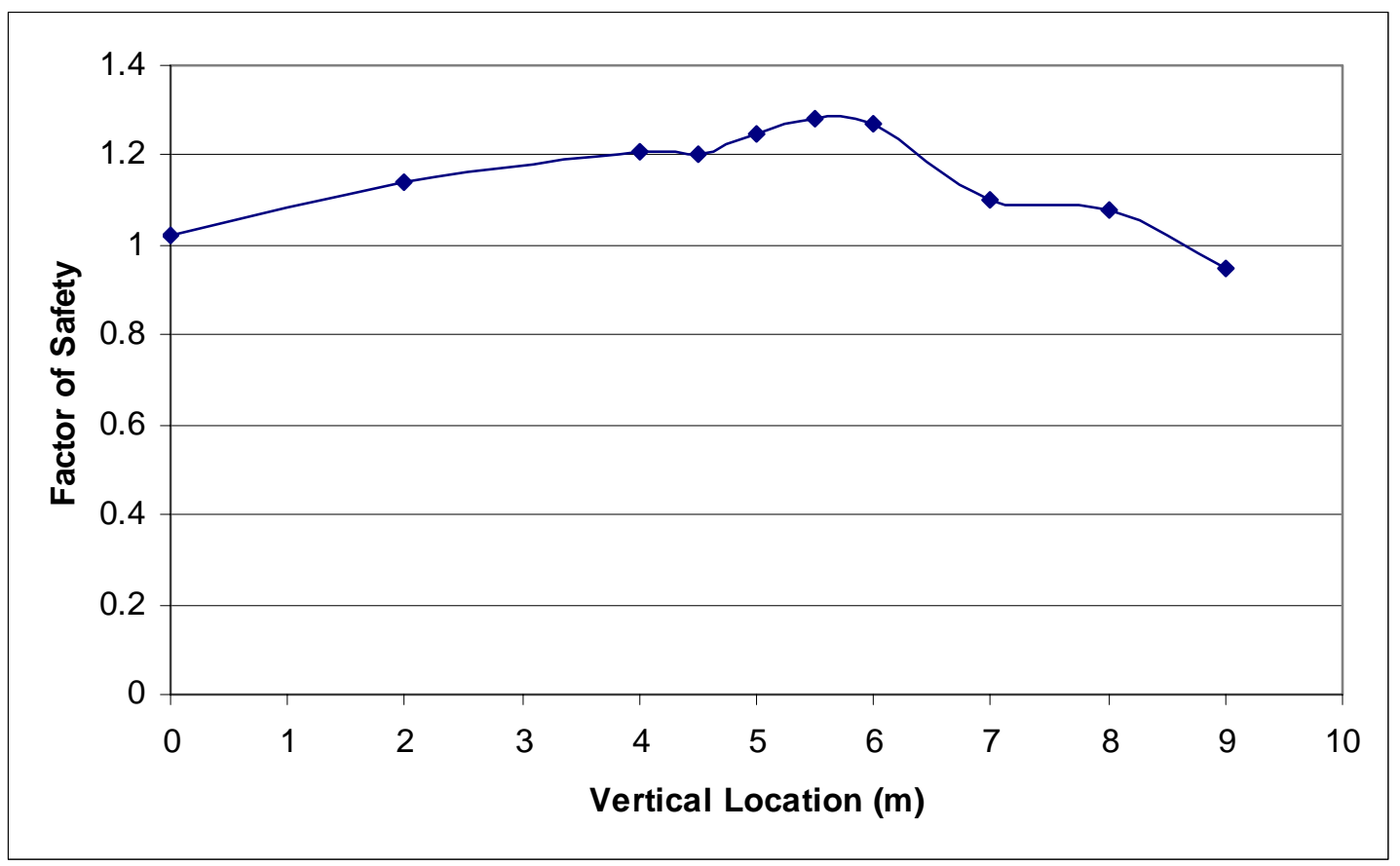

Figure 4.24: Variation of factor of safety with nail location 


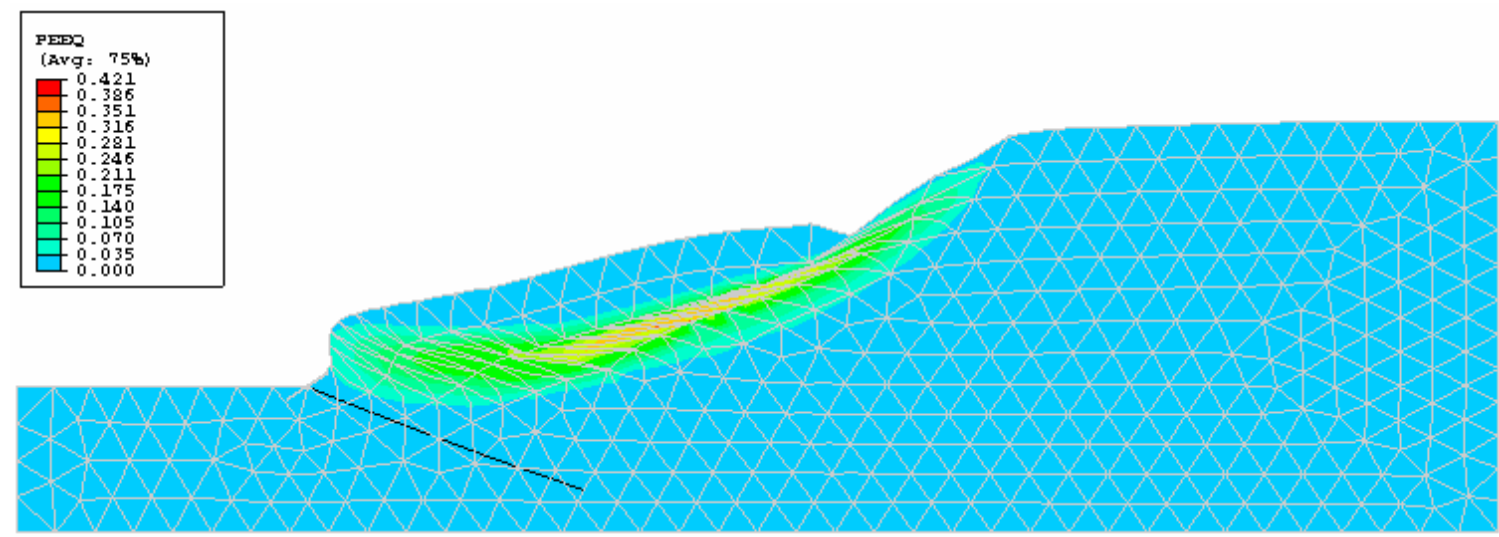

Figure 4.25: The equivalent plastic strain contours for the case in which nail was located at the toe.

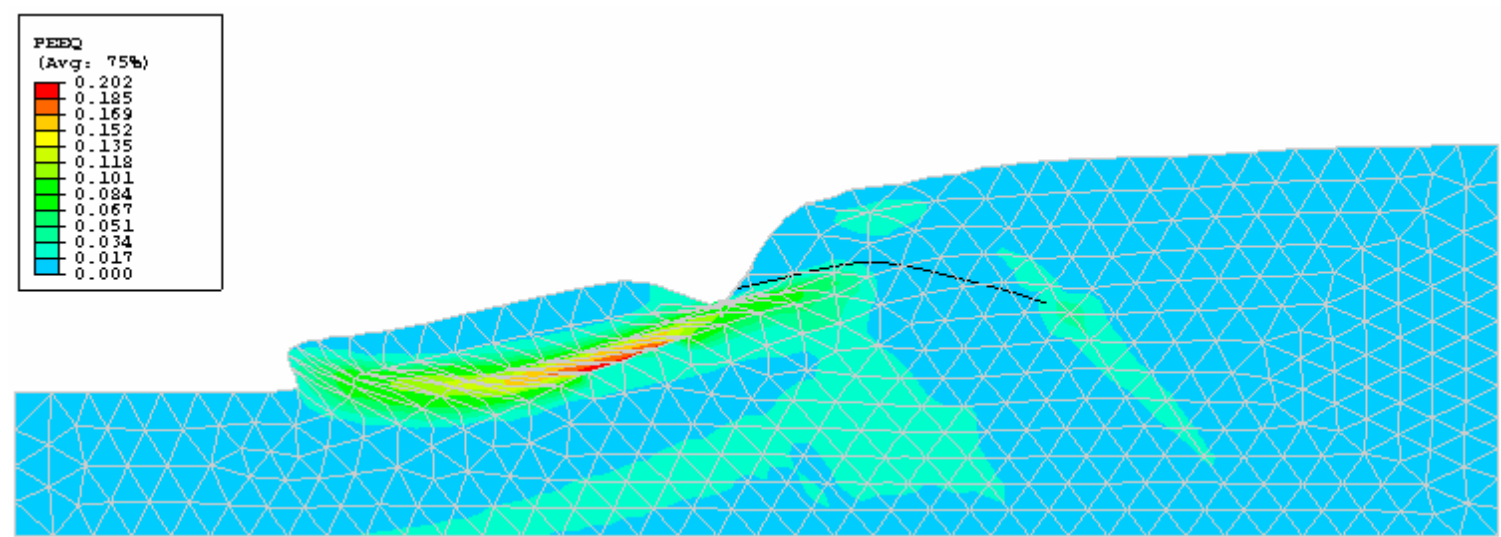

Figure 4.26: The equivalent plastic strain contours for one nail at $9 \mathrm{~m}$ above from the toe of slope 


\subsubsection{Influence of Number of Nails}

In this section, the number of nails was increased from one to three to examine the influence of number of nails on the factor of safety. The unreinforced case and the case with one nail were studied in earlier cases (Section 3.10.4). After the addition of the second nail, the factor of safety increased by about 3.5\%; it was determined as 1.154 compared to the case with one nail. When the third nail was introduced in the slope, the factor of safety of the slope increased significantly, up by about $22 \%$. This is a very large increase compared to the unreinforced, and single-nail slope cases. The variation of factor of safety values are shown in Table 4.4.

Table 4.4: Factor of safety results for influence of number of nails on the factor of safety

\begin{tabular}{|c|c|c|c|}
\hline \multirow{2}{*}{$\begin{array}{c}\text { Unreinforced } \\
\text { Slope }\end{array}$} & \multicolumn{3}{|c|}{ Case 2 with soil nails } \\
\cline { 2 - 4 } & One-Nail & Two-Nails & Three-Nails \\
\hline 0.995 & 1.10 & 1.154 & 1.406 \\
\hline
\end{tabular}

Figures 4.27 and 4.28 show that the failure plane in the three-nail model was raised above the nails when compared to single-nail model. 


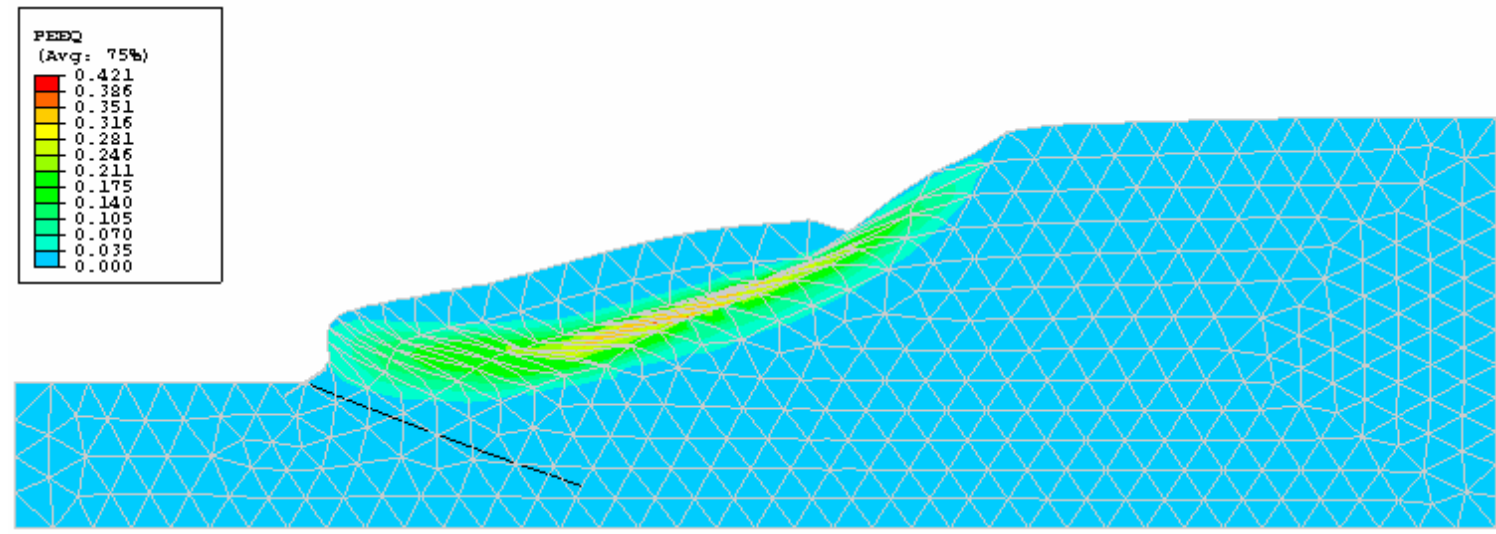

Figure 4.27: The equivalent plastic strain contour for one nail at the toe of slope

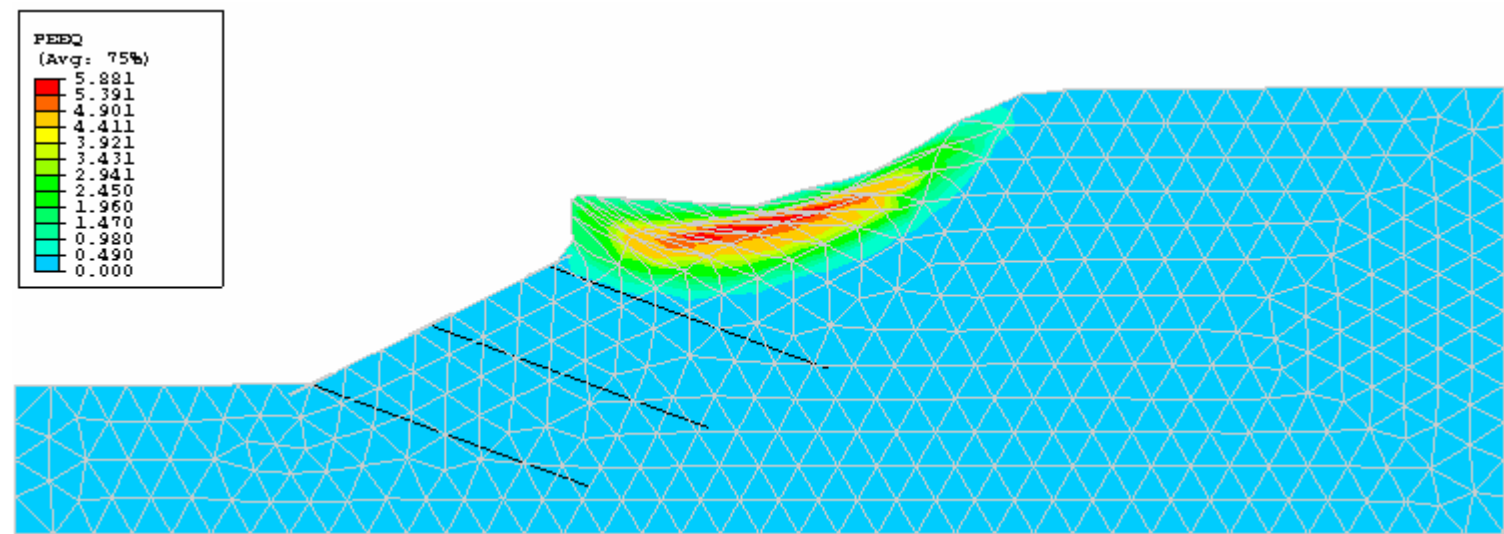

Figure 4.28: Displacement contour of three-nail case 


\section{CHAPTER 5}

\section{SUMMARY AND CONCLUSIONS}

\subsection{Summary}

The factor of safety of slope stability was determined by using the finite element method in conjunction with the Shear Strength Reduction (SSR) technique which was explained in previous chapters. The primary focus of this research was to study: (a) the influence of meshing and soil nailing on the factor of safety values, and (b) the failure mechanism of slopes by using the finite element analysis. Seven cases were studied in this research as summarized below. Summary of results and findings are presented in Table 5.1 and 5.2.

Table 5.1: Factor of safety results for homogeneous slope with no base (Case 1)

\begin{tabular}{|l|c|l|}
\hline \multirow{2}{*}{ Case 1 } & \multicolumn{2}{|c|}{ Factor of Safety } \\
\cline { 2 - 3 } $\begin{array}{l}\text { Unreinforced } \\
\text { Slope }\end{array}$ & $\begin{array}{c}\text { Limit Equilibrium Method } \\
\text { max. 1.382 (with Bishop) }\end{array}$ & \multicolumn{1}{c|}{ Finite Element Method 1.341 (with 1,496 CPE8 Elements) } \\
& & max. 1.401 (with 790 CPE6 Elements) \\
\hline \multirow{2}{*}{$\begin{array}{l}\text { Reinforced Slope } \\
\text { with one-nail } \\
\text { (Figure 3.18) }\end{array}$} & & $\begin{array}{l}\text { min. 1.46 (when L=10m) } \\
\text { max. 1.58 (when L=20m) }\end{array}$ \\
\cline { 2 - 3 } & & $\begin{array}{l}\text { The failure plane of the slope was raised } \\
\text { above the nail (Figure 4.12) }\end{array}$ \\
\hline
\end{tabular}

*M-P: Morgenstern-Price Method (1965) 
Table 5.2: Factor of safety results for homogeneous slope with base (Case 2)

\begin{tabular}{|c|c|c|}
\hline \multirow[b]{2}{*}{ Case 2} & \multicolumn{2}{|c|}{ Factor of Safety } \\
\hline & Limit Equilibrium Method & Finite Element Method \\
\hline $\begin{array}{l}\text { Unreinforced } \\
\text { Slope }\end{array}$ & $\begin{array}{l}\text { min. } 0.989 \text { (with Spencer) } \\
\text { max. } 0.999 \text { (with M-P*) }\end{array}$ & $\begin{array}{l}\text { min. } 0.980 \text { (with 1,397 Elements (CPE6)) } \\
\text { max. } 1.03 \text { (with } 728 \text { Elements (CPE6)) }\end{array}$ \\
\hline \multicolumn{3}{|l|}{$\begin{array}{l}\text { Reinforced } \\
\text { Slope }\end{array}$} \\
\hline $\begin{array}{l}\text { Influence of Nail } \\
\text { Length }\end{array}$ & & $\begin{array}{l}\min .1 .07 \text { (when } \mathrm{L}=4 \mathrm{~m}) \\
\max .1 .33(\text { when } \mathrm{L}=10 \mathrm{~m})\end{array}$ \\
\hline $\begin{array}{l}\text { Influence of Nail } \\
\text { Inclination }\end{array}$ & & $\begin{array}{l}\min .1 .01 \text { (when } \alpha=20^{\circ} \text { counterclockwise) } \\
\max .1 .33 \text { (when } \alpha=20^{\circ} \text { clockwise) }\end{array}$ \\
\hline $\begin{array}{l}\text { Influence of Nail } \\
\text { Location }\end{array}$ & & $\begin{array}{l}\text { min. } 1.02 \text { (when vertical distance above toe level }=0 \mathrm{~m} \text { ) } \\
\text { max. } 1.28 \text { (when vertical distance above toe level }=5.5 \mathrm{~m} \text { ) }\end{array}$ \\
\hline \multirow[b]{2}{*}{$\begin{array}{l}\text { Influence of } \\
\text { Number of Nails }\end{array}$} & & $\begin{array}{l}\min .1 .46(\text { when } \mathrm{L}=10 \mathrm{~m}) \\
\max .1 .58 \text { (when } \mathrm{L}=20 \mathrm{~m})\end{array}$ \\
\hline & & $\begin{array}{l}\text { The failure plane of the slope was raised above the last } \\
\text { nail (Figures } 4.27 \text { and } 4.28 \text { ) }\end{array}$ \\
\hline
\end{tabular}

*M-P: Morgenstern-Price Method (1965)

\subsection{Numerical Modeling of Unreinforced Slopes}

In this section, numerical modeling of unreinforced slopes was studied on a homogenous slope model with no base soil, and a homogenous slope with base soil.

\subsubsection{Case 1: A Homogenous Slope with No Base}

In this case, 6-noded quadratic plane strain triangle elements (CPE6) elements and 8-noded biquadratic plane strain quadrilateral elements (CPE8) elements were used in section. Results show that the minimum and maximum values of factor of safety are less than $3 \%$ of the limit equilibrium values. However, the difference of computed factor of safety using CPE6 elements and CPE8 elements are slightly larger than 5\%. The factor of safety using CPE6 and CPE8 from Analyses 1 and 2 are very close to the results presented in the literature for Q8 elements (Griffiths et. al.). Although, the computed factors of safety were close to limit equilibrium values, finer mesh with CPE8 elements did not perform well in replicating the failure surface. Moreover, CPE6 elements performed better than CPE8 elements on the shape of failure plane. 


\subsubsection{Case 2: A Homogenous Slope with Base}

In this case, only CPE6 elements were used in all three models. The computed factor of safety using ranged from 0.98 to 1.03 in this case. These minimum and maximum values are less than 5\% from the limit equilibrium values. The limit equilibrium methods lead to a factor of safety value in the range of 0.989 to 0.999 (see Table 4.1). However, the difference of computed factor of safety using 728 elements (Analysis 1) and 1397 elements (Analysis 3) elements are slightly larger than 5\%. This shows that the finer refined mesh system could lead more conservative predictions.

\subsection{Numerical Modeling of Reinforced Slopes}

In this section, numerical modeling of reinforced slopes was studied on a homogenous slope model with no base soil, and a homogenous slope with base soil.

\subsubsection{Influence of Soil Nail Length}

Two cases are analyzed in this section: a) benchmark with no soil base with one nail and b) benchmark with soil base with one nail.

\section{a) Benchmark with No Soil Base with One Nail}

When the slope did not have any reinforcement, the computed factor of safety was 1.40. After the addition of a $10 \mathrm{~m}$ long nail, the factor of safety was increased by about $4.3 \%$ and it was determined as 1.46. In the second case, a $15 \mathrm{~m}$ long nail was used. This trial resulted in a significantly higher factor of safety value of 1.58 . This is about $12.86 \%$ increase compared to the unreinforced slope case. Clearly, the finite element method is capable of computing the factor of safety of reinforced slopes. Traditional methods have not been used with reinforced slopes. 


\section{b) Benchmark with Soil Base with One Nail}

The greatest factor of safety 1.33 was obtained when the soil nail length was $12 \mathrm{~m}$. There was a significant difference in displacement when the length of the nail was between $5 \mathrm{~m}$ and $9 \mathrm{~m}$. The results show that the slope starts to become stable after a soil nail with a length of $9 \mathrm{~m}$ to $12 \mathrm{~m}$ was used (Figure 4.13).

\subsubsection{Influence of Nail Inclination}

The highest calculated numerical value factor of safety of 1.33 was obtained when the nail inclination angle $(\alpha)$ was at $20^{\circ}$ in clockwise direction. The factor of safety was close to 1.30 with small variations for the range of $\alpha$ between $0^{\circ}$ and $20^{\circ}$ in the clockwise direction. The factor of safety decreased considerably as the inclination angle $\alpha$ increased beyond $20^{\circ}$.

\subsubsection{Influence of Nail Location}

The maximum factor of safety value of 1.28 was obtained when the nail was installed at $5.5 \mathrm{~m}$ above the toe level. The factor of safety values started to decrease beyond this height.

\subsubsection{Influence of Number of Nails}

The factor of safety increased by about 3.5\% after addition of the second nail. It was determined as 1.154 compared to one-nail case. When the third nail was introduced in the slope, the factor of safety of the slope increased significantly 1.406 (up to about $22 \%$ ). The failure plane of the slope was raised above the last nail. 


\subsection{Conclusions}

Following conclusions were drawn based on the results presented in this research work:

- The primary focus of this research was to obtain factor of safety of earth slopes by finite element analysis. The performance of the finite element method for determining factor of safety and the failure surface in conjunction with the strength reduction method was excellent. Obtaining the factor of safety of a soil slope by finite element analysis is an effective method for slope failure investigations.

- Soil nailing is an effective slope stabilization method. The finite element method can predict the factor of safety and the failure plane on reinforced slopes. Conventional Limit Equilibrium methods have not been used for reinforced slopes.

- Finer mesh refinement could lead more conservative predictions.

- The location of the critical slip plane of a slope is accurately determined by using the finite element analysis. Unlike the traditional methods, finite element method does not require an arbitrary partitioning of the critical surface selection prior to calculations.

- The location of soil nails is an important factor on slope stability. Placing the first nail at the toe of a slope is less effective then placing the nail in the middle.

- The inclination of a soil nail has a significant influence on the factor of safety of an earth slope and the extent of the critical slip surface. Finite element analysis is an accurate method to determine the optimal inclination amount of a soil nail for a given slope geometry and soil properties. 


\subsection{Recommendations}

- The validity of the finite element analysis results for both unreinforced and reinforced have been compared with other analysis methods; however, field data and case studies are still needed to further calibrate the method.

- Soil nails have a significant importance in soil stabilizing. However, soil nail and nail head design were out of scoop of this project. Therefore, soil nail and nail head design with finite element analysis can be the subject of a future study.

- The finite element prediction using the Mohr-Coulomb model was acceptable. However, it is recommended to use advanced soil models such as a strainhardening soil model with a laboratory testing program to achieve more reliable predictions.

- The additional research is needed to investigate slope stability with broader range of soils and element types. 


\section{REFERENCES}

ABAQUS version 6.6 (2006) ABAQUS user's manual. Hibbitt, Karlson \& Sorensen, Inc., Pawtucket, RI.

Ann,T., Hai, O., Lum, C., and Tan, D. (2004), Finite Element Analysis of A Soil Nailed Slope-Some Recent Experience. pp. 183-189

ASTM A615/A615M-96 (1996) Standard Specification for Deformed and Plain BilletSteel Bars for Concrete Reinforcement. American Standard for Testing Materials.

Baker, R. (2004) Nonlinear Mohr Envelopes Based on Triaxial Data. Journal of Geotechnical \& Geoenvironmental Engineering, Vol. 130 Issue 5, pp. 498-506

Banerjee, S., Finney, A., Wentworth, T. and Bahiradhan, M. (1998) Evaluation of Design Methodologies for Soil-Nailed Walls. Volume 3: An Evaluation of SoilNailing Analysis Packages," FHWA Publication No. WA-RD 371.1, pp. 154

Bishop, A.W. (1955) The Use of the Slip Circle in the Stability Analysis of Slopes. Géotechnique, London, England, Vol. 5, No. 1, pp. 7-17

Bromhead, E. N. (1992) Stability of Slopes. Second Edition, Blackie Academic \& Professional

Broms, B.B. and Wong, K.S. (1991) Landslides in Fang, H., ed., Foundation Engineering Handbook: New York, Van Nostrand Reinhold, pp. 410-446.

Byrne, R. J., Cotton, D., Porterfield, J., Wolschlag, C., and Ueblacker, G. (1998) Manual for Design and Construction Monitoring of Soil Nail Walls. Report FHWA-SA96-69R, Federal Highway Administration, Washington, D.C.

Chance Company, Retention Wall System Design Manual [Online], (1999) Available: http://www.abchance.com/ch_tech/soilscrew_designman/chapter1.htm\#anchor1 1 14753

Chen, J. Lin, C. and Lee, W. (2003) Dilative Behavior of Granular Material International Journal of Offshore and Polar Engineering Vol. 13, No. 4

Chen, W. R. (1995) The Civil Engineering Handbook. Editor-in-Chief, CRC Press, Inc., Boca Raton, Florida, pp. 774-798.

Das, B. M. (2002) Principles of Geotechnical Engineering. Fifth Edition. Pacific Grove, CA: Brooks/Cole. 
Dawson, E. M., Roth, W.H. and Drescher, A. (1999) Slope Stability Analysis by Strength Reduction. Geotechnique, Vol. 49, No. 6, pp. 835-840

Duncan, J.M. and Wright, S.G. (2005) Soil Strength and Slope Stabilty. John Wiley \& Sons, Inc., pp. 199

Fenton, G.A. (1990) Simulation and Analysis of Random Fields. thesis presented to Princeton University, at Princeton, New Jersey, in partial fulfillment of the requirements for the degree of Doctor of Philosophy, 178 pg., Jan. 1990.

FHWA, (1993). French National Research Project CLOUTERRE, 1991Recommendations CLOUTERRE 1991, (English Translation) Soil Nailing Recommendations, Publication FHWA-SA-93-026, Federal Highway Administration, Washington, D.C.

GeoStudio 2004, version 6.2, Student Edition, Geo-Slope International Ltd.

Goldstein, N. (2001) [Online] "Soil Nailing” Available: http://www.forester.net/ec_0109_soil.html

Griffiths, D.V., and Lane P.A. (1999) Slope Stability Analysis by Finite Elements. Geotechnique, Vol. 49, No. 3, pp. 387-403

Hammah, R.E., Curran, J.H., Yacoub T., Corkum, B. (2004) Stability Analysis of Rock Slopes using the Finite Element Method. EUROCK 2004 \& 53rd Geomechanics Colloquium. Schubert (ed.)

Holtz, R.D, and Kovacs, W.D. (1981) An Introduction to Geotechnical Engineering. Prentice-Hall, Inc. pp. 448

Joshi, B. (2003) Behavior of Calculated Nail Head Strength in Soil-Nailed Structures Journal of Geotechnical and Geoenvironemtal Engineering, Vol. 129, Issue 9, pp. $819-828$

Karakus, M. and Fowell, R.J. (2004) An insight into the New Austrian Tunnelling Method (NATM), ROCKMEC'2004-VIIth Regional Rock Mechanics Symposium, Sivas, Turkey

KUTC, Newsletter, Spring (2006) Kansas Local Technical Assistance Program (LTAP) at the University of Kansas Transportation Center

Morgenstern, N.R. and Price, V.E. (1965) The analysis of the stability of general slip Surfaces, Géotechnique, Vol. 15, No. 1, pp. 79-93

Rocscience (2004) A New Era in Slope Stability Analysis: Shear Strength Reduction Finite Element Technique, Article 
Shiu, Y. K., Chang G.W.K., and Cheung, W.M. (2006) Review of Limit Equilibrium Methods for Soil Nail Design, Special Project Report SPR3, Geotechnical Engineering Office, Hong Kong

Shiu, Y. K., and Chang G.W.K. (2004) Numerical Study on Soil Nail Heads and Inclination, Geotechnical Engineering Office, Civil Engineering and Development Department, HKSAR, China

Shong, L.S. (2005) Soil Nailing for Slope Strengthening, Geotechnical Engineering, pp. $1-9$

Spencer, E. (1967) A Method of Analysis of the Stability of Embankments Assuming Parallel Interslice Forces, Géotechnique, Vol. 17, No. 1, pp. 11-26

Terzaghi, K., Peck, R.B., and Mesri, G. (1996) Soil Mechanics in Engineering Practice. Third Edition, John Wiley \& Sons, Inc. Article 18, pp. 135

U.S. Army Corps of Engineers, (2003) Engineer Manual. [Online] Available: http://www.usace.army.mil/publications/eng-manuals/em1110-2-1902/entire.pdf

Williams Form Engineering Corporation [Online], (2006) Available: http://www.williamsform.com/Threaded_Bars/Grade_75_All-

Thread_Rebar/grade_75_all-thread_rebar.html

Yu, H. S. (2000) Cavity Expansion Methods in Geomechanics, Kluwer Academic Publishers, pp. 404 


\section{APPENDIX A}

\section{Influence of Soil Base on Factor of Safety}

In this section, a base was added to Case 1 model. Figure A 2 shows the additional $5 \mathrm{~m}$ base and a $10 \mathrm{~m}$ stretch to the toe section to study the failure surface. Soil\#1 properties were used in both analyses. In this model, material properties were kept same in order to have an accurate comparison between these models. The factor of safety was computed when there was no reinforcement in the embankment.

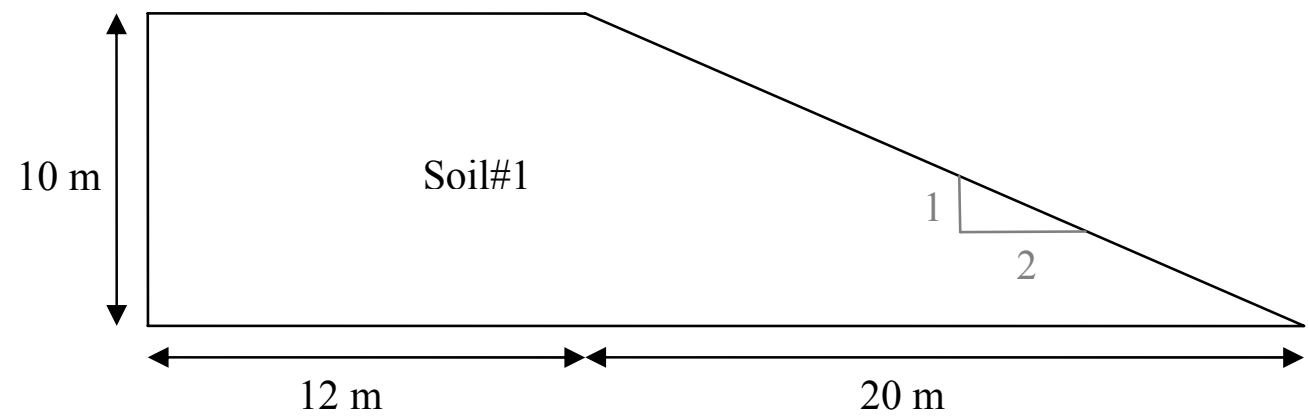

Figure A 1: Geometry of the benchmark model with no base model (Case 1)

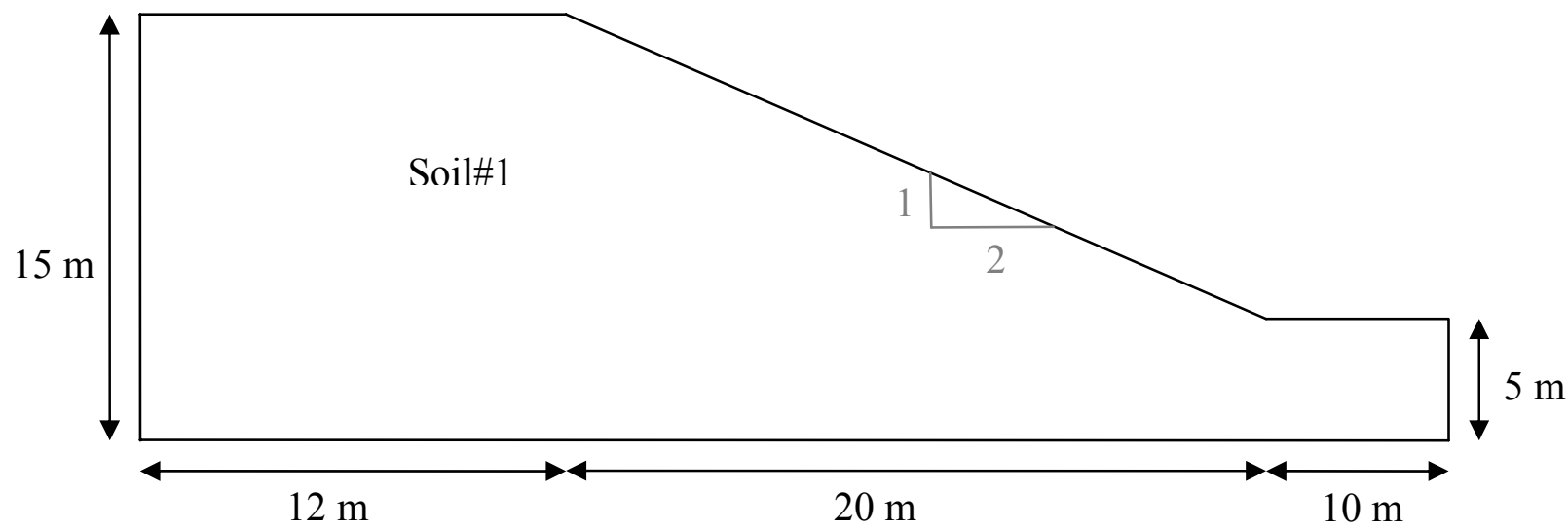

Figure A 2: Geometry of the benchmark model with a 5m deep base added 
The deformed finite element meshes corresponding to these cases are shown in Figures A 1 and A 2. When the slope did not have a base (Figure A 1), the obtained factor of safety was 1.40. After the addition of the $5 \mathrm{~m}$ base (Figure A 2), the factor of safety was determined as 1.395 .

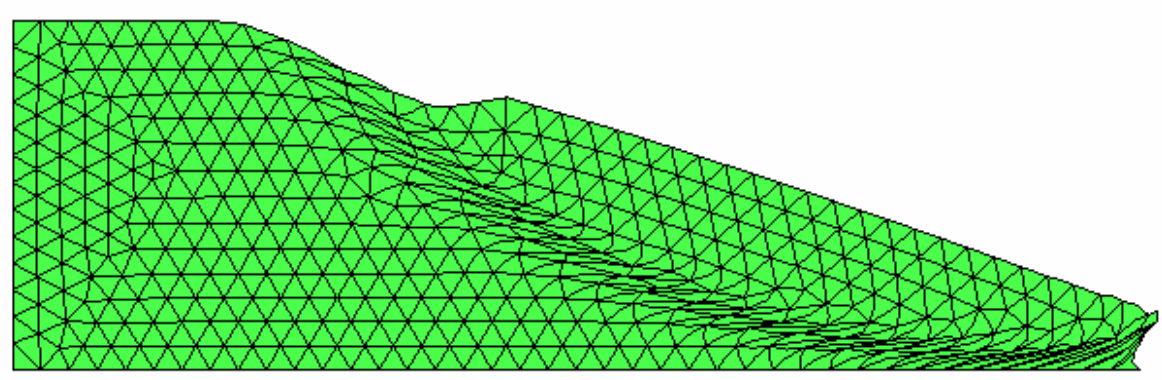

Figure A 3: Deformed mesh for Case 1 (from Analysis 1)

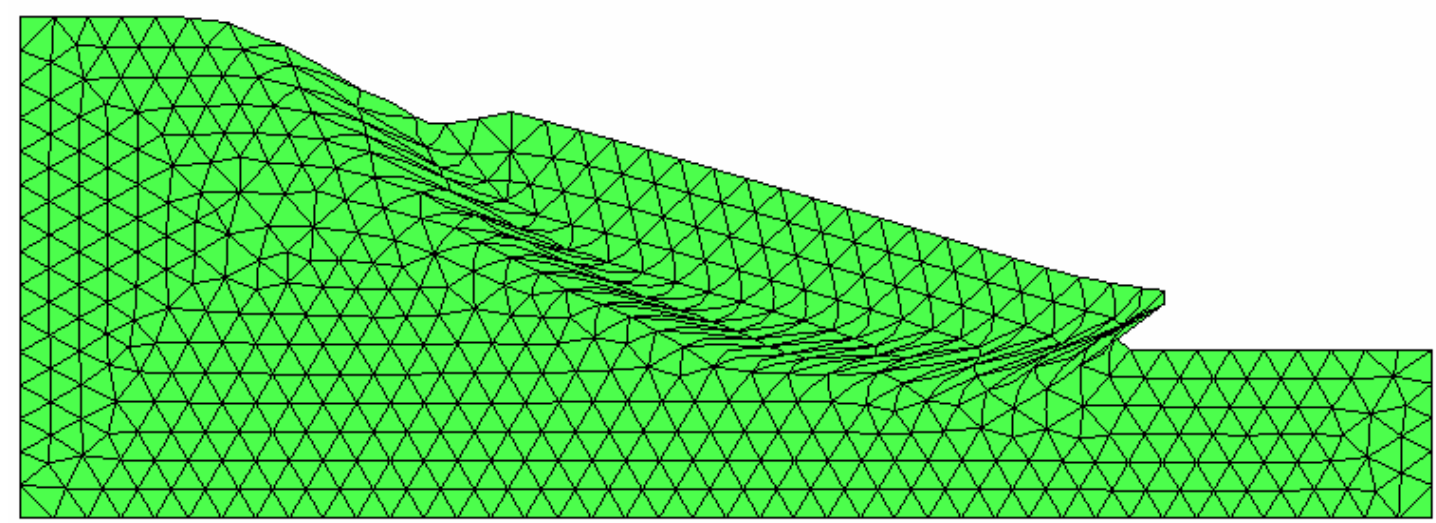

Figure A 4: Deformed mesh for Case 1 with base

The equivalent plastic strain measure in finite element analysis can be used to assess the accumulation of plastic strain in the soil region (Abaqus, 2006). Figure A 5 shows displacement and Figure A 6 shows contours of the equivalent plastic strain for Case 1 with a $5 \mathrm{~m}$ base. Figure 4.1 (b) in Chapter 4 shows the equivalent plastic strain contour for Case 1. 


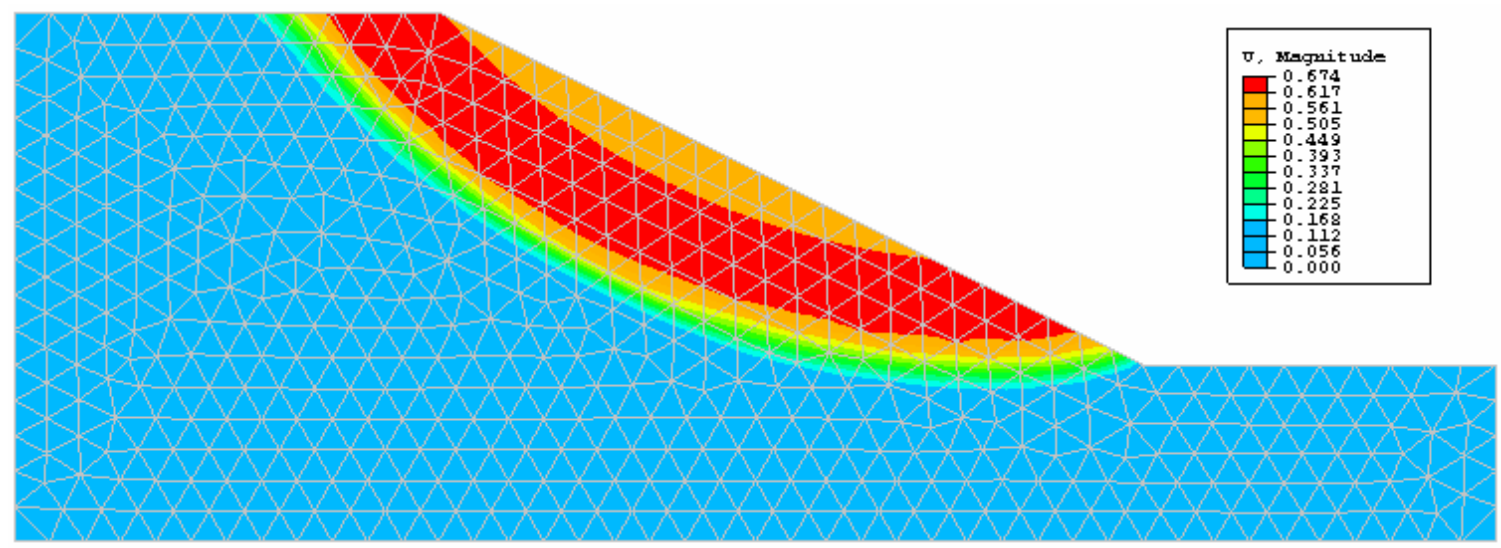

Figure A 5: Displacement contours

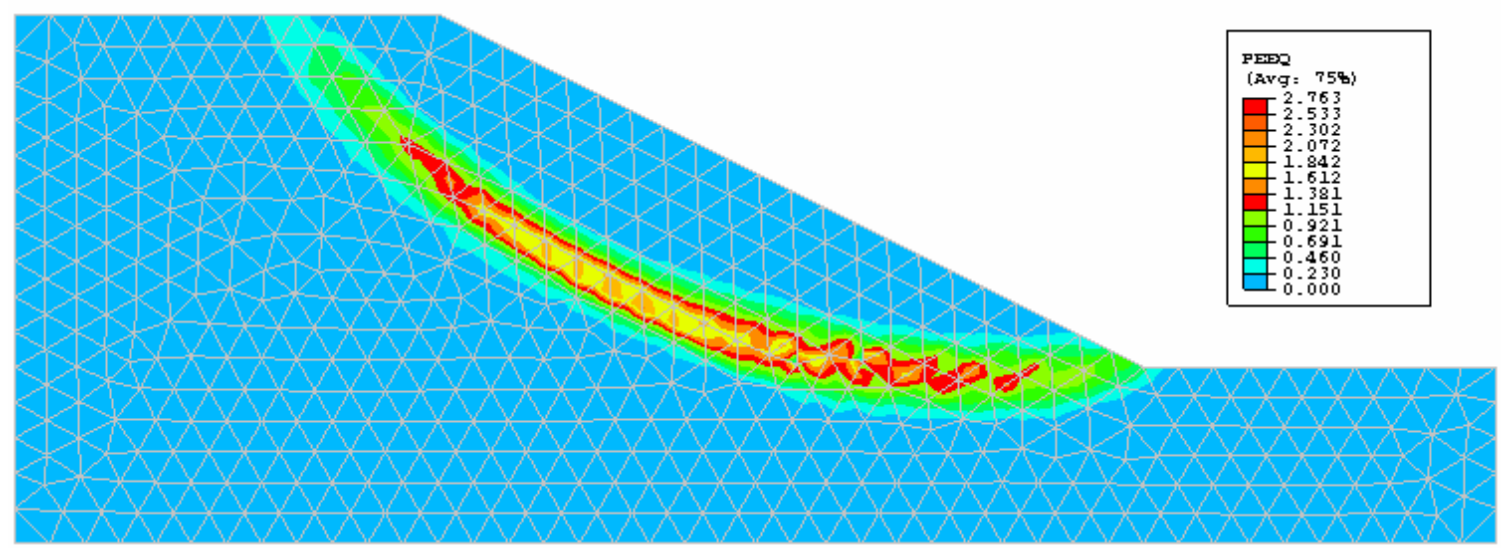

Figure A 6: The equivalent plastic strain contours 


\section{Summary}

Table A 1 shows the computed factor of safety for Case 1 and Case 1 with a $5 \mathrm{~m}$ deep base added. The computed factor of safety values for Case 1 and Case 1 with base are shown in Table A.1. The error percentage is less than $0.4 \%$.

Table A1: Computed Factor of safety for Case 1 and Case 1 with a $5 \mathrm{~m}$ deep base added

\begin{tabular}{|c|c|c|c|}
\hline & Case 1 & Case 1 with Base & Error percentage \\
\hline Factor of Safety & 1.4 & 1.395 & $0.36 \%$ \\
\hline
\end{tabular}

